\title{
Appendix 1. LIST OF STATIONS. Research Vessels and Research Programs
}

\section{Research Vessels}

\section{Research Vessel, Latitude, N} Station

\begin{tabular}{lc}
\hline Akademik Kurchatov, Cruise $6(1969)$ \\
431 & $43^{\circ} 03^{\prime} 5$ \\
432 & $40^{\circ} 29^{\prime}$ \\
432 & $40^{\circ} 34^{\prime}$ \\
441 & $29^{\circ} 58.0^{\prime}$ \\
443 & $30^{\circ} 02^{\prime} 5$ \\
444 & $40^{\circ} 35^{\prime}$
\end{tabular}

Akademik Kurchatov, Cruise 36 (1983)

Akademik Mstyslav Keldysh, Cruise 1 (1981)

$\begin{array}{ll}123 & 34^{\circ} 52^{\prime} 5 \\ 131 & 39^{\circ} 43^{\prime} 0\end{array}$

Akademik Mstyslav Keldysh, Cruise 4 (1982)

Akademik Mstyslav Keldysh, Cruise 15 (1988) 1897

$\begin{array}{ll}268 & 58^{\circ} 52^{\prime} \\ 268-1 & 58^{\circ} 52.3^{\prime}-58^{\circ} 53.9^{\prime} \\ 268-2 & 58.87^{\circ} \\ 316-1 & 58^{\circ} 45^{\prime} \\ 316-3 & 58^{\circ} 45^{\prime} \\ 316-5 & 58^{\circ} 45^{\prime} \\ 317 & 58^{\circ} 40.05^{\prime} \\ 317-2 & 58^{\circ} 40.05^{\prime} \\ 317-3 & 58.73^{\circ} \\ 317-4 & 58^{\circ} 40.05^{\prime}-58^{\circ} 40.08^{\prime} \\ 352 & 58^{\circ} 24^{\prime} \\ 390 & 58^{\circ} 34.01^{\prime}-58^{\circ} 33.09^{\prime} \\ 390-3 & 58^{\circ} 34.01^{\prime}-58^{\circ} 33.09^{\prime} \\ 499 & 58^{\circ} 03^{\prime} \\ 500 & 46^{\circ} 08.2^{\prime}-46^{\circ} 07.7^{\prime} \\ 501 & 34^{\circ} 28^{\prime} 5-34^{\circ} 28^{\prime} 4 \\ 503 & 34^{\circ} 23.2^{\prime} \\ 511 & 34^{\circ} 27.7^{\prime}-34^{\circ} 27.0^{\prime}\end{array}$

Longitude, $\mathrm{W}$

( $\mathrm{E}$ - when indicated)
Depth, m

$5900-5001$

$2900-2780$

2340-3347

3835

$2500-2780$

$13^{\circ} 00^{\prime} 3 \quad 4860$

$12^{\circ} 43^{\prime} 2$

$14^{\circ} 40^{\prime} 3$

4404-4409

5310

$24^{\circ} 05^{\prime}$

2670

$24^{\circ} 09.08^{\prime}-24^{\circ} 02.0^{\prime} \quad 2667-2665$

$24.37^{\circ} \quad 2617$

$27^{\circ} 13^{\prime}$

$27^{\circ} 13^{\prime}$

$27^{\circ} 13^{\prime} 5^{\prime \prime}$

$28^{\circ} 41.07^{\prime}$

$28^{\circ} 41.07^{\prime}$

$28.70^{\circ}$

$28^{\circ} 41.07^{\prime}-28^{\circ} 39.06^{\prime}$

$31^{\circ} 45^{\prime}$

$34^{\circ} 54.05^{\prime}-34^{\circ} 52.04^{\prime}$

$34^{\circ} 54.05^{\prime}-34^{\circ} 52.04^{\prime}$

$30^{\circ} 26^{\prime}$

$15^{\circ} 11.5^{\prime}-16^{\circ} 10.3^{\prime}$

$29^{\circ} 58^{\prime} 3-29^{\circ} 56^{\prime} 4$

$29^{\circ} 57.8^{\prime}$

$29^{\circ} 56.1^{\prime}-29^{\circ} 55.8^{\prime}$

2200-2190

2200-2190

2200-2190

2132-2151

2132-2151

2154

2132-2151

2005

2930-2951

2930-2951

2429-2440

4297

2740-2500

2020

2820-2350

3650

$2500-2350$

1963

$36^{\circ} 34^{\prime} 09^{\prime \prime}-36^{\circ} 36^{\prime} 02^{\prime \prime} 11^{\circ} 12^{\prime} 08^{\prime \prime}-11^{\circ} 02^{\prime} 06^{\prime \prime}$

$44^{\circ} 58.70^{\prime}$

$07^{\circ} 16.30^{\prime}-07^{\circ} 16.90^{\prime} \mathrm{E}$

2870-3000

2920-2942

3572

$14^{\circ} 45.02$

$73^{\circ} 12.80^{\prime}-73^{\circ} 22.10^{\prime}$

$33^{\circ} 53^{\prime}-34^{\prime}$ $33^{\circ} 53^{\prime}-34^{\prime}$

$33^{\circ} 53^{\prime}-34^{\prime}$

2400

2400

2400

3982

$36^{\circ} 13^{\prime}-14^{\prime}$
$36^{\circ} 13^{\prime}-14^{\prime}$
$36^{\circ} 13^{\prime}-14^{\prime}$

$28^{\circ} 00^{\prime} 9$

2000

3162-3136

4234

$44^{\circ} 57^{\prime} 4$

$49^{\circ} 38.55^{\prime}$

$35^{\circ} 1^{\prime}$

$34^{\circ} 45^{\prime}$

2156

4313

4540

$52^{\circ} 47^{\prime}$

$14^{\circ} 01.83^{\prime}$

2410 $36^{\circ} 47.56$

$69.2^{\circ} 00^{\prime}$
4

aid (1978) 


\section{Research Vessel, Latitude, N} Station

Alaid (1978) (continued)

$\begin{array}{ll}5 & 72^{\circ} 50^{\prime} \\ 30.4 & 69^{\circ} 12^{\prime} \\ 30.5 & 72^{\circ} 30^{\prime}\end{array}$

$30.5 \quad 72^{\circ} 30^{\prime}$

Archimede$$
2
$$

Archimede (1969) (Bathyscaphe)

AC 15

$37^{\circ} 20^{\prime}$

$84^{\circ} 11.6^{\prime}$

Longitude, $\mathrm{W}$

( $E$ - when indicated)

Arlis II (1962)

29

Atlantis, Cruise 152 (1948)

$15 \quad 35^{\circ} 17^{\prime}$

$\begin{array}{ll}20 & 37^{\circ} 50^{\prime} 30^{\prime \prime} \\ 28 & 34^{\circ} 50^{\prime}\end{array}$

$30 \quad 34^{\circ} 53^{\prime}$

Atlantis II (1966)

$\begin{array}{ll}106 & 32^{\circ} 10^{\prime} 5 \\ 108 & 36^{\circ} 24^{\prime} \\ 119 & 32^{\circ} 15^{\prime} 8 \\ 125 & 37^{\circ} 24^{\prime} \\ 131 & 39^{\circ} 38^{\prime} 5\end{array}$

Bartlett (1975)

11

$37^{\circ} 14^{\prime}$

Caudan

2

$46^{\circ} 28^{\prime}$

Chain, Cruise 50 (1965)

$\begin{array}{ll}76(\mathrm{HH}) & 39^{\circ} 38^{\prime} 3 \\ 82(\mathrm{MM}) & 34^{\circ} 46^{\prime} 5 \\ 83(\mathrm{MM}) & 34^{\circ} 46.5^{\prime} \\ 85(\mathrm{II}) & 37^{\circ} 59^{\prime} 2\end{array}$

Chain, Cruise 58 (1966)

$\begin{array}{lc}103 G & 39^{\circ} 43^{\prime} 6 \\ \text { Chain, Cruise } 106(1972) \\ 316 & 50^{\circ} 58.7^{\prime} \\ 318 & 50^{\circ} 04^{\prime} \\ 321 & 50^{\circ} 12^{\prime} 03 \\ 323 & 50^{\circ} 08^{\prime} 09 \\ 325 & 50^{\circ} 06^{\prime} \\ 326 & 50^{\circ} 04^{\prime} 09^{\prime} \\ 328 & 50^{\circ} 04^{\prime} 07 \\ 328 & 50^{\circ} 05^{\prime} \\ 329 & 50^{\circ} 43^{\prime} \\ 330 & 50^{\circ} 43^{\prime} 05 \\ 330 \mathrm{c} & 50^{\circ} 43^{\prime} 05 \\ 334 & 40^{\circ} 44^{\prime} 00\end{array}$

HMS Challenger (1872-1876)

$41^{\circ} 58^{\prime}$

$3 \quad 25^{\circ} 45^{\prime}$

$6 \quad 36^{\circ} 23^{\prime}$

$50 \quad 38^{\circ} 25^{\prime}$

$70 \quad 38^{\circ} 25^{\prime}$

$79 \quad 36^{\circ} 21^{\prime}$

83

$\begin{array}{ll}10^{\circ} 30^{\prime} \mathrm{E} & 2130-2140 \\ 08^{\circ} 00^{\prime} \mathrm{E} & 3170 \\ 10^{\circ} 18^{\prime} \mathrm{E} & 2130 \\ & \\ 17^{\circ} 25.9^{\prime}-17^{\circ} 26.7^{\prime} & 4160\end{array}$

$25^{\circ} 27^{\prime}$

2200

$170^{\circ} 03^{\prime} \mathrm{E}$

3175

$30^{\circ} 51^{\prime}$

$26^{\circ} 00^{\prime}$

$39^{\circ} 20^{\prime}$

$46^{\circ} 24^{\prime} \quad 4550$

$64^{\circ} 40^{\prime} 7 \quad 2291$

$48^{\circ} 04^{\prime} 8 \quad 4739$

$64^{\circ} 31^{\prime} 6$ 2095-2223

$65^{\circ} 54^{\prime} \quad 4825$

$70^{\circ} 36^{\prime} 5 \quad 2178$

$33^{\circ} 16^{\prime}-2000$

$07^{\circ} 00^{\prime} \quad 3130$

$67^{\circ} 57^{\prime} 8 \quad 2862$

$66^{\circ} 30^{\prime} \quad 5000$

$66^{\circ} 30^{\prime} \quad 5000$

$69^{\circ} 26^{\prime} 2$

$70^{\circ} 37^{\prime} 4$

$13^{\circ} 01.6^{\prime}$

$14^{\circ} 23^{\prime} \quad 2506$

$13^{\circ} 35^{\prime} 08 \quad 2890-2868$

$13^{\circ} 50^{\prime} 09 \quad 3356-3338$

$14^{\circ} 20^{\prime} \quad 3822-3846$

$14^{\circ} 23.08^{\prime} \quad 3859$

$15^{\circ} 44^{\prime} 08$

$15^{\circ} 45^{\prime} \quad 4431$

$17^{\circ} 44^{\prime} \quad 4632$

$17^{\circ} 51^{\prime} 07$

$17^{\circ} 51^{\prime} 07$

$16^{\circ} 14^{\prime} 06 \quad 4400$

$\begin{array}{ll}09^{\circ} 42^{\prime} & 2058 \\ 20^{\circ} 12^{\prime} & 2789 \\ 11^{\circ} 18^{\prime} & 2775 \\ 35^{\circ} 80^{\prime} & 3070 \\ 35^{\circ} 50^{\prime} & 3065 \\ 23^{\circ} 31^{\prime} & 3705 \\ 18^{\circ} 13^{\prime} & 3018\end{array}$


Research Vessel, Latitude, N Station

RRS Challenger (1979-1999)

\section{BN}

50511

50514

$50514 / 1$

50515

$50515 / 1$

$50518 / 1$

50518

$50603 / 1$ BN

50604

$50604 / 1$ BN

50604/1

50605

$50605 / 1$

50613

$50613 / 1$

50701

50711

$50711 / 1$

50712

$50811 / 1$

50812 BN

$50812 / 2$

50906

50907

50910

$50910 / 1$ OT

51001

51110

$51214 / 1$

51216

51216/4

51301 OTSB

51309/1

$51214 / 1$

51414

51414/1

51415/1 BN

51417

51608/1

$51610 / 1$

51611

$52216 / 8$

$52403 / 13$

$52403 / 25$

$52602 / 1$

$52602 / 13$

$52701 / 5$

$52701 / 9$

$52701 / 10$

$52701 / 17$

$52701 / 24$

$52701 / 25$

$52701 / 29$

$52701 / 42$

$52701 / 45$ $56^{\circ} 12^{\prime}$

$50^{\circ} 31^{\prime}$

$49^{\circ} 44^{\prime}$

$49^{\circ} 44^{\prime}$

$49^{\circ} 44^{\prime}$

$49^{\circ} 43.9^{\prime}-49^{\circ} 46.9^{\prime}$

$49^{\circ} 27.3^{\prime}$

$49^{\circ} 29^{\prime}$

$49^{\circ} 46.2^{\prime}$

$50^{\circ} 06^{\prime}$

$50^{\circ} 06.1^{\prime}$

$50^{\circ} 06^{\prime}$

$50^{\circ} 11.6^{\prime}$

$50^{\circ} 11.6^{\prime}$

$50^{\circ} 30^{\prime}$

$50^{\circ} 29^{\prime}$

$54^{\circ} 34^{\prime}$

$49^{\circ} 53^{\prime}$

$49^{\circ} 53^{\prime}$

$50^{\circ} 10^{\prime}$

$49^{\circ} 39^{\prime}$

$49^{\circ} 45^{\prime}$

$49^{\circ} 52.7^{\prime}$

$50^{\circ} 25^{\prime}$

$49^{\circ} 53^{\prime}$

$49.82^{\circ}$

$49^{\circ} 50^{\prime}$

$54^{\circ} 45^{\prime}$

$50^{\circ} 16.4^{\prime}-50^{\circ} 15.4^{\prime}$

$50^{\circ} 00^{\prime}$

$49^{\circ} 49^{\prime}$

$49^{\circ} 49^{\prime}$

$54^{\circ} 46^{\prime}$

$49^{\circ} 35^{\prime}$

$49^{\circ} 59^{\prime}$

$49^{\circ} 43^{\prime}$

$49^{\circ} 44^{\prime}$

$50^{\circ} 6.9^{\prime}$

$50^{\circ} 10^{\prime}$

$49^{\circ} 35.6^{\prime}-49^{\circ} 38.8^{\prime}$

$50^{\circ} 01^{\prime}$

$50^{\circ} 17^{\prime}$

$48^{\circ} 47.5^{\prime}-48^{\circ} 47.59^{\prime}$

$48^{\circ} 55^{\prime}$

$48^{\circ} 15.5^{\prime}-49^{\circ} 15.3^{\prime}$

$48^{\circ} 48.6^{\prime}-48^{\circ} 50.51^{\prime}$

$48^{\circ} 48^{\prime}$

$48^{\circ} 51.6^{\prime}$

$48^{\circ} 51.6^{\prime}$

$48^{\circ} 51^{\prime}$

$48^{\circ} 49^{\prime}$

$48^{\circ} 50.9^{\prime}$

$48^{\circ} 50.4^{\prime}$

$48^{\circ} 50.5^{\prime}$

$48^{\circ} 52.7^{\prime}-4851.2^{\prime}$

$48^{\circ} 51.0^{\prime}$
Longitude, W

(E - when indicated)

$\begin{array}{ll}18^{\circ} 05^{\prime} & 2056 \\ 20^{\circ} 12^{\prime} & 3063 \\ 24^{\circ} 26^{\prime} & 3330\end{array}$

$\begin{array}{ll}12^{\circ} 02^{\prime} & 2600 \\ 12^{\circ} 58^{\prime} & 2420 \\ 14^{\circ} 02^{\prime} & 4017 \\ 14^{\circ} 02^{\prime} & 4017-4095 \\ 15^{\circ} 06^{\prime} & 4510 \\ 15^{\circ} 04.6^{\prime}-15^{\circ} 08.2^{\prime} & 4505-4515 \\ 13^{\circ} 21.1^{\prime} & 2045-2110 \\ 13^{\circ} 24^{\prime} & 2078 \\ 14^{\circ} 01.5^{\prime} & 4000 \\ 13^{\circ} 52^{\prime} & 3490-3550 \\ 13^{\circ} 53^{\prime} & 3490-3550\end{array}$

$13^{\circ} 51^{\prime}$

$13^{\circ} 32.4^{\prime}$

$13^{\circ} 32.4^{\prime}$

$13^{\circ} 03^{\prime}$

$13^{\circ} 02^{\prime}$

$11^{\circ} 54^{\prime}$

$15^{\circ} 36^{\prime}$

$15^{\circ} 36^{\prime}$

$13^{\circ} 21^{\prime}$

$14^{\circ} 34^{\prime}$

$14^{\circ} 10^{\prime}$

$14^{\circ} 17.3^{\prime}$

$13^{\circ} 28^{\prime}$

$13^{\circ} 32^{\prime}$

$14.67^{\circ}$

$14^{\circ} 41^{\prime}$

$12^{\circ} 24^{\prime}$

$13^{\circ} 30.9^{\prime}-13^{\circ} 30.6^{\prime}$

$14^{\circ} 05^{\prime}$

$14^{\circ} 07^{\prime}$

$14^{\circ} 07^{\prime}$

$12^{\circ} 14^{\prime}$

$14^{\circ} 01^{\prime}$

$14^{\circ} 05^{\prime}$

$14^{\circ} 10^{\prime}$

$14^{\circ} 10^{\prime}$

$13^{\circ} 53.6-13^{\circ} 52.1^{\prime}$

$13^{\circ} 22^{\prime}$

$14^{\circ} 30.3^{\prime}-14^{\circ} 24.3^{\prime}$

$13^{\circ} 58^{\prime}$

$13^{\circ} 24^{\prime}$

$16^{\circ} 37.59^{\prime}-16^{\circ} 39.68^{\prime}$

$16^{\circ} 01^{\prime}$

$16^{\circ} 17.4^{\prime}-16^{\circ} 20.3^{\prime}$

$16^{\circ} 31.7^{\prime}-16^{\circ} 40.28^{\prime}$

$16^{\circ} 32^{\prime}$

$16^{\circ} 29.4^{\prime}$

$16^{\circ} 29.4^{\prime}$

$16^{\circ} 29^{\prime}$

$16^{\circ} 33^{\prime}$

$16^{\circ} 29.2$

$16^{\circ} 29.6^{\prime}$

$16^{\circ} 29.5^{\prime}$

$16^{\circ} 38.5^{\prime}-16^{\circ} 28.5^{\prime}$

$16^{\circ} 30.5^{\prime}$
Depth, m

2056

3330

3515

2820-2930

2820-2930

2240-4715

2440

2880

4786

4595-4580

2737

4080-4100

4140-4035

2635

2970

4283-4341

4283-4341

2885-2895

2785-2800

3800-3820

4000

3970-4000

2925

4190-4255

3810

4097-4212

4180-4310

3510-3470

2770-2790

4370-4270

3310-3660

2640-2700

4803-4832

4849

4860-4880

4850

4853

4842

4842

4843

4844

4845

4844

4838

4849-4843

4845
4350-4400 
Research Vessel, Latitude, N Station

\begin{tabular}{|c|c|c|c|}
\hline $52701 / 47$ & $48^{\circ} 50.6^{\prime}$ & $16^{\circ} 29.9^{\prime}$ & 4841 \\
\hline $53201 / 1$ & $48^{\circ} 51.5^{\prime}-48^{\circ} 46.5^{\prime}$ & $16^{\circ} 41.2^{\prime}-16^{\circ} 51.2^{\prime}$ & $4834-4836$ \\
\hline $53201 / 23$ & $48^{\circ} 51.0^{\prime}$ & $16^{\circ} 29.6^{\prime}$ & $4844-5035$ \\
\hline $53201 / 24$ & $48^{\circ} 53.7^{\prime}-48^{\circ} 51.7^{\prime}$ & $16^{\circ} 36.8^{\prime}-16^{\circ} 19.2^{\prime}$ & $4846-4843$ \\
\hline $53201 / 26$ & $48^{\circ} 51.0^{\prime}$ & $16^{\circ} 29.6^{\prime}$ & $4844-5035$ \\
\hline $53201 / 28$ & $48^{\circ} 55.5^{\prime}-48^{\circ} 52.2^{\prime}$ & $17^{\circ} 00.1^{\prime}-16^{\circ} 51.9^{\prime}$ & $4846-4843$ \\
\hline $53201 / 29$ & $48^{\circ} 51.0^{\prime}$ & $16^{\circ} 29.6^{\prime}$ & $4844-5035$ \\
\hline $53205 / 3$ & $48^{\circ} 54.6^{\prime}-48^{\circ} 50.3^{\prime}$ & $16^{\circ} 47.4^{\prime}-16^{\circ} 35.9^{\prime}$ & $4829-4850$ \\
\hline $54301 / 6$ & $48^{\circ} 46.9^{\prime}-48^{\circ} 48.6^{\prime}$ & $16^{\circ} 49.7^{\prime}-16^{\circ} 40.5^{\prime}$ & $4837-4846$ \\
\hline $54301 / 8$ & $48^{\circ} 49.1^{\prime}-48^{\circ} 50.5^{\prime}$ & $16^{\circ} 38.4^{\prime}-16^{\circ} 27.0^{\prime}$ & 4839-4844 \\
\hline 54901 & $48^{\circ} 47.4^{\prime}$ & $16^{\circ} 48.9^{\prime}$ & 4836 \\
\hline $54901 / 2$ & $48^{\circ} 42.2^{\prime}-48^{\circ} 48.0^{\prime}$ & $16^{\circ} 51.6^{\prime}-16^{\circ} 50.4^{\prime}$ & $4811-4837$ \\
\hline $54901 / 5$ & $48^{\circ} 44.9^{\prime}-48^{\circ} 48.2^{\prime}$ & $16^{\circ} 40.5^{\prime}-16^{\circ} 36.2^{\prime}$ & $4835-4838$ \\
\hline $54901 / 7$ & $48^{\circ} 47.4^{\prime}-48^{\circ} 50.8^{\prime}$ & $16^{\circ} 48.9^{\prime}-16^{\circ} 46.0^{\prime}$ & $4835-4838$ \\
\hline $54902 / 1$ & $48^{\circ} 26.4^{\prime}-48^{\circ} 24.3^{\prime}$ & $15^{\circ} 39.7^{\prime}-15^{\circ} 34.9^{\prime}$ & $4843-4845$ \\
\hline $54903 / 1$ & $49^{\circ} 32.1^{\prime}-49^{\circ} 28.1^{\prime}$ & $15^{\circ} 56.0^{\prime}-15^{\circ} 56.5^{\prime}$ & $4810-4817$ \\
\hline $54903 / 1$ & $49^{\circ} 32.1^{\prime}-49^{\circ} 28.1^{\prime}$ & $15^{\circ} 56.0^{\prime}-15^{\circ} 56.5^{\prime}$ & $4810-4817$ \\
\hline $54905 / 1$ & $50^{\circ} 32.7^{\prime}-50^{\circ} 28.7^{\prime}$ & $16^{\circ} 57.8^{\prime}-16^{\circ} 59.5^{\prime}$ & $4764-4786$ \\
\hline ES 02 & $55^{\circ} 04^{\prime}$ & $12^{\circ} 33^{\prime}$ & 2857 \\
\hline ES 04 & $56^{\circ} 52^{\prime}$ & $10^{\circ} 01^{\prime}$ & 1993 \\
\hline ES 06 & $55^{\circ} 03^{\prime}$ & $12^{\circ} 29^{\prime}$ & 2900 \\
\hline 7 OTSB & $55^{\circ} 37^{\prime}$ & $10^{\circ} 25^{\prime}$ & 2410 \\
\hline ES 08 & $54^{\circ} 45^{\prime}$ & $12^{\circ} 10^{\prime}$ & 2900 \\
\hline ES 10 & $56^{\circ} 37^{\prime}$ & $11^{\circ} 04^{\prime}$ & 2540 \\
\hline ES $10 / 1$ & $56^{\circ} 37^{\prime}$ & $11^{\circ} 04^{\prime}$ & 2540 \\
\hline ES 12 & $56^{\circ} 49^{\prime}$ & $10^{\circ} 15^{\prime}$ & 2076 \\
\hline SWT 12 & $53^{\circ} 26^{\prime}$ & $15^{\circ} 20^{\prime}$ & 2996 \\
\hline SWT 15 & $49^{\circ} 30^{\prime}$ & $16^{\circ} 12^{\prime}$ & 4810 \\
\hline ES 27 & $54^{\circ} 40^{\prime}$ & $12^{\circ} 16^{\prime}$ & 2880 \\
\hline SWT 27 & $61^{\circ} 50^{\prime}-54^{\circ} 40^{\prime}$ & $56^{\circ} 21^{\prime}-12^{\circ} 16^{\prime}$ & $2700-2800$ \\
\hline ES 28 & $54^{\circ} 33^{\prime}$ & $12^{\circ} 21^{\prime}$ & 2880 \\
\hline ES 32 & $55^{\circ} 16^{\prime}$ & $12^{\circ} 58^{\prime}$ & 2871 \\
\hline SWT 32 & $56^{\circ} 50^{\prime}$ & $09^{\circ} 51^{\prime}$ & 2006 \\
\hline ES 34 & $56^{\circ} 36^{\prime}$ & $11^{\circ} 30^{\prime}$ & 2515 \\
\hline SBC 48 & $55^{\circ} 04^{\prime}$ & $12^{\circ} 04^{\prime}$ & 2875 \\
\hline ES 52 & $54^{\circ} 40^{\prime \prime}$ & $12^{\circ} 16^{\prime}$ & 2886 \\
\hline ES 53 & $54^{\circ} 40^{\prime \prime}$ & $12^{\circ} 16^{\prime}$ & 2886 \\
\hline ES 54 & $54^{\circ} 40^{\prime \prime}$ & $12^{\circ} 16^{\prime}$ & 2878 \\
\hline ES 55 & $54^{\circ} 40^{\prime \prime}$ & $12^{\circ} 16^{\prime}$ & 2878 \\
\hline ES 56 & $54^{\circ} 40^{\prime \prime}$ & $12^{\circ} 16^{\prime}$ & 2886 \\
\hline ES 57 & $54^{\circ} 41^{\prime \prime}$ & $12^{\circ} 23^{\prime}$ & 2900 \\
\hline SBC 58 & $54^{\circ} 41^{\prime}$ & $12^{\circ} 17^{\prime}$ & 2900 \\
\hline ES 59 & $54^{\circ} 40^{\prime}$ & $12^{\circ} 20^{\prime}$ & 2900 \\
\hline 61 & $57^{\circ} 08^{\prime}$ & $12^{\circ} 09^{\prime}$ & 2000 \\
\hline SBC 61 & $57^{\circ} 08^{\prime}$ & $12^{\circ} 09^{\prime}$ & 2000 \\
\hline AT 107A & $57^{\circ} 07^{\prime}$ & $12^{\circ} 06^{\prime}$ & 2000 \\
\hline 110 & $54^{\circ} 41^{\prime}$ & $12^{\circ} 14^{\prime}$ & 2886 \\
\hline ES 111 & $54^{\circ} 40^{\prime}$ & $12^{\circ} 16^{\prime}$ & 2886 \\
\hline 111 & $54^{\circ} 40^{\prime}$ & $12^{\circ} 16^{\prime}$ & 2886 \\
\hline AT 114 & $56^{\circ} 48^{\prime}$ & $10^{\circ} 54^{\prime}$ & 2400 \\
\hline ES 118 & $54^{\circ} 39^{\prime}$ & $12^{\circ} 14^{\prime}$ & 2910 \\
\hline 118 & $54^{\circ} 39^{\prime}$ & $12^{\circ} 14^{\prime}$ & 2910 \\
\hline AT 119 & $54^{\circ} 40^{\prime \prime}$ & $12^{\circ} 14^{\prime}$ & 2908 \\
\hline AT 119(1), & $54^{\circ} 40^{\prime \prime}$ & $12^{\circ} 14^{\prime}$ & 2908 \\
\hline 120 & $54^{\circ} 39^{\prime}$ & $12^{\circ} 16^{\prime}$ & 2911 \\
\hline AT 121 & $54^{\circ} 37^{\prime}$ & $12^{\circ} 09^{\prime}$ & 2910 \\
\hline AT 121(1) & $54^{\circ} 37^{\prime}$ & $12^{\circ} 09^{\prime}$ & 2910 \\
\hline 121 & $54^{\circ} 37^{\prime}$ & $12^{\circ} 09^{\prime}$ & 2910 \\
\hline ES 122 & $54^{\circ} 31^{\prime}$ & $12^{\circ} 31^{\prime}$ & 2951 \\
\hline 124 & $53^{\circ} 30^{\prime}$ & $13^{\circ} 15^{\prime}$ & 2900 \\
\hline ES 129 & $53^{\circ} 39^{\prime}$ & $12^{\circ} 17^{\prime}$ & 2900 \\
\hline
\end{tabular}

Longitude, W Depth, m

( $\mathrm{E}$ - when indicated)

$16^{\circ} 412^{\prime}-16^{\circ} 512^{\prime}$

4834-4836

$4837-4846$

$4811-4837$

$4843-4845$

4817

2410

2540

2076

2700-2800

2006

2886

2878

2878

2900

2900

2000

2886

2910

2908

2911 
Research Vessel, Latitude, N Station

\begin{tabular}{|c|c|c|c|}
\hline 129 & $53^{\circ} 39^{\prime}$ & $12^{\circ} 17^{\prime}$ & 2900 \\
\hline AT 130 & $54^{\circ} 46^{\prime}$ & $12^{\circ} 19^{\prime}$ & 2900 \\
\hline AT 131 & $55^{\circ} 03^{\prime}$ & $12^{\circ} 20^{\prime}$ & 2900 \\
\hline ES 135 & $54^{\circ} 39^{\prime}$ & $12^{\circ} 16^{\prime}$ & 2900 \\
\hline 135 & $54^{\circ} 39^{\prime}$ & $12^{\circ} 16^{\prime}$ & 2900 \\
\hline ES 137 & $54^{\circ} 34^{\prime}$ & $12^{\circ} 19^{\prime}$ & 2900 \\
\hline 137 & $54^{\circ} 34^{\prime}$ & $12^{\circ} 19^{\prime}$ & 2900 \\
\hline AT 138 & $55^{\circ} 31^{\prime}$ & $10^{\circ} 24^{\prime}$ & 2450 \\
\hline ES 138 & $55^{\circ} 31^{\prime}$ & $10^{\circ} 24^{\prime}$ & 2450 \\
\hline AT 139 & $55^{\circ} 35^{\prime}$ & $10^{\circ} 25^{\prime}$ & 2450 \\
\hline ES 139 & $55^{\circ} 35^{\prime}$ & $10^{\circ} 25^{\prime}$ & 2450 \\
\hline ES 140 & $54^{\circ} 40^{\prime}$ & $12^{\circ} 16^{\prime}$ & 2912 \\
\hline 140 & $54^{\circ} 40^{\prime}$ & $12^{\circ} 40^{\prime}$ & 2912 \\
\hline AT 141 & $54^{\circ} 44^{\prime}$ & $12^{\circ} 14^{\prime}$ & 2909 \\
\hline 141 & $54^{\circ} 44^{\prime}$ & $12^{\circ} 19^{\prime}$ & 2909 \\
\hline ES 141 & $57^{\circ} 13^{\prime}$ & $12^{\circ} 14^{\prime}$ & 2909 \\
\hline ES 143 & $54^{\circ} 41^{\prime}$ & $12^{\circ} 14^{\prime}$ & 2892 \\
\hline 143 & $54^{\circ} 41^{\prime}$ & $12^{\circ} 14^{\prime}$ & 2892 \\
\hline AT 144 & $57^{\circ} 13^{\prime}$ & $10^{\circ} 20^{\prime}$ & 2240 \\
\hline ES 147 & $54^{\circ} 36^{\prime}$ & $12^{\circ} 19^{\prime}$ & 2921 \\
\hline ES 147(3) & $54^{\circ} 36^{\prime}$ & $12^{\circ} 19^{\prime}$ & 2921 \\
\hline 147 & $54^{\circ} 36^{\prime}$ & $12^{\circ} 19^{\prime}$ & 2921 \\
\hline SBC 150 & $54^{\circ} 37^{\prime}$ & $12^{\circ} 13^{\prime}$ & 2916 \\
\hline AT 151 & $57^{\circ} 21^{\prime}$ & $10^{\circ} 22^{\prime}$ & 2175 \\
\hline 151 & $57^{\circ} 21^{\prime}$ & $10^{\circ} 22^{\prime}$ & 2175 \\
\hline ES 152 & $54^{\circ} 42^{\prime}$ & $12^{\circ} 02^{\prime}$ & 2900 \\
\hline AT 153 & $57^{\circ} 20^{\prime}$ & $10^{\circ} 27^{\prime}$ & 2200 \\
\hline 153 & $57^{\circ} 20^{\prime}$ & $10^{\circ} 27^{\prime}$ & 2200 \\
\hline AT 154 & $57^{\circ} 08^{\prime}$ & $10^{\circ} 22^{\prime}$ & 2264 \\
\hline AT 154 & $57^{\circ} 08^{\prime}$ & $10^{\circ} 19^{\prime}$ & 2170-2264 \\
\hline SBC 156 & $50^{\circ} 55^{\prime}$ & $12^{\circ} 21^{\prime}$ & 2036 \\
\hline SBC 159 & $50^{\circ} 55^{\prime}$ & $12^{\circ} 21^{\prime}$ & 2036 \\
\hline SBC 160 & $50^{\circ} 55^{\prime}$ & $12^{\circ} 20^{\prime}$ & 2030 \\
\hline 159 & $50^{\circ} 55^{\prime}$ & $12^{\circ} 21^{\prime}$ & 2036 \\
\hline 160 & $50^{\circ} 55^{\prime}$ & $12^{\circ} 20^{\prime}$ & 2030 \\
\hline AT 161 & $50^{\circ} 52^{\prime}$ & $12^{\circ} 22^{\prime}$ & 2055 \\
\hline SBC 163 & $54^{\circ} 41^{\prime}$ & $12^{\circ} 24^{\prime}$ & 2910 \\
\hline ES 164 & $54^{\circ} 37^{\prime}$ & $12^{\circ} 22^{\prime}$ & 2925 \\
\hline SBC 166 & $57^{\circ} 07^{\prime}$ & $10^{\circ} 20^{\prime}$ & 2274 \\
\hline AT 167 & $57^{\circ} 05^{\prime}$ & $10^{\circ} 25^{\prime}$ & 2300 \\
\hline 167 & $57^{\circ} 05^{\prime}$ & $10^{\circ} 25^{\prime}$ & 2300 \\
\hline AT 169 & $54^{\circ} 40^{\prime}$ & $12^{\circ} 17^{\prime}$ & 2910 \\
\hline 169 & $54^{\circ} 40^{\prime}$ & $12^{\circ} 17^{\prime}$ & 2910 \\
\hline ES 169 & $54^{\circ} 40^{\prime}$ & $12^{\circ} 17^{\prime}$ & 2910 \\
\hline ES 169(1), & $54^{\circ} 40^{\prime}$ & $12^{\circ} 17^{\prime}$ & 2910 \\
\hline AT 171 & $57^{\circ} 16^{\prime}$ & $10^{\circ} 17^{\prime}$ & 2225 \\
\hline ES 172 & $54^{\circ} 39^{\prime}$ & $12^{\circ} 17^{\prime}$ & 2910 \\
\hline AT 173 & $56^{\circ} 05^{\prime}$ & $10^{\circ} 28^{\prime}$ & 2185 \\
\hline SBC 174 & $54^{\circ} 44^{\prime}$ & $12^{\circ} 17^{\prime}$ & 2885 \\
\hline SBC 174 & $54^{\circ} 44^{\prime}$ & $12^{\circ} 18^{\prime}$ & 2885 \\
\hline AT 175 & $57^{\circ} 19^{\prime}$ & $10^{\circ} 16^{\prime}$ & 2210 \\
\hline AT 175 & $57^{\circ} 17^{\prime}$ & $119^{\circ} 21^{\prime}$ & 2210 \\
\hline ES 176 & $57^{\circ} 15^{\prime}$ & $10^{\circ} 26^{\prime}$ & 2245 \\
\hline 176 & $57^{\circ} 15^{\prime}$ & $10^{\circ} 26^{\prime}$ & 2245 \\
\hline AT 177 & $57^{\circ} 18^{\prime}$ & $10^{\circ} 16^{\prime}$ & 2220 \\
\hline 177 & $57^{\circ} 18^{\prime}$ & $10^{\circ} 16^{\prime}$ & 2220 \\
\hline ES 180 & $54^{\circ} 42^{\prime}$ & $12^{\circ} 11^{\prime}$ & 2886 \\
\hline ES 180 & $54^{\circ} 42^{\prime}$ & $12^{\circ} 12^{\prime}$ & 2886-2907 \\
\hline AT 181 & $57^{\circ} 19^{\prime}$ & $10^{\circ} 28^{\prime}$ & 2220 \\
\hline ES 182 & $57^{\circ} 19^{\prime}$ & $10^{\circ} 28^{\prime}$ & 2170 \\
\hline ES 184 & $57^{\circ} 14^{\prime}$ & $10^{\circ} 24^{\prime}$ & 2260 \\
\hline
\end{tabular}

Longitude, w Depth, m

(E - when indicated)

$12^{\circ} 16^{\prime}$

2900

2900

2450

2912

2892

2921

2916

2170-2264

2030

2055

2910

2300

2910

2910

2885

2885

2220

2260 
Research Vessel, Latitude, N Station

184
ES 185
185
AT 186
SBC, 188
188

ES 190

190

AT 191

ES 195

AT 195

ES 197

AT 198

AT 200

ES 200

AT 201

ES 202

ES 204

ES 204(2)

SBC 205

ES 207

SBC 215

215

ES 216

SBC 216

ES 218

AT 228

ES 231

231

ES 232

232

AT 233

ES 234

ES 244

AT 245

ES 245

AT 247

ES 247

ES 264

ES 266

AT 267

AT 271

SBC 272

272

AT 273

273

AT 282

AT 283

ES 283

AT 284

AT 285

ES 285

AT 286

AT 286(9)

ES 286

AT 288

ES 289

AT 349

AT 355

AT 393

AT 394

AT 400

$57^{\circ} 14^{\prime}$

$54^{\circ} 44^{\prime}$

$54^{\circ} 44^{\prime}$

$57^{\circ} 22^{\prime}$

$54^{\circ} 40^{\prime}$

$54^{\circ} 40^{\prime}$

$54^{\circ} 41^{\prime}$

$54^{\circ} 41^{\prime}$

$56^{\circ} 00^{\prime}$

$57^{\circ} 23^{\prime}$

$57^{\circ} 23^{\prime}$

$57^{\circ} 21^{\prime}$

$57^{\circ} 15^{\prime}$

$57^{\circ} 20^{\prime}$

$57^{\circ} 20^{\prime}$

$57^{\circ} 22^{\prime}$

$57^{\circ} 22^{\prime}$

$54^{\circ} 40^{\prime}$

$54^{\circ} 40^{\prime}$

$54^{\circ} 40^{\prime}$

$54^{\circ} 40^{\prime}$

$57^{\circ} 02^{\prime}$

$57^{\circ} 02^{\prime}$

$57^{\circ} 19^{\prime}$

$57^{\circ} 19^{\prime}$

$57^{\circ} 22^{\prime}$

$57^{\circ} 01^{\prime}$

$54^{\circ} 42^{\prime}$

$54^{\circ} 42^{\prime}$

$57^{\circ} 17^{\prime}$

$57^{\circ} 17^{\prime}$

$57^{\circ} 17^{\prime}$

$57^{\circ} 23^{\prime}$

$57^{\circ} 23^{\prime}$

$57^{\circ} 21^{\prime}$

$57^{\circ} 21^{\prime}$

$59^{\circ} 02^{\prime}$

$59^{\circ} 02^{\prime}$

$56^{\circ} 26^{\prime}$

$56^{\circ} 24^{\prime}$

$56^{\circ} 24^{\prime}$

$56^{\circ} 39^{\prime}$

$56^{\circ} 40^{\prime}$

$56^{\circ} 40^{\prime}$

$56^{\circ} 05^{\prime}$

$56^{\circ} 05^{\prime}$

$55^{\circ} 06^{\prime}$

$54^{\circ} 39^{\prime}$

$54^{\circ} 39^{\prime}$

$54^{\circ} 40^{\prime}$

$54^{\circ} 39^{\prime}$

$54^{\circ} 39^{\prime}$

$55^{\circ} 44^{\prime}$

$54^{\circ} 44^{\prime}$

$55^{\circ} 44^{\prime}$

$57^{\circ} 18^{\prime}$

$57^{\circ} 19^{\prime}$

$57^{\circ} 20^{\prime}$

$57^{\circ} 18^{\prime}$

$57^{\circ} 18^{\prime}$

$57^{\circ} 21^{\prime}$

$57^{\circ} 19^{\prime}$
Longitude, W

( $E$ - when indicated)

$10^{\circ} 24^{\prime} \quad 2260$

$12^{\circ} 15^{\prime} \quad 2907$

$12^{\circ} 15^{\prime} \quad 2907$

$10^{\circ} 19^{\prime}$

$12^{\circ} 16^{\prime}$

$12^{\circ} 16^{\prime} \quad 2876$

$12^{\circ} 18^{\prime} \quad 2898$

$12^{\circ} 18^{\prime} \quad 2898$

$13^{\circ} 58^{\prime}$

$10^{\circ} 27^{\prime}$

$10^{\circ} 27^{\prime} \quad 2190$

$10^{\circ} 29^{\prime} \quad 2120-2220$

$10^{\circ} 20^{\prime}$

$10^{\circ} 32^{\prime}$

$10^{\circ} 32^{\prime}$

$10^{\circ} 30^{\prime}$

$10^{\circ} 30^{\prime} \quad 2180$

$12^{\circ} 20^{\prime} \quad 2904$

$12^{\circ} 20^{\prime} \quad 2906$

$12^{\circ} 15^{\prime} \quad 2906$

$12^{\circ} 11^{\prime}$

$09^{\circ} 47^{\prime} \quad 2001$

$09^{\circ} 47^{\prime} \quad 2001$

$10^{\circ} 23^{\prime}$

$10^{\circ} 23^{\prime}$

$10^{\circ} 24^{\prime}$

$09^{\circ} 51^{\prime}$

$12^{\circ} 12^{\prime}$

$12^{\circ} 12^{\prime} \quad 2898$

$10^{\circ} 16^{\prime}$

$10^{\circ} 16^{\prime}$

$10^{\circ} 12^{\prime}$

$10^{\circ} 20^{\prime} \quad 2150$

$10^{\circ} 20^{\prime}$

$10^{\circ} 21^{\prime}$

$10^{\circ} 21^{\prime} \quad 2165$

$10^{\circ} 55^{\prime}$

$10^{\circ} 55^{\prime}$

$13^{\circ} 31^{\prime}$

$11^{\circ} 59^{\prime}$

$11^{\circ} 58^{\prime}$

$10^{\circ} 35^{\prime} \quad 2255$

$10^{\circ} 30^{\prime}$

$10^{\circ} 30^{\prime}$

$10^{\circ} 28^{\prime}$

$10^{\circ} 28^{\prime}$

$11^{\circ} 22^{\prime} \quad 2760$

$12^{\circ} 15^{\prime}$

$12^{\circ} 15^{\prime} \quad 2946$

$12^{\circ} 12^{\prime} \quad 2906$

$12^{\circ} 14^{\prime} \quad 2906$

$12^{\circ} 14^{\prime} \quad 2906$

$12^{\circ} 17^{\prime} \quad 2896$

$12^{\circ} 17^{\prime} \quad 2896$

$12^{\circ} 17^{\prime} \quad 2896$

$10^{\circ} 22^{\prime} \quad 2190$

$10^{\circ} 23^{\prime}$

$10^{\circ} 28^{\prime}$

$10^{\circ} 24^{\prime}$

$10^{\circ} 22^{\prime}$

$10^{\circ} 25^{\prime}$

$10^{\circ} 20^{\prime} \quad 2205$ 
Research Vessel, Latitude, N
Station

AT 408

401

$74 / 90$

3/85/5 OTSB

3/85/7 OTSB

50515 OTSB

50604/1 BN

50711 OTSB

50811 OTSB

51001 OTSB

51301 OTSB

10114/1 BN

10115/1 BN

\section{Cirrus (1964)}

\section{4}

Disco
1275
7423

7423

$7709 / 62$

$7709 / 73$

$7709 / 85$

7711

$7711 / 52$

$7711 / 57$

$7711 / 58$

$7711 / 62$

$7711 / 66$

$7711 / 78$

$7711 / 85$

$8511 / 1$

$8511 / 2$

$8512 / 4$

$8514 / 1$

$8521 / 6$

$8524 / 1$

8967

8968

8970

8971

8973

8976

9021

9035

$9131 / 11$

$9131 / 12$

9133/5

9133/7

9576/14 BN

9638/1 OT

$9638 / 2$

9640

9640/1

9753/4

9753/7

9753/8

$9756 / 3$

$9756 \mathrm{BN}$

9756/4 BN

9756/6

$$
\begin{aligned}
& 57^{\circ} 15^{\prime} \\
& 54^{\circ} 10^{\prime} \\
& 57^{\circ} 18^{\prime} \\
& 54^{\circ} 27^{\prime} \\
& 55^{\circ} 47^{\prime} \\
& 49^{\circ} 44^{\prime} \\
& 50^{\circ} 06^{\prime} \\
& 49^{\circ} 53^{\prime} \\
& 49^{\circ} 39^{\prime} \\
& 54^{\circ} 45^{\prime} \\
& 56^{\circ} 46^{\prime} \\
& 49^{\circ} 46^{\prime} \\
& 49^{\circ} 46^{\prime}
\end{aligned}
$$

$62^{\circ} 00^{\prime}$

(1962-present)

$31^{\circ} 6.1^{\prime}$

$37^{\circ} 51^{\prime}$

$43^{\circ} 51^{\prime}$

$60^{\circ}$

$60^{\circ}$

$60^{\circ}$

$52^{\circ} 50^{\prime}$

$52^{\circ} 53.3^{\prime}$

$52^{\circ} 53.3^{\prime}$

$53^{\circ}$

$52^{\circ} 50^{\prime}$

$53^{\circ} 11.6^{\prime}$

$53^{\circ} 10^{\prime}$

$53^{\circ} 05.8^{\prime}$

$41^{\circ} 54.9^{\prime}-41^{\circ} 54.3^{\prime}$

$41^{\circ} 49.6^{\prime}-41^{\circ} 49.1^{\prime}$

$42^{\circ}$

$42^{\circ}$

$20^{\circ} 47.9^{\prime}$

$20^{\circ} 46^{\prime}$

$31^{\circ} 25.9^{\prime}$

$31^{\circ} 35^{\prime}$

$31^{\circ} 30.4^{\prime}$

$31^{\circ} 47^{\prime}$

$32^{\circ} 02^{\prime}$

$32^{\circ} 55^{\prime}$

$30^{\circ} 04.2^{\prime}$

$34^{\circ} 06^{\prime}$

$20^{\circ} 09^{\prime}$

$20^{\circ} 07^{\prime}$

$21^{\circ}$

$21^{\circ}$

$50^{\circ} 04^{\prime}$

$49^{\circ} 50^{\prime}$

$49^{\circ} 50.2^{\prime}-49^{\circ} 50.3^{\prime}$

$50^{\circ} 03^{\prime}$

$50^{\circ} 03.2^{\prime}-50^{\circ} 08.0^{\prime}$

$50^{\circ} 54.9^{\prime}$

$50^{\circ} 54.5^{\prime}$

$50^{\circ} 54.6^{\prime}$

$49^{\circ} 48^{\prime}$

$50^{\circ} 04^{\prime}$

$50^{\circ} 04^{\prime}$

$49^{\circ} 44.2^{\prime}$
Longitude, W

( $\mathrm{E}$ - when indicated)

$10^{\circ} 21^{\prime}$
$12^{\circ} 16^{\prime}$
$10^{\circ} 23^{\prime}$
$12^{\circ} 25^{\prime}$
$10^{\circ} 52^{\prime}$
$15^{\circ} 05^{\prime}$
$13^{\circ} 53^{\prime}$
$15^{\circ} 36^{\prime}$
$14^{\circ} 34^{\prime}$
$12^{\circ} 24^{\prime}$
$12^{\circ} 14^{\prime}$
$14^{\circ} 08^{\prime}$
$13^{\circ} 56^{\prime}$

$33^{\circ} 00^{\prime}$

$21^{\circ} 10.9^{\prime}$

$27^{\circ} 06^{\prime}$

$03^{\circ} 43^{\prime}$

$20^{\circ}$

$20^{\circ}$

$20^{\circ}$

$20^{\circ} 02.8^{\prime}$

$19^{\circ} 52.4^{\prime}$

$19^{\circ} 52.4^{\prime}$

$20^{\circ}$

$20^{\circ} 02.8^{\prime}$

$20^{\circ} 05.1^{\prime}$

$20^{\circ} 14^{\prime}$

$19^{\circ} 55.7^{\prime}$

$11^{\circ} 15.7^{\prime}-11^{\circ} 14.8^{\prime}$

$11^{\circ} 06.0^{\prime}-11^{\circ} 05.4^{\prime}$

$11^{\circ}$

$11^{\circ}$

$18^{\circ} 53^{\prime}$

$22^{\circ}$

$10^{\circ} 25.9^{\prime}$

$11^{\circ} 02^{\prime}$

$11^{\circ} 4.4^{\prime}$

$11^{\circ} 09^{\prime}$

$11^{\circ} 19^{\prime}$

$11^{\circ} 40^{\prime}$

$11^{\circ} 51.7^{\prime}$

$11^{\circ} 54^{\prime}$

$21^{\circ} 39^{\prime}$

$21^{\circ} 25^{\prime}$

$18^{\circ}$

$18^{\circ}$

$13^{\circ} 54^{\prime}$

$14^{\circ} 09^{\prime}$

$14^{\circ} 07.3^{\prime}-12^{\circ} 06^{\prime}$

$13^{\circ} 51^{\prime}$

$13^{\circ} 50.6^{\prime}-13^{\circ} 52.7^{\prime}$

$12^{\circ} 12^{\prime}$

$12^{\circ} 10.9^{\prime}$

$12^{\circ} 11.1^{\prime}$

$14^{\circ} 02^{\prime}$

$13^{\circ} 56^{\prime}$

$13^{\circ} 55^{\prime}$

$14^{\circ} 01.4^{\prime} \mathrm{E}$
Depth, m

\section{0}

2900

2250

2970-2980

2500-2455

4510

3650

4787

4375

2890

2925

4050

3925

3800

4944

2283

3100

2174

2633-2646

2708

2727

2734-2742

2656-2734

2615-2621

2720-2727

2432-2380

1430-2425

2626

2384-2399

2574-2584

2281-2465

2622-2632

3064-3070

4412

1140-1222

1767-1846

1910-1932

2485

3003-3008

3610-3646

2122-2173

4453-4457

3921

3858

2112-2160

2130-2191

3688

4073

4043-4104

3719-3757

3749-3757

1942-1947

1942

1942

4055

3690

3690

3000-3500 


\begin{tabular}{|c|c|c|c|}
\hline $\begin{array}{l}\text { Research Vessel, } \\
\text { Station }\end{array}$ & Latitude, N & $\begin{array}{l}\text { Longitude, } \mathbf{W} \\
\text { (E - when indicated) }\end{array}$ & Depth, m \\
\hline $9756 / 9$ & $49^{\circ} 47.1^{\prime}$ & $14^{\circ} 01.5^{\prime}$ & 4039-4069 \\
\hline $9756-9$ & $49^{\circ} 48^{\prime}$ & $14^{\circ} 01.5^{\prime}$ & 4039-4069 \\
\hline $9756 / 14$ & $50^{\circ} 04^{\prime}$ & $13^{\circ} 55^{\prime}$ & 3690 \\
\hline $9756-14$ & $50^{\circ} 04^{\prime}$ & $13^{\circ} 54^{\prime}$ & 3688 \\
\hline $9775 / 3$ & $50^{\circ} 56.8^{\prime}$ & $12^{\circ} 21$ & 2019-2012 \\
\hline 9801 & $42^{\circ} 30^{\prime}$ & $17^{\circ} 30^{\prime}$ & $1900-4520$ \\
\hline 10106 & $50.68^{\circ}$ & $12.97^{\circ}$ & 2300 \\
\hline $10106 / 1$ & $50^{\circ} 41^{\prime}$ & $12^{\circ} 50^{\prime}$ & 2300-2315 \\
\hline $10112 / 1$ & $50^{\circ} 26^{\prime}$ & $13^{\circ} 18^{\prime}$ & $2640-2660$ \\
\hline $10112 / 1$ & $50^{\circ} 25^{\prime}$ & $13^{\circ} 20^{\prime}$ & $2640-2650$ \\
\hline $10112 / 1$ & $50^{\circ} 19^{\prime}$ & $13^{\circ} 26^{\prime}$ & $2740-2755$ \\
\hline 10112 & $50.43^{\circ}$ & $13.30^{\circ}$ & 2640-2660 \\
\hline 10113 & $50.27^{\circ}$ & $13.53^{\circ}$ & $2755-2760$ \\
\hline $10113 / 1$ & $50.27^{\circ}$ & $13.53^{\circ}$ & $2755-2760$ \\
\hline 10114 & $49.75^{\circ}$ & $14.13^{\circ}$ & $4040-4060$ \\
\hline $10114 / 1$ & $49^{\circ} 46^{\prime}$ & $14^{\circ} 08^{\prime}$ & 4050 \\
\hline 10115 & $49^{\circ} 46^{\prime}$ & $13^{\circ} 56^{\prime}$ & 3925 \\
\hline $10115 / 1$ & $49^{\circ} 46.3^{\prime}-49^{\circ} 45.6^{\prime}$ & $13^{\circ} 56.0^{\prime}-13^{\circ} 56.6^{\prime}$ & $3900-3950$ \\
\hline 11121 & $42^{\circ} 30^{\prime}$ & $21^{\circ} 30^{\prime}$ & $3465-4021$ \\
\hline $11121 / 10$ & $42^{\circ} 30^{\prime}$ & $21^{\circ} 30^{\prime}$ & $3465-4021$ \\
\hline 10141 & $24^{\circ} 33.8^{\prime}-24^{\circ} 34.8^{\prime}$ & $19^{\circ} 48.6^{\prime}-19^{\circ} 48.7^{\prime}$ & $3460-3470$ \\
\hline 10143 & $24^{\circ} 43.6^{\prime}-24^{\circ} 44.5^{\prime}$ & $20^{\circ} 3.7^{\prime}-20^{\circ} 4.5^{\prime}$ & $3700-3810$ \\
\hline 10145 & $24^{\circ} 51.5^{\prime}-24^{\circ} 53.2^{\prime}$ & $20^{\circ} 44.4^{\prime}-20^{\circ} 43.5^{\prime}$ & $4250-4260$ \\
\hline 10148 & $25^{\circ} 16.8^{\prime}-25^{\circ} 17.4^{\prime}$ & $22^{\circ} 21.3^{\prime}-22^{\circ} 24^{\prime}$ & 4879 \\
\hline 11261 & $31^{\circ} 30^{\prime}$ & $25^{\circ} 30^{\prime}$ & $5410-5430$ \\
\hline 11262 & $31^{\circ} 30^{\prime}$ & $25^{\circ} 30^{\prime}$ & $5340-5430$ \\
\hline $11891 / 3$ & $55^{\circ} 12^{\prime}$ & $20^{\circ} 20^{\prime}$ & 2080 \\
\hline $11908 / 3$ & $48^{\circ} 55.2^{\prime}$ & $16^{\circ} 29.7^{\prime}$ & 4847 \\
\hline $11908 / 12$ & $48^{\circ} 53.2^{\prime}$ & $16^{\circ} 28.9^{\prime}$ & 4851 \\
\hline $11908 / 18$ & $48.83^{\circ}$ & $16.50^{\circ}$ & 4850 \\
\hline $11908 / 23$ & $48^{\circ} 30.8^{\prime}$ & $16^{\circ} 28.9^{\prime}$ & 4844 \\
\hline $11908 / 25$ & $48^{\circ} 50.9^{\prime}$ & $16^{\circ} 28.6^{\prime}$ & 4847 \\
\hline $11908 / 39$ & $48^{\circ} 49.9^{\prime}$ & $16^{\circ} 30.1^{\prime}$ & 4845 \\
\hline $11908 / 40$ & $48^{\circ} 49^{\prime}$ & $16^{\circ} 36^{\prime}$ & 4850 \\
\hline $11908 / 44$ & $48^{\circ} 47.3^{\prime}-48^{\circ} 56.8^{\prime}$ & $16^{\circ} 29.9^{\prime}-16^{\circ} 27.6^{\prime}$ & $4843-4849$ \\
\hline $11908 / 48$ & $48^{\circ} 49.5^{\prime}$ & $16^{\circ} 28.5^{\prime}$ & 4851 \\
\hline $11908 / 51$ & $48^{\circ} 49^{\prime}$ & $16^{\circ} 36^{\prime}$ & 4850 \\
\hline $11908 / 52$ & $48^{\circ} 49^{\prime}$ & $16^{\circ} 36^{\prime}$ & 4850 \\
\hline $11908 / 68$ & $48^{\circ} 52.0^{\prime}-48^{\circ} 47.6^{\prime}$ & $16^{\circ} 24.1^{\prime}-16^{\circ} 36.1$ & $4853-4877$ \\
\hline $12174 / 35$ & $31^{\circ} 5.7^{\prime}-31^{\circ} 5.7^{\prime}$ & $21^{\circ} 10.2^{\prime}-21^{\circ} 10.2^{\prime}$ & 4942 \\
\hline $12174 / 43$ & $31^{\circ} 5.3^{\prime}$ & $21^{\circ} 10.9^{\prime}-21^{\circ} 11.0^{\prime}$ & 4947 \\
\hline $12174 / 53$ & $31^{\circ} 5.2^{\prime}$ & $21^{\circ} 10.2^{\prime}-21^{\circ} 10.3^{\prime}$ & 4945 \\
\hline $12174 / 60$ & $31^{\circ} 5.6^{\prime}$ & $21^{\circ} 10.0^{\prime}$ & 4947 \\
\hline $12174 / 80$ & $31^{\circ} 5.2^{\prime}$ & $21^{\circ} 10.2^{\prime}$ & 4942 \\
\hline $12600 / 32$ & $21^{\circ} 3.6^{\prime}$ & $31^{\circ} 10.0^{\prime}$ & 4545 \\
\hline 12930 & $48^{\circ} 50^{\prime}$ & $16^{\circ} 30^{\prime}$ & 4850 \\
\hline $12930 / 26$ & $48^{\circ} 52.93^{\prime}-48^{\circ} 50.97^{\prime}$ & $16^{\circ} 42.95^{\prime}-16^{\circ} 32.99^{\prime}$ & $4836-4843$ \\
\hline 13078 & $48^{\circ} 50^{\prime}$ & $16^{\circ} 30^{\prime}$ & 4850 \\
\hline 13200 & $48^{\circ} 50^{\prime}$ & $16^{\circ} 30^{\prime}$ & 4850 \\
\hline 13368 & $48^{\circ} 50^{\prime}$ & $16^{\circ} 30^{\prime}$ & 4850 \\
\hline 13627 & $48^{\circ} 50^{\prime}$ & $16^{\circ} 30^{\prime}$ & 4850 \\
\hline $13078 / 29$ & $48^{\circ} 56.20^{\prime}-48^{\circ} 47.35^{\prime}$ & $16^{\circ} 22.77^{\prime}-16^{\circ} 33.23^{\prime}$ & $4844-4847$ \\
\hline $13078 / 31$ & $42^{\circ} 52.80^{\prime}-48^{\circ} 49.88^{\prime}$ & $16^{\circ} 21.48^{\prime}-16^{\circ} 30.34^{\prime}$ & $4850-4844$ \\
\hline $13078 / 37$ & $48^{\circ} 52.16^{\prime}-48^{\circ} 49.63^{\prime}$ & $16^{\circ} 35.32^{\prime}-16.28 .30^{\prime}$ & $4842-4844$ \\
\hline $13200 / 09$ & $48^{\circ} 51.96^{\prime}-48^{\circ} 46.21^{\prime}$ & $16^{\circ} 24.61^{\prime}-16^{\circ} 31.63^{\prime}$ & $4844-4840$ \\
\hline $13200 / 27$ & $48^{\circ} 52.50^{\prime}-48^{\circ} 42.44^{\prime}$ & $16^{\circ} 39.9^{\prime}-16^{\circ} 41.00^{\prime}$ & 4848-4839 \\
\hline $13200 / 35$ & $48^{\circ} 44.03^{\prime}-48^{\circ} 55.85^{\prime}$ & $16^{\circ} 32.82^{\prime}-16^{\circ} 40.22^{\prime}$ & $4842-4845$ \\
\hline $13200 / 60$ & $48^{\circ} 52.11^{\prime}-48^{\circ} 48.34^{\prime}$ & $16^{\circ} 26.66^{\prime}-16^{\circ} 42.01^{\prime}$ & $4847-4843$ \\
\hline $13200 / 88$ & $48^{\circ} 52.10^{\prime}-48^{\circ} 48.52^{\prime}$ & $16^{\circ} 25.47^{\prime}-16^{\circ} 36.01^{\prime}$ & $4852-4845$ \\
\hline $13200 / 99$ & $48^{\circ} 51.36^{\prime}-48^{\circ} 52.27^{\prime}$ & $16^{\circ} 43.42^{\prime}-16^{\circ} 48.67^{\prime}$ & $4847-4850$ \\
\hline $13368 / 23$ & $48^{\circ} 50.70^{\prime}-48^{\circ} 44.84^{\prime}$ & $16^{\circ} 28.34^{\prime}-16^{\circ} 40.44^{\prime}$ & $4844-4842$ \\
\hline $13368 / 51$ & $48^{\circ} 49.71^{\prime}-48^{\circ} 48.88^{\prime}$ & $16^{\circ} 28.42^{\prime}-16^{\circ} 20.61^{\prime}$ & 4840 \\
\hline
\end{tabular}




\begin{tabular}{|c|c|c|c|}
\hline $\begin{array}{l}\text { Research Vessel, } \\
\text { Station }\end{array}$ & Latitude, N & $\begin{array}{l}\text { Longitude, } \mathbf{W} \\
(\mathrm{E}-\text { when indicated })\end{array}$ & Depth, m \\
\hline $\begin{array}{l}13369 / 1 \\
13627 / 10 \\
13627 / 23 \\
13906 / 1 \\
13907 / 1 \\
13910 / 1 \\
13914 / 1 \\
13925 / 1 \\
14137 / 1 \\
14141 / 1 \\
14143 / 1 \\
14158 / 1 \\
14317 / 1 \\
15735 / 1 \\
15758 / 2 \\
15758 / 3 \\
15758 / 5 \\
15759 / 5 \\
15765 / 1 \\
15765 / 2\end{array}$ & $\begin{array}{l}48^{\circ} 55.79^{\prime}-48^{\circ} 53.33^{\prime} \\
48^{\circ} 53.64^{\prime}-49^{\circ} 01.98^{\prime} \\
48^{\circ} 58.93^{\prime}-49^{\circ} 03.88^{\prime} \\
50^{\circ} 11.92^{\prime}-50^{\circ} 17.52^{\prime} \\
49^{\circ} 55.85^{\prime} \\
49^{\circ} 50.55^{\prime}-49^{\circ} 49.88^{\prime} \\
49^{\circ} 54.84^{\prime}-49^{\circ} 52.88^{\prime} \\
48^{\circ} 53.46^{\prime}-48^{\circ} 56.79^{\prime} \\
49^{\circ} 36.9^{\prime}-49^{\circ} 37.8^{\prime} \\
49^{\circ} 59.3^{\prime}-49^{\circ} 59.6^{\prime} \\
49^{\circ} 45.7^{\prime} \\
49^{\circ} 32.15^{\prime}-49^{\circ} 33.03^{\prime} \\
49^{\circ} 35^{\prime} \\
39.58^{\circ} \\
39.58^{\circ} \\
39.58^{\circ} \\
39.58^{\circ} \\
39.58^{\circ} \\
39.58^{\circ} \\
39.58^{\circ}\end{array}$ & $\begin{array}{l}15^{\circ} 44.66^{\prime}-15^{\circ} 38.85^{\prime} \\
16^{\circ} 42.65^{\prime}-16^{\circ} 53.26^{\prime} \\
16^{\circ} 45.22^{\prime}-16^{\circ} 40.66^{\prime} \\
14^{\circ} 39.56^{\prime}-14^{\circ} 49.87^{\prime} \\
14^{\circ} 30.34^{\prime} \\
12^{\circ} 56.84^{\prime}-13^{\circ} 00.42^{\prime} \\
13^{\circ} 34.34^{\prime}-13^{\circ} 38.99^{\prime} \\
16^{\circ} 45.86^{\prime}-16^{\circ} 54.73^{\prime} \\
14^{\circ} 04.6^{\prime}-14^{\circ} 07.8^{\prime} \\
12^{\circ} 53.4^{\prime}-12^{\circ} 57.7^{\prime} \\
12^{\circ} 53.5^{\prime}-12^{\circ} 58.3^{\prime} \\
14^{\circ} 23.27^{\prime}-14^{\circ} 19.27^{\prime} \\
14^{\circ} 20^{\prime} \\
10.32^{\circ} \\
10.32^{\circ} \\
10.32^{\circ} \\
10.32^{\circ} \\
10.32^{\circ} \\
10.32^{\circ} \\
10.32^{\circ}\end{array}$ & $\begin{array}{l}4826-4841 \\
4837-4835 \\
4837-4814 \\
3986-4016 \\
4220 \\
2456-2467 \\
2981-3115 \\
4835-4845 \\
4108-4146 \\
2494-2514 \\
2275-2308 \\
4311-4286 \\
4263 \\
4350 \\
4332 \\
4435 \\
4335 \\
4335 \\
4336 \\
4336\end{array}$ \\
\hline $\begin{array}{l}\text { Ermak (1899) } \\
31 \\
14 / 50 \\
34 / 60\end{array}$ & $\begin{array}{l}79^{\circ} 41^{\prime} \\
70^{\circ} 42^{\prime} \\
73^{\circ} 22^{\prime}\end{array}$ & $\begin{array}{l}04^{\circ} 58^{\prime \prime} E \\
07^{\circ} 21^{\prime \prime} E \\
10^{\circ} 20^{\prime \prime E}\end{array}$ & $\begin{array}{l}2857 \\
2992 \\
2203\end{array}$ \\
\hline $\begin{array}{l}\text { F. Litke (1955) } \\
32 \\
35 \\
36 \\
37\end{array}$ & $\begin{array}{l}81^{\circ} 49^{\prime} \\
82^{\circ} 36^{\prime} \\
82^{\circ} 39^{\prime} \\
82^{\circ} 39^{\prime}\end{array}$ & $\begin{array}{l}13^{\circ} 20^{\prime \prime} \mathrm{E} \\
23^{\circ} 51^{\prime \prime} \mathrm{E} \\
33^{\circ} 30^{\prime \prime} \mathrm{E} \\
33^{\circ} 30^{\prime \prime} \mathrm{E}\end{array}$ & $\begin{array}{l}2040 \\
4000 \\
2899 \\
2899\end{array}$ \\
\hline $\begin{array}{l}\text { Fram I (1979) } \\
1 \\
3 \\
4 \\
10 \\
11 \\
12 \\
15 \\
17 \\
18\end{array}$ & $\begin{array}{l}84^{\circ} 19^{\prime} \\
84^{\circ} 19^{\prime} \\
84^{\circ} 19^{\prime} \\
84.26^{\circ} \\
84.26^{\circ} \\
84^{\circ} 13^{\prime} \\
84^{\circ} 00^{\prime} \\
83^{\circ} 48^{\prime} \\
83^{\circ} 40^{\prime}\end{array}$ & $\begin{array}{l}08^{\circ} 19^{\prime} \\
08^{\circ} 15^{\prime} \\
08^{\circ} 13^{\prime} \\
08.04^{\circ} \\
08.04^{\circ} \\
07^{\circ} 56^{\prime} \\
07^{\circ} 16^{\prime} \\
06^{\circ} 50^{\prime} \\
06^{\circ} 49^{\prime}\end{array}$ & $\begin{array}{l}3930 \\
3500 \\
3300 \\
3940 \\
3970 \\
3965 \\
3500 \\
3000 \\
2300\end{array}$ \\
\hline $\begin{array}{l}\text { G.O.Sars, Cruise } \\
40 / 367 \\
42 / 368 \\
46 / 372 \\
50 / 373 \\
52 / 374 \\
54 / 377 \\
64 / 381 \\
66 / 383 \\
68 / 384 \\
72 / 386 \\
74 / 387\end{array}$ & $\begin{array}{l}\text { R-ECO }(2004) \\
42.92^{\circ}-42.89^{\circ} \\
42.81^{\circ}-42.78^{\circ} \\
42.77^{\circ}-42.76^{\circ} \\
43.03^{\circ}-43.01^{\circ} \\
42.92^{\circ}-42.88^{\circ} \\
51.33^{\circ}-51.34^{\circ} \\
51.55^{\circ}-51.58^{\circ} \\
53.03^{\circ}-53.01^{\circ} \\
53.14^{\circ}-53.15^{\circ} \\
53.28^{\circ}-53.26^{\circ} \\
53,29^{\circ}-53,31^{\circ}\end{array}$ & $\begin{array}{l}30.34^{\circ}-30.35^{\circ} \\
29.64^{\circ}-29.64^{\circ} \\
29.27^{\circ}-29.28^{\circ} \\
28.55^{\circ}-28.57^{\circ} \\
28.14^{\circ}-28.14^{\circ} \\
28.87^{\circ}-28.91^{\circ} \\
30.97^{\circ}-30.98^{\circ} \\
33.61^{\circ}-33.6^{\circ} \\
34.77^{\circ}-34.77^{\circ} \\
35.53^{\circ}-35.53^{\circ} \\
36,79^{\circ}-36.81^{\circ}\end{array}$ & $\begin{array}{l}2954-2968 \\
2063-2107 \\
3024-3068 \\
2593-2607 \\
2973-2979 \\
3505-3527 \\
3452-3465 \\
2995-3071 \\
2306-2374 \\
2522-2567 \\
3048-3063\end{array}$ \\
\hline $\begin{array}{l}\text { G. Sedov (1937-19 } \\
59 \\
100 \\
101\end{array}$ & $\begin{array}{l}82^{\circ} 42^{\prime} \\
81^{\circ} 10^{\prime} \\
82^{\circ} 51^{\prime}\end{array}$ & $\begin{array}{l}87^{\circ} 03^{\prime} \\
137^{\circ} 17^{\prime} \\
137^{\circ} 23^{\prime}\end{array}$ & $\begin{array}{l}2363 \\
2500 \\
3700-3800\end{array}$ \\
\hline $\begin{array}{l}\text { Ho̊kon Mosby } \\
81.06 .07 .3 \\
81.08 .14 .5\end{array}$ & $\begin{array}{l}65^{\circ} 39^{\prime} 5 \\
64^{\circ} 16^{\prime} 9\end{array}$ & $\begin{array}{l}02^{\circ} 38^{\prime} 0 \mathrm{E} \\
00^{\circ} 11^{\prime} 7\end{array}$ & $\begin{array}{l}2019 \\
2630\end{array}$ \\
\hline
\end{tabular}


Research Vessel, Latitude, N Station

81.08.15.4

82.11.21.2

82.11.21.4

82.11.24.1

83.06.10.1

83.06.11.1

84.03.17.1

84.03.17.2

85.01.10.1

85.01.11.3

86.06.12.1

87.06 .13 .2

86.07.24.1

86.07.26.1

86.07.28.1

87.06.14.1
Longitude, $\mathrm{W}$

( $\mathrm{E}$ - when indicated)

$\begin{array}{ll}00^{\circ} 23^{\prime} 0 & 2090 \\ 07^{\circ} 39^{\prime} 2 & 2680 \\ 06^{\circ} 07^{\prime} 5 & 3900 \\ 01^{\circ} 33^{\prime} 0 & 3000 \\ 00^{\circ} 44^{\prime} 2 & 2791 \\ 00^{\circ} 29^{\prime} 9 & 2497 \\ 07^{\circ} 30^{\prime} 4 & 2003 \\ 06^{\circ} 47^{\prime} 3 & 2407 \\ 01^{\circ} 50^{\prime} 4 & 3098 \\ 00^{\circ} 07^{\prime} 8 \mathrm{E} & 2086 \\ 07^{\circ} 00^{\prime} 6 & 2791 \\ 00^{\circ} 44^{\prime} 2 & 2791 \\ 06^{\circ} 46^{\prime} 9 & 2538 \\ 09^{\circ} 54^{\prime} 6 & 2212 \\ 06^{\circ} 31^{\prime} 8 & 2525 \\ 09^{\circ} 30^{\prime} 6 & 2200\end{array}$

\section{Healy, HLY0502 (2005)}

$\begin{array}{ll}6 & 73^{\circ} 52,9^{\prime} \\ 11 & 75^{\circ} 59,94^{\prime} \\ 13 & 75^{\circ} 18,75^{\prime} \\ 15 & 73^{\circ} 00^{\prime} \\ 248 & 41^{\circ} 40^{\prime} 41^{\prime \prime} \\ 650 & 36^{\circ} 54^{\prime} \\ 695 & 38^{\circ} 23^{\prime} \\ 749 & 38^{\circ} 54^{\prime} \\ 794 & 38^{\circ} 55^{\prime} \\ 821 & 30^{\circ} 45^{\prime}\end{array}$

$153^{\circ} 33,78^{\prime}$
$160^{\circ} 37,23^{\prime}$
$161^{\circ} 37,38^{\prime}$
$156^{\circ} 00^{\prime} \mathrm{E}$
$29^{\circ} 04^{\prime} 23^{\prime \prime}$
$23^{\circ} 06,5^{\prime}$
$23^{\circ} 34^{\prime}$
$23^{\circ} 27^{\prime}$
$23^{\circ} 10,45^{\prime}$
$25^{\circ} 20^{\prime}$

3500

2000

2100

2500

2870

4400

2540

5005

5005

5440

\section{Ingolf (1895-1896)}

10
11
18
19

$61^{\circ} 44^{\prime}$

$64^{\circ} 34^{\prime}$

$61^{\circ} 44^{\prime}$

$60^{\circ} 29^{\prime}$

$58^{\circ} 20^{\prime}$

$58^{\circ} 01^{\prime}$

$63^{\circ} 06^{\prime}$

$61^{\circ} 50^{\prime}$

$60^{\circ} 17^{\prime}$

$59^{\circ} 12^{\prime}$

$61^{\circ} 39^{\prime}$

$62^{\circ} 07^{\prime}$

$62^{\circ} 06^{\prime}$

$61^{\circ} 33^{\prime}$

$49^{\circ} 27^{\prime}$

$64^{\circ} 44^{\prime}$

$67^{\circ} 57^{\prime}$

$69^{\circ} 31^{\prime}$

$68^{\circ} 27^{\prime}$

$43^{\circ} 40^{\prime}$

401

Ingolf (1977)

$\begin{array}{ll}21 & 58.02^{\circ} \\ 36 & 61.85^{\circ} \\ 87 & 65.03^{\circ}\end{array}$

James Cook, ECOMAR cruises (2007-2010)

JC10/92

JC10/130

JC11/17

JC11/23

JC11/75

JC11/101 $39.58^{\circ}$

$39.58^{\circ}$

$49^{\circ} 14.68^{\prime}-49^{\circ} 03.43^{\prime}$

$48^{\circ} 54.59^{\prime}-49^{\circ} 15.85^{\prime}$

$53^{\circ} 51.10^{\prime}-54^{\circ} 06.02^{\prime}$

$54^{\circ} 06.33^{\prime}-53^{\circ} 47.47^{\prime}$ $30^{\circ} 29^{\prime}$

$31^{\circ} 12^{\prime}$

$30^{\circ} 29^{\prime}$

$34^{\circ} 14^{\prime}$

$40^{\circ} 48^{\prime}$

$44^{\circ} 45^{\prime}$

$56^{\circ} 00^{\prime}$

$56^{\circ} 21^{\prime}$

$54^{\circ} 05^{\prime}$

$51^{\circ} 05^{\prime}$

$17^{\circ} 10^{\prime}$

$15^{\circ} 07^{\prime}$

$19^{\circ} 00^{\prime}$

$19^{\circ} 00^{\prime}$

$13^{\circ} 33^{\prime}$

$31^{\circ} 00^{\prime}$

$06^{\circ} 44^{\prime}$

$07^{\circ} 06^{\prime}$

$08^{\circ} 20^{\prime}$

$18^{\circ} 45^{\prime}$

$44.75^{\circ}$

$56.35^{\circ}$

$23.93^{\circ}$

$10.30^{\circ}$

$10.30^{\circ}$

$27^{\circ} 42.31^{\prime}-27^{\circ} 53.86^{\prime}$

$27^{\circ} 50.00^{\prime}-27^{\circ} 50.00^{\prime}$

$36^{\circ} 11.36^{\prime}-36^{\circ} 07.20^{\prime}$

$33^{\circ} 58.27^{\prime}-34^{\circ} 02.89^{\prime}$
2137

2377-2448

2066-2134

2819

3192

2505

2193

2624

3136-3229

3330-3403

2266-2340

2038

1957-2050

2051

2100

2450

2280

2382-2465

1993

5000-5025

2505

2402

2044

4356

4356

2687-2727

2631-2724

2605-2630

2405-2435 


\begin{tabular}{|c|c|c|c|}
\hline $\begin{array}{l}\text { Research Vessel, } \\
\text { Station }\end{array}$ & Latitude, N & $\begin{array}{l}\text { Longitude, } \mathbf{w} \\
\text { (E - when indicated) }\end{array}$ & Depth, m \\
\hline $\begin{array}{l}\text { JC11/106 } \\
\text { JC11/111 } \\
\text { JC37/15 } \\
\text { JC37/19 } \\
\text { JC37/27 } \\
\text { JC37/61 } \\
\text { JC37/67 } \\
\text { JC37/70 } \\
\text { JC37/79 } \\
\text { JC48/16, Dive } 162 \\
\text { JC48/28, Dive } 168 \\
\text { JC48/40, Dive } 173 \\
\text { JC48/43, Dive } 174 \\
\text { JC48/53, Dive } 178 \\
\text { JC48/54, Dive } 179\end{array}$ & $\begin{array}{l}54^{\circ} 05.68^{\prime}-53^{\circ} 46.94^{\prime} \\
54^{\circ} 05.68^{\prime}-53^{\circ} 47.71^{\prime} \\
48^{\circ} 58.73^{\prime}-49^{\circ} 11.14^{\prime} \\
48^{\circ} 58.05^{\prime}-49^{\circ} 14.36^{\prime} \\
48^{\circ} 57.34^{\prime}-49^{\circ} 13.55^{\prime} \\
54^{\circ} 19.62^{\prime}-54^{\circ} 04.96^{\prime} \\
54^{\circ} 19.50^{\prime}-54^{\circ} 06.55^{\prime} \\
54^{\circ} 19.23^{\prime}-54^{\circ} 03.65^{\prime} \\
54^{\circ} 03.60^{\prime}-53^{\circ} 57.69^{\prime} \\
53^{\circ} 59.39^{\prime} \\
54^{\circ} 01.47^{\prime} \\
48^{\circ} 44.11^{\prime} \\
48^{\circ} 43.87^{\prime} \\
49^{\circ} 01.43^{\prime} \\
49^{\circ} 05.91^{\prime}\end{array}$ & $\begin{array}{l}33^{\circ} 58.54^{\prime}-34^{\circ} 03.02^{\prime} \\
33^{\circ} 58.54^{\prime}-34^{\circ} 02.83^{\prime} \\
27^{\circ} 51.01^{\prime}-27^{\circ} 49.17^{\prime} \\
27^{\circ} 51.06^{\prime}-27^{\circ} 49.29^{\prime} \\
27^{\circ} 49.83^{\prime}-27^{\circ} 50.92^{\prime} \\
36^{\circ} 00.87^{\prime}-36^{\circ} 07.98^{\prime} \\
36^{\circ} 01.11^{\prime}-36^{\circ} 07.14^{\prime} \\
36^{\circ} 01.17^{\prime}-36^{\circ} 08.42^{\prime} \\
33^{\circ} 58.84^{\prime}-34^{\circ} 00.55^{\prime} \\
36^{\circ} 11.66^{\prime} \\
34^{\circ} 10.63^{\prime} \\
28^{\circ} 39.33^{\prime} \\
28^{\circ} 39.01^{\prime} \\
27^{\circ} 41.26^{\prime} \\
27^{\circ} 50.33^{\prime}\end{array}$ & $\begin{array}{l}2410-2445 \\
2404-2430 \\
2630 \\
2750 \\
2700 \\
2618 \\
2620-2676 \\
2621-2630 \\
2452 \\
2450-2272 \\
2445-2435 \\
2623-2428 \\
2620-2547 \\
2442-2630 \\
2700\end{array}$ \\
\hline $\begin{array}{l}\text { James Cook, Cruis } \\
\text { JC36/4 } \\
\text { JC36/21 }\end{array}$ & $\begin{array}{l}\text { JC } 36 \\
48^{\circ} 9.078^{\prime}-48^{\circ} 8.590^{\prime} \\
48^{\circ} 21.472^{\prime}-48^{\circ} 21.411^{\prime}\end{array}$ & $\begin{array}{l}10^{\circ} 34.607^{\prime}-10^{\circ} 34.119^{\prime} \\
10^{\circ} 55.043^{\prime}-10^{\circ} 55.342^{\prime}\end{array}$ & $\begin{array}{l}3647 \\
3062\end{array}$ \\
\hline $\begin{array}{l}\text { Jean Charcot }(196 \\
\text { P-3 } \\
69 \\
\text { P-92 } \\
\text { P-111 } \\
P-113 \\
P-115 \\
P-117 \\
201-12 \\
202-15\end{array}$ & $\begin{array}{l}53^{\circ} 55^{\prime} \\
36^{\circ} 49^{\prime} \\
35^{\circ} 59^{\prime} \\
45^{\circ} 35^{\prime} \\
45^{\circ} 08^{\prime} \\
45^{\circ} 14^{\prime} \\
40^{\circ} 42^{\prime} \\
38^{\circ} 04^{\prime} \\
37^{\circ} 19^{\prime}\end{array}$ & $\begin{array}{l}17^{\circ} 52^{\prime} \\
27^{\circ} 06^{\prime} \\
04^{\circ} 30^{\prime} \\
03^{\circ} 52^{\prime} \\
05^{\circ} 31^{\prime} \\
05^{\circ} 31^{\prime} \\
09^{\circ} 57^{\prime} \\
25^{\circ} 27^{\prime} \\
26^{\circ} 28^{\prime}\end{array}$ & $\begin{array}{l}2460 \\
3663 \\
4350 \\
4152 \\
4760 \\
4700 \\
4660 \\
2100 \\
2200\end{array}$ \\
\hline $\begin{array}{l}\text { Jean Charcot }(197 \\
\text { DS } 1 \\
\text { DS } 10 \\
\text { DS } 12 \\
\text { DS } 21 \\
36 \\
92 \\
95 \\
120 \\
126 \\
129 \\
130 \\
131 \\
163 \\
165 \\
171 \\
173 \\
174 \\
176 \\
185 \\
202 \\
206 \\
227 \\
235 \\
245 \\
249 \\
250 \\
251 \\
252\end{array}$ & $\begin{array}{l}-1972) \\
39^{\circ} 43^{\prime} \\
40^{\circ} 59^{\prime} \\
42^{\circ} 15^{\prime} \\
35^{\circ} 59^{\prime} \\
38^{\circ} 11^{\prime} \\
39^{\circ} 04^{\prime} \\
39^{\circ} 04^{\prime} \\
39^{\circ} 04^{\prime} \\
39^{\circ} 20^{\prime} \\
38^{\circ} 58^{\prime} \\
38^{\circ} 55^{\prime} \\
39^{\circ} 05^{\prime} \\
37^{\circ} 27^{\prime} \\
37^{\circ} 33^{\prime} \\
37^{\circ} 59^{\prime} \\
37^{\circ} 56^{\prime} \\
38^{\circ} 06^{\prime} \\
38^{\circ} 00.5^{\prime} \\
38^{\circ} 01^{\prime} \\
37^{\circ} 27^{\prime} \\
37^{\circ} 21^{\prime} \\
37^{\circ} 10^{\prime} \\
37^{\circ} 19^{\prime} \\
40^{\circ} 07^{\prime} \\
42^{\circ} 50^{\prime} \\
45^{\circ} 55^{\prime} \\
47^{\circ} 38^{\prime} \\
47^{\circ} 36^{\prime}\end{array}$ & $\begin{array}{l}04^{\circ} 42^{\prime \prime} \mathrm{E} \\
05^{\circ} 05^{\prime \prime} \mathrm{E} \\
04^{\circ} 28^{\prime \prime} \mathrm{E} \\
01^{\circ} 13^{\prime} \\
29^{\circ} 39^{\prime} \\
28^{\circ} 28^{\prime} \\
28^{\circ} 26^{\prime} \\
32^{\circ} 44^{\prime} \\
33^{\circ} 47^{\prime} \\
33^{\circ} 26.5^{\prime} \\
33^{\circ} 22^{\prime} \\
32^{\circ} 44^{\prime} \\
26^{\circ} 03^{\prime} \\
25^{\circ} 58^{\prime} \\
26^{\circ} 07^{\prime} \\
26^{\circ} 07^{\prime} \\
26^{\circ} 15^{\prime} \\
26^{\circ} 21.5^{\prime} \\
24^{\circ} 58^{\prime} \\
25^{\circ} 00^{\prime} \\
25^{\circ} 29^{\prime} \\
25^{\circ} 20^{\prime} \\
25^{\circ} 33^{\prime} \\
22^{\circ} 16^{\prime} \\
17^{\circ} 32.5^{\prime} \\
17^{\circ} 30^{\prime} \\
08^{\circ} 56^{\prime} \\
08^{\circ} 47^{\prime}\end{array}$ & $\begin{array}{l}2560 \\
2668 \\
2052 \\
2415 \\
2670 \\
2450 \\
2440 \\
2100 \\
3360 \\
3056-3000 \\
2953 \\
2120 \\
2350 \\
2050-2085 \\
3215 \\
3225 \\
3075 \\
2720-2440 \\
2200 \\
2900 \\
2090 \\
2170 \\
2100 \\
4270 \\
4690-4620 \\
4680 \\
3330 \\
2625\end{array}$ \\
\hline $\begin{array}{l}\text { Jean Charcot }(197 \\
\text { DS } 05 \\
\text { DS } 08\end{array}$ & $\begin{array}{l}1975) \\
65^{\circ} 22.09^{\prime} \\
69^{\circ} 14.03^{\prime}\end{array}$ & $\begin{array}{l}00^{\circ} 02.01^{\prime} \mathrm{E} \\
04^{\circ} 18.04^{\prime} \mathrm{E}\end{array}$ & $\begin{array}{l}2970 \\
3213\end{array}$ \\
\hline
\end{tabular}




\begin{tabular}{|c|c|c|c|}
\hline $\begin{array}{l}\text { Research Vessel, } \\
\text { Station }\end{array}$ & Latitude, $\mathbf{N}$ & $\begin{array}{l}\text { Longitude, } \mathbf{W} \\
\text { (E - when indicated) }\end{array}$ & Depth, m \\
\hline $\begin{array}{l}\text { DS } 10 \\
\text { DS } 11 \\
\text { DS } 12 \\
\text { DS } 13 \\
\text { DS } 14 \\
\text { DS } 15 \\
\text { DS } 18 \\
\text { CP } 13 \\
\text { CP } 14 \\
\text { CP } 15 \\
\text { CP } 16 \\
\text { CP } 17 \\
\text { KR } 05 \\
\text { KR } 18 \\
\text { KR } 19\end{array}$ & $\begin{array}{l}69^{\circ} 38.04^{\prime} \\
69^{\circ} 32.09^{\prime} \\
76^{\circ} 54.04^{\prime} \\
76^{\circ} 54.03^{\prime} \\
76^{\circ} 02.07^{\prime} \\
74^{\circ} 42.09^{\prime} \\
73^{\circ} 36.03^{\prime} \\
76^{\circ} 01.07^{\prime} \\
74^{\circ} 42^{\prime} \\
73^{\circ} 33^{\prime} \\
73^{\circ} 28.02^{\prime} \\
73^{\circ} 30.07^{\prime} \\
66^{\circ} 46.04^{\prime} \\
73^{\circ} 37.09^{\prime} \\
73^{\circ} 37.02^{\prime}\end{array}$ & $\begin{array}{l}10^{\circ} 28.06^{\prime} \mathrm{E} \\
10^{\circ} 02.03^{\prime} \mathrm{E} \\
01^{\circ} 44.06^{\prime} \mathrm{E} \\
01^{\circ} 49^{\prime \prime} \mathrm{E} \\
01^{\circ} 47^{\prime} \\
03^{\circ} 27.06^{\prime} \\
13^{\circ} 35.01^{\prime} \\
01^{\circ} 49.04^{\prime} \\
03^{\circ} 03.06^{\prime} \\
07^{\circ} 37.09^{\prime} \\
10^{\circ} 06.06^{\prime} \\
13^{\circ} 39.06^{\prime} \\
01^{\circ} 33.02^{\prime} \\
07^{\circ} 26.03^{\prime} \\
07^{\circ} 26.03^{\prime}\end{array}$ & $\begin{array}{l}2939 \\
2957 \\
3200 \\
3193 \\
3709 \\
3595 \\
2470 \\
3709 \\
3617 \\
3210 \\
2937 \\
2502 \\
3665 \\
3306 \\
3294\end{array}$ \\
\hline $\begin{array}{l}\text { Jean Charcot (198 } \\
9 / 21\end{array}$ & $47^{\circ} 33^{\prime}$ & $98^{\circ} 27^{\prime}$ & 2200 \\
\hline $\begin{array}{l}\text { Jean Charcot (Cru } \\
57\end{array}$ & $\begin{array}{l}\text { Zarco) } \\
32.42^{\circ}\end{array}$ & $16.68^{\circ}$ & 2800 \\
\hline $\begin{array}{l}\text { Lena (1955) } \\
35 \\
37\end{array}$ & $\begin{array}{l}82^{\circ} 34.05^{\prime} \\
82^{\circ} 39.07^{\prime}\end{array}$ & $\begin{array}{l}22^{\circ} 57^{\prime} \mathrm{E} \\
38^{\circ} 30^{\prime} \mathrm{E}\end{array}$ & $\begin{array}{l}4000 \\
2892\end{array}$ \\
\hline $\begin{array}{l}\text { Marvel } \\
\text { PL } 1196\end{array}$ & 36 13.78' & $3354.14^{\prime}$ & 2295 \\
\hline $\begin{array}{l}\text { Meteor, Cruise } 3 \text { ( } \\
24 \text { AT2 } \\
\text { 30 AT } \\
\text { 30AT } 3 \\
37 A T 4 \\
38 \text { AT5 } \\
38 \text { AT } \\
\text { 100AT } 152\end{array}$ & $\begin{array}{l}\text { 66) } \\
42^{\circ} 26.08^{\prime} \\
42^{\circ} 55.4^{\prime} \\
42^{\circ} 49.08^{\prime} \\
42^{\circ} 06.03^{\prime} \\
42^{\circ} 24.06^{\prime} \\
42^{\circ} 10.7^{\prime} \\
21^{\circ} 27.1^{\prime}\end{array}$ & $\begin{array}{l}14^{\circ} 49.00^{\prime} \\
14^{\circ} 07.9^{\prime} \\
14^{\circ} 14.08^{\prime} \\
14^{\circ} 42.00^{\prime} \\
14^{\circ} 32.05^{\prime} \\
14^{\circ} 20.8^{\prime} \\
18^{\circ} 16.1^{\prime}\end{array}$ & $\begin{array}{l}5325 \\
5260 \\
5315 \\
5330 \\
5330 \\
5275 \\
2049-2120\end{array}$ \\
\hline $\begin{array}{l}\text { Meteor, Cruise } 5 \\
14 \\
15 \\
30 \\
42\end{array}$ & $\begin{array}{l}34^{\circ} 31^{\prime} \\
34^{\circ} 40^{\prime} \\
34^{\circ} 39^{\prime}-68^{\prime} \\
43^{\circ} 08^{\prime}\end{array}$ & $\begin{array}{l}26^{\circ} 03^{\prime} \mathrm{E} \\
26^{\circ} 00^{\prime} \mathrm{E} \\
25^{\circ} 55-54^{\prime} \mathrm{E} \\
31^{\circ} 52^{\prime} \mathrm{E}\end{array}$ & $\begin{array}{l}3259 \\
2069 \\
2173-2142 \\
2563\end{array}$ \\
\hline $\begin{array}{l}\text { Meteor, Cruise } 17 \\
\text { B1 } \\
\text { B2 } \\
\text { D1 }\end{array}$ & $\begin{array}{l}969) \\
36^{\circ} 10^{\prime} \\
36^{\circ} 14^{\prime} \\
36^{\circ} 28^{\prime}\end{array}$ & $\begin{array}{l}18^{\circ} 23^{\prime} \mathrm{E} \\
18^{\circ} 09^{\prime} \mathrm{E} \\
20^{\circ} 38^{\prime} \mathrm{E}\end{array}$ & $\begin{array}{l}4072 \\
3910 \\
2760\end{array}$ \\
\hline $\begin{array}{l}\text { Meteor, Cruise } 25 \\
33 \\
36 \\
36 \\
36 \\
37\end{array}$ & $\begin{array}{l}60^{\circ} \\
61^{\circ} \\
63^{\circ} \\
63^{\circ} \\
65^{\circ}\end{array}$ & $\begin{array}{l}28.57^{\circ} \mathrm{E} \\
21.57^{\circ} \mathrm{E} \\
21.51^{\circ} \mathrm{E} \\
21.52^{\circ} \mathrm{E} \\
18.41^{\circ} \mathrm{E}\end{array}$ & $\begin{array}{l}2074-3947 \\
2074-3947 \\
2074-3947 \\
2074-3947 \\
2074-3947\end{array}$ \\
\hline $\begin{array}{l}\text { Meteor, Cruise } 36 \\
\text { 100AT } 152\end{array}$ & $\begin{array}{l}\text { (975) } \\
21^{\circ} 27.1^{\prime}\end{array}$ & $18^{\circ} 16.1^{\prime}$ & $2049-2120$ \\
\hline $\begin{array}{l}\text { Meteor (1988) } \\
233 \\
240 \\
246 \\
255 \\
\text { B-4 }\end{array}$ & $\begin{array}{l}47^{\circ} 15^{\prime} \\
47^{\circ} 26^{\prime} \\
47^{\circ} 24.90^{\prime} \\
47^{\circ} 22^{\prime} \\
47^{\circ} 09.09^{\prime}\end{array}$ & $\begin{array}{l}19^{\circ} 36^{\prime} \\
19^{\circ} 42^{\prime} \\
19^{\circ} 48.20^{\prime} \\
19^{\circ} 43^{\prime} \\
19^{\circ} 35.06^{\prime} \mathrm{E}\end{array}$ & $\begin{array}{l}4550 \\
4524 \\
4550 \\
3800 \\
4565 \text { (100 m above seabed) }\end{array}$ \\
\hline
\end{tabular}




\begin{tabular}{|c|c|c|c|}
\hline $\begin{array}{l}\text { Research Vessel, } \\
\text { Station }\end{array}$ & Latitude, $\mathbf{N}$ & $\begin{array}{l}\text { Longitude, } \mathbf{W} \\
\text { (E - when indicated) }\end{array}$ & Depth, m \\
\hline $\begin{array}{l}\text { B-5 } \\
\text { B-6 } \\
\text { B-7 } \\
\text { B-8 } \\
\text { B-9 }\end{array}$ & $\begin{array}{l}47^{\circ} 10.09^{\prime} \\
47^{\circ} 01.08^{\prime} \\
47^{\circ} 12.06^{\prime} \\
47^{\circ} 13.03^{\prime} \\
47^{\circ} 14.00^{\prime}\end{array}$ & $\begin{array}{l}19^{\circ} 36.01^{\prime} \mathrm{E} \\
19^{\circ} 36.06^{\prime} \mathrm{E} \\
19^{\circ} 37.00^{\prime} \mathrm{E} \\
19^{\circ} 37.07^{\prime} \mathrm{E} \\
19^{\circ} 38.03^{\prime} \mathrm{E}\end{array}$ & $\begin{array}{l}4565 \text { (200 } \mathrm{m} \text { above seabed) } \\
4565 \text { (200 } \mathrm{m} \text { above seabed) } \\
4565(200 \mathrm{~m} \text { above seabed) }) \\
4560 \text { (400 } \mathrm{m} \text { above seabed) } \\
4550 \text { (400 } \mathrm{m} \text { above seabed) }\end{array}$ \\
\hline $\begin{array}{l}\text { Meteor (1993) } \\
426 \\
427 \\
501\end{array}$ & $\begin{array}{l}75^{\circ} 20.20^{\prime}-75^{\circ} 19.80^{\prime} \\
75^{\circ} 18.50^{\prime}-75^{\circ} 18.20^{\prime} \\
75^{\circ} 9^{\prime}-75^{\circ} 9.60^{\prime}\end{array}$ & $\begin{array}{l}09^{\circ} 55.3^{\prime}-09^{\circ} 53.50^{\prime} \mathrm{E} \\
09^{\circ} 46.20^{\prime}-09^{\circ} 44.40^{\prime} \mathrm{E} \\
12^{\circ} 40.20^{\prime}-12^{\circ} 37.90^{\prime} \mathrm{E}\end{array}$ & $\begin{array}{l}2538-2548 \\
2564-2609 \\
2000-2021\end{array}$ \\
\hline $\begin{array}{l}\text { Meteor (1996) } \\
\text { Me5-45ku } \\
\text { Me25-15ku } \\
\text { Me25-16ku } \\
\text { Me25-20es } \\
\text { Me25-20ku } \\
\text { Me25-21ku } \\
\text { Me25-38ku }\end{array}$ & $\begin{array}{l}34.09^{\circ} \\
37.63^{\circ} \\
36.59^{\circ} \\
34.05^{\circ} \\
34.05^{\circ} \\
33.60^{\circ} \\
34.46^{\circ}\end{array}$ & $\begin{array}{l}32.02^{\circ} \mathrm{E} \\
18.39^{\circ} \mathrm{E} \\
21.53^{\circ} \mathrm{E} \\
27.77^{\circ} \mathrm{E} \\
27.75^{\circ} \mathrm{E} \\
28.58^{\circ} \mathrm{E} \\
32.46^{\circ} \mathrm{E}\end{array}$ & $\begin{array}{l}2572-2569 \\
2996-3018 \\
3832-3947 \\
2453-2492 \\
2454-2461 \\
2734-3009 \\
2427-4400\end{array}$ \\
\hline $\begin{array}{l}\text { Meteor } \\
49-22 \\
49-23 \\
49-24 \\
49-26 \\
49-30\end{array}$ & $\begin{array}{l}64^{\circ} 59^{\prime} \\
64^{\circ} 41^{\prime} \\
65^{\circ} 48^{\prime} \\
65^{\circ} 10^{\prime} \\
63^{\circ} 32^{\prime}\end{array}$ & $\begin{array}{l}01^{\circ} 28^{\prime} \mathrm{E} \\
01^{\circ} 38^{\prime} \mathrm{E} \\
01^{\circ} 46^{\prime} \mathrm{E} \\
02^{\circ} 15^{\prime} \mathrm{E} \\
03^{\circ} 04^{\prime} \mathrm{E}\end{array}$ & $\begin{array}{l}2926 \\
2842 \\
2876 \\
2878 \\
2360\end{array}$ \\
\hline $\begin{array}{l}\text { Meteor } \\
\text { AT } 2 \\
\text { AT } 3 \\
\text { AT } 4 \\
\text { AT } 5 \\
\text { AT } 90 \\
\text { AT } 91 \\
\text { A } 2 \\
\text { B } 2 \\
\text { D } \\
\text { D } 1 \\
\text { 2-AT4 } \\
3-A T 2 \\
3-A T 4 \\
3-29 \\
13 \\
14 \\
15 \\
30 \\
37 \\
42 \\
191\end{array}$ & $\begin{array}{l}42^{\circ} 26.8^{\prime}-42^{\circ} 40.9^{\prime} \\
42^{\circ} 49.8^{\prime}-42^{\circ} 42.4^{\prime} \\
42^{\circ} 06.3^{\prime}-42^{\circ} 08.1^{\prime} \\
42^{\circ} 24.6^{\prime}-42^{\circ} 36.1^{\prime} \\
42^{\circ} 38.5^{\prime}-42^{\circ} 42.0^{\prime} \\
42^{\circ} 44.5^{\prime}-42^{\circ} 36.5^{\prime} \\
35^{\circ} 45.6^{\prime} \\
36^{\circ} 14.0^{\prime} \\
36^{\circ} 28.8^{\prime} \\
36^{\circ} 29^{\prime} \\
42^{\circ} 06^{\prime} \\
42^{\circ} 27^{\prime} \\
42^{\circ} 06^{\prime} \\
42^{\circ} 17.2^{\prime} \\
34^{\circ} 25.00^{\prime} \\
34^{\circ} 31.00^{\prime} \\
34^{\circ} 40.22^{\prime} \\
34^{\circ} 39^{\prime} \\
42^{\circ} 06^{\prime} \\
43^{\circ} 08.27^{\prime} \\
33^{\circ} 46^{\prime}\end{array}$ & $\begin{array}{l}14^{\circ} 49.0^{\prime}-14^{\circ} 49.2^{\prime} \\
14^{\circ} 14.8^{\prime}-14^{\circ} 24.3^{\prime} \\
14^{\circ} 42.0^{\prime}-14^{\circ} 30.7^{\prime} \\
14^{\circ} 32.5^{\prime}-14^{\circ} 44.0^{\prime} \\
13^{\circ} 31.0^{\prime}-13^{\circ} 28.0^{\prime} \\
13^{\circ} 29.8^{\prime}-13^{\circ} 34.3^{\prime} \\
17^{\circ} 53.2^{\prime} \mathrm{E} \\
18^{\circ} 09.4^{\prime} \mathrm{E} \\
20^{\circ} 38.5^{\prime} \mathrm{E} \\
20^{\circ} 39^{\prime} \mathrm{E} \\
14^{\circ} 42^{\prime} \\
14^{\circ} 49^{\prime} \\
14^{\circ} 42^{\prime} \\
14^{\circ} 46.3^{\prime} \\
26^{\circ} 04.10^{\prime} \mathrm{E} \\
26^{\circ} 03.10^{\prime} \mathrm{E} \\
26^{\circ} 00.83^{\prime} \mathrm{E} \\
25^{\circ} 55^{\prime} \mathrm{E} \\
14^{\circ} 42^{\prime} \\
31^{\circ} 52.52^{\prime} \mathrm{E} \\
15^{\circ} 33^{\prime}\end{array}$ & $\begin{array}{l}5325 \\
5315 \\
5330 \\
5330 \\
5318 \\
5315 \\
4100 \\
3910 \\
2760 \\
2700 \\
5330 \\
5325 \\
5330 \\
5270 \\
4396 \\
3259 \\
2069 \\
2173-2142 \\
5330 \\
2563 \\
3290-4002\end{array}$ \\
\hline $\begin{array}{l}\text { Mikhail Lomonos } \\
352 \\
363\end{array}$ & $\begin{array}{l}(1959) \\
56^{\circ} 28.2^{\prime} \\
33^{\circ} 30.0^{\prime}\end{array}$ & $\begin{array}{l}30^{\circ} 07.0^{\prime} \\
29^{\circ} 56.5^{\prime}\end{array}$ & $\begin{array}{l}2836 \\
3984\end{array}$ \\
\hline $\begin{array}{l}\text { Michael Sars, Nor } \\
9 \\
10 \\
25 \\
35 \\
37 \\
53 \\
88\end{array}$ & $\begin{array}{l}\text { Atlantic Deep-Sea E } \\
63^{\circ} 55^{\prime} \\
45^{\circ} 26^{\prime} \\
35^{\circ} 36^{\prime} \\
27^{\circ} 27^{\prime} \\
45^{\circ} 26^{\prime} \\
34^{\circ} 59^{\prime} \\
45^{\circ} 26^{\prime}\end{array}$ & $\begin{array}{l}\text { tion }(1910) \\
06^{\circ} 24^{\prime} \\
09^{\circ} 20^{\prime} \\
08^{\circ} 25^{\prime} \\
14^{\circ} 52^{\prime} \\
09^{\circ} 20^{\prime} \\
33^{\circ} 01^{\prime} \\
25^{\circ} 45^{\prime}\end{array}$ & $\begin{array}{l}2100 \\
4700 \\
2300 \\
2603 \\
4700 \\
2615-2865 \\
3120\end{array}$ \\
\hline $\begin{array}{l}\text { Nautile } \\
\text { Dive } 1196 \\
\text { Dive } 1206\end{array}$ & $\begin{array}{l}36^{\circ} 13.81^{\prime} \\
36^{\circ} 13.81^{\prime}\end{array}$ & $\begin{array}{l}33^{\circ} 54.07^{\prime} \\
33^{\circ} 54.07^{\prime}\end{array}$ & $\begin{array}{l}2260 \\
2260\end{array}$ \\
\hline
\end{tabular}




\begin{tabular}{|c|c|c|c|}
\hline $\begin{array}{l}\text { Research Vessel, } \\
\text { Station }\end{array}$ & Latitude, N & $\begin{array}{l}\text { Longitude, } \mathbf{w} \\
(\mathrm{E}-\text { when indicated })\end{array}$ & Depth, m \\
\hline $\begin{array}{l}\text { Ob' (1956) } \\
6 \\
22 \\
35 \\
45\end{array}$ & $\begin{array}{l}78^{\circ} 05^{\prime} \\
82^{\circ} 02^{\prime} \\
81^{\circ} 08^{\prime} \\
79^{\circ} 47.3^{\prime}\end{array}$ & $\begin{array}{l}02^{\circ} 12^{\prime} \\
09^{\circ} 22^{\prime} \\
06^{\circ} 47^{\prime} \\
01^{\circ} 41^{\prime}\end{array}$ & $\begin{array}{l}2860-2870 \\
2565 \\
1950 \\
2754\end{array}$ \\
\hline $\begin{array}{l}\text { Pola (1891) } \\
82\end{array}$ & $32^{\circ} 30^{\prime}$ & $29^{\circ} 08^{\prime \prime} \mathrm{E}$ & 2420 \\
\hline $\begin{array}{l}\text { Polarstern, ARK VI } \\
78 \\
108\end{array}$ & $\begin{array}{l}\text { 12, Arctic EPc } \\
79^{\circ} 00^{\prime} \\
81^{\circ} 36^{\prime}\end{array}$ & $\begin{array}{l}05^{\circ} 45^{\prime} \mathrm{E} \\
30^{\circ} 25^{\prime} \mathrm{E}\end{array}$ & $\begin{array}{l}2000 \\
2090-2166\end{array}$ \\
\hline $\begin{array}{l}\text { Polarstern, ARK IX } \\
32 \\
32 \mathrm{AGT} \\
50 \mathrm{AGT} \\
50 \\
54 \\
27054\end{array}$ & $\begin{array}{l}(1993) \\
78^{\circ} 42^{\prime} 7 \\
78^{\circ} 42^{\prime} 7 \\
77^{\circ} 41^{\prime} \\
77^{\circ} 41^{\prime} \\
79^{\circ} 11.33^{\prime} \\
79^{\circ} 11^{\prime}\end{array}$ & $\begin{array}{l}132^{\circ} 33^{\prime} 8-132^{\circ} 39^{\prime} 4 \mathrm{E} \\
132^{\circ} 33^{\prime} 8-132^{\circ} 39^{\prime} 4 \mathrm{E} \\
125^{\circ} 55^{\prime} \mathrm{E} \\
125^{\circ} 55^{\prime} \mathrm{E} \\
119^{\circ} 56.37^{\prime}-56.22^{\prime} \mathrm{E} \\
119^{\circ} 56^{\prime} \mathrm{E}\end{array}$ & $\begin{array}{l}3012-3098 \\
3012-3098 \\
1992-1993 \\
1992-1993 \\
3039-3081 \\
3039-3042\end{array}$ \\
\hline $\begin{array}{l}\text { Polarstern, ARK XI } \\
23 \\
23 a \\
42-G K G(\text { bio1) } \\
\text { 44-GKG(bio1) } \\
\text { 44-GKG(bio2) } \\
\text { 49-GKG(bio2) }\end{array}$ & $\begin{array}{l}(1995) \\
78^{\circ} 16.22^{\prime} \\
78^{\circ} 12.02^{\prime} \\
78^{\circ} 41.46^{\prime} \\
79^{\circ} 06.02^{\prime} \\
79^{\circ} 05.06^{\prime} \\
81^{\circ} 04.02^{\prime}\end{array}$ & $\begin{array}{l}130^{\circ} 02,48^{\prime} \mathrm{E} \\
129^{\circ} 58,07^{\prime} \mathrm{E} \\
134^{\circ} 39,09^{\prime} \mathrm{E} \\
135^{\circ} 09,05^{\prime} \mathrm{E} \\
135^{\circ} 08,04^{\prime} \mathrm{E} \\
136^{\circ} 20,02^{\prime} \mathrm{E}\end{array}$ & $\begin{array}{l}2410 \\
2340 \\
2086 \\
2769 \\
2757 \\
2784\end{array}$ \\
\hline $\begin{array}{l}\text { Polarstern, ARK XI } \\
\text { 23à.AGT } \\
\text { 27a.AGT }\end{array}$ & $\begin{array}{l}(1995) \\
78^{\circ} 12^{\prime} \\
81^{\circ} 10^{\prime}\end{array}$ & $\begin{array}{l}129^{\circ} 58^{\prime} \mathrm{E} \\
107^{\circ} 47^{\prime} \mathrm{N}\end{array}$ & $\begin{array}{l}2330 \\
3310\end{array}$ \\
\hline $\begin{array}{l}\text { Polarstern, ARK XI } \\
4493 a \\
059 \\
068 \\
093 \\
100\end{array}$ & $\begin{array}{l}2(1997) \\
81^{\circ} 16.32^{\prime} \\
81^{\circ} 06.07^{\prime} \\
81^{\circ} 24.02^{\prime} \\
81^{\circ} 19.04^{\prime} \\
79^{\circ} 06.05^{\prime}\end{array}$ & $\begin{array}{l}13^{\circ} 07.36^{\prime} \mathrm{E} \\
16^{\circ} 13.01^{\prime} \mathrm{E} \\
00^{\circ} 57.01^{\prime} \\
13^{\circ} 35.08^{\prime} \mathrm{E} \\
03^{\circ} 05.07^{\prime} \mathrm{E}\end{array}$ & $\begin{array}{l}2234 \\
2065 \\
2911 \\
2149 \\
5416\end{array}$ \\
\hline $\begin{array}{l}\text { Polarstern, ARK XI } \\
\text { Victor } 6000\end{array}$ & 1 (1999) & $04^{\circ} 1102^{\prime} \mathrm{F}$ & 2400 \\
\hline $\begin{array}{l}\text { Victor } 6000 \\
\text { Dive } 3, \text { Site Ila } \\
\text { Victor } 6000 \\
\text { Dive } 4, \text { Site lib }\end{array}$ & $\begin{array}{l}79^{\circ} 08.03^{\prime} \\
79^{\circ} 27.08^{\prime}\end{array}$ & $02^{\circ} 33.07^{\prime} \mathrm{E}$ & $\begin{array}{l}\angle 400 \\
5552 \\
2800\end{array}$ \\
\hline $\begin{array}{l}\text { Polarstern, ARK XI } \\
81-1\end{array}$ & $\begin{array}{l}\text { I/1 (2001) } \\
74^{\circ} 31.1^{\prime}\end{array}$ & $11^{\circ} 06.71^{\prime} \mathrm{E}$ & 3100 \\
\hline $\begin{array}{l}\text { Polarstern, ARK XI } \\
62-42 \\
62-60\end{array}$ & $\begin{array}{c}\text { II/1a (2002) } \\
74^{\circ} 39.11^{\prime} \\
74^{\circ} 31.01^{\prime}\end{array}$ & $\begin{array}{l}05^{\circ} 01^{\prime} \\
11^{\circ} 06^{\prime}\end{array}$ & $\begin{array}{l}3600 \\
3000\end{array}$ \\
\hline $\begin{array}{l}\text { Polarstern, ARK XI } \\
\text { PS } 64 / 440 \\
\text { PS } 64 / 441 \\
\text { PS } 64 / 442 \\
\text { PS } 64 / 454 \\
\text { PS } 64 / 455 \\
\text { PS } 64 / 456 \\
\text { PS } 64 / 461 \\
\text { PS } 64 / 462 \\
\text { PS } 64 / 463\end{array}$ & $\begin{array}{l}13 c(2003) \\
79^{\circ} 04.79^{\prime} \\
79^{\circ} 04.89^{\prime} \\
79^{\circ} 05.22^{\prime} \\
78^{\circ} 55.01^{\prime} \\
78^{\circ} 54.97^{\prime} \\
78^{\circ} 54.97^{\prime} \\
78^{\circ} 56.02^{\prime} \\
78^{\circ} 56.04^{\prime} \\
78^{\circ} 56.21^{\prime}\end{array}$ & $\begin{array}{l}4^{\circ} 06.05^{\prime} \mathrm{E} \\
4^{\circ} 05.77^{\prime} \mathrm{E} \\
4^{\circ} 06.13^{\prime} \mathrm{E} \\
5^{\circ} 00.27^{\prime} \mathrm{E} \\
5^{\circ} 00.24^{\prime} \mathrm{E} \\
5^{\circ} 00.04^{\prime} \mathrm{E} \\
4^{\circ} 59.60^{\prime} \mathrm{E} \\
4^{\circ} 59.62^{\prime} \mathrm{E} \\
4^{\circ} 59.18^{\prime} \mathrm{E}\end{array}$ & $\begin{array}{l}2500 \\
2500 \\
2482 \\
2637 \\
2637 \\
2638 \\
2610 \\
2610 \\
2606\end{array}$ \\
\hline
\end{tabular}




\begin{tabular}{llll}
$\begin{array}{l}\text { Research Vessel, } \\
\text { Station }\end{array}$ & Latitude, N & $\begin{array}{l}\text { Longitude, W } \\
(\mathrm{E}-\text { when indicated) }\end{array}$ & Depth, m \\
\hline $\begin{array}{l}\text { Porcupine (1869) } \\
17\end{array}$ & $54^{\circ} 28^{\prime}$ & $11^{\circ} 44^{\prime}$ & $2239-2251$ \\
19 & $54^{\circ} 53^{\prime}$ & $10^{\circ} 56^{\prime}$ & $2475-2489$ \\
$19 a$ & $54^{\circ} 53^{\prime}$ & $10^{\circ} 56^{\prime}$ & 2475 \\
20 & $55^{\circ} 11^{\prime}$ & $11^{\circ} 31^{\prime}$ & 2626 \\
21 & $55^{\circ} 40^{\prime}$ & $12^{\circ} 46^{\prime}$ & 2686 \\
22 & $56^{\circ} 08^{\prime}$ & $13^{\circ} 34^{\prime}$ & 2299 \\
28 & $56^{\circ} 44^{\prime}$ & $12^{\circ} 52^{\prime}$ & 2211 \\
30 & $56^{\circ} 24^{\prime}$ & $11^{\circ} 49^{\prime}$ & 2512 \\
31 & $56^{\circ} 15^{\prime}$ & $11^{\circ} 25^{\prime}$ & 2475 \\
37 & $47^{\circ} 38.0^{\prime}$ & $12^{\circ} 08.0^{\prime}$ & 4453 \\
38 & $47^{\circ} 39^{\prime}$ & $11^{\circ} 33^{\prime}$ & 3824 \\
43 & $50^{\circ} 01^{\prime}$ & $12^{\circ} 26^{\prime}$ & 2207 \\
Porcupine (1870) & & & 2000 \\
17 & $39^{\circ} 42^{\prime}$ & & 2488 \\
19 & $54^{\circ} 53^{\prime}$ & $09^{\circ} 43^{\prime}$ & 2686 \\
21 & $55^{\circ} 40^{\prime}$ & $10^{\circ} 56^{\prime}$ & 2488 \\
31 & $56^{\circ} 15^{\prime}$ & $12^{\circ} 46^{\prime}$ & 2589 \\
51 & $36^{\circ} 55^{\prime}$ & $11^{\circ} 25^{\prime}$ & 2760 \\
54 & $37^{\circ} 41^{\prime}$ & $01^{\circ} 10^{\prime} \mathrm{E}$ & 2650 \\
55 & $37^{\circ} 30^{\prime}$ & $06^{\circ} 27^{\prime} \mathrm{E}$ & \\
Porcupine (1890) & & $06^{\circ} 51^{\prime} \mathrm{E}$ & 2563 \\
37 & $48^{\circ} 38^{\prime}$ & & \\
Pourquoi Pas? (1910) & $12^{\circ} 08^{\prime}$ & \\
2990 & $43^{\circ} 45^{\prime} 3$ & $09^{\circ} 41^{\prime}$ & \\
\hline
\end{tabular}

Princesse Alice et Hirondelle (1886-1915)

1886-1888 "Hirondelle" St. 1-266; 1891-1897 "Princesse Alice" 267-917; 1898-1910 "Princesse Alice II" 918-3059; 1911-1915 "Hirondelle II" 3060-3698

$\begin{array}{llll}20 & 36^{\circ} 54^{\prime} & 23^{\circ} 06^{\prime} & 4400 \\ 22 & 36^{\circ} 55^{\prime} & 24^{\circ} 43^{\prime} & 4261 \\ 31 & 37^{\circ} 54^{\prime} & 27^{\circ} 03^{\prime} & 2178 \\ 45 & 34^{\circ} 04^{\prime} & 11^{\circ} 19^{\prime} & 3745 \\ 117 & 38^{\circ} 59^{\prime} & 30^{\circ} 38^{\prime} & 2102 \\ 120 & 38^{\circ} 54^{\prime} & 23^{\circ} 27^{\prime} & 5005 \\ 124 & 39^{\circ} 50^{\prime} & 20^{\circ} 18^{\prime} & 4360 \\ 188 & 38^{\circ} 59^{\prime} & 28^{\circ} 20^{\prime} 57^{\prime \prime} & 2000 \\ 248 & 41^{\circ} 40,41^{\prime} & 29^{\circ} 04,23^{\prime} & 2870 \\ 274 & 46.20^{\circ} & 8^{\circ} 54.83^{\prime} & 4808 \\ 375 & 43^{\circ} 33^{\prime} 00^{\prime \prime} & 07^{\circ} 36^{\prime} 45^{\prime \prime} & 2230 \\ 515 & 38^{\circ} 21^{\prime} 00^{\prime \prime}-38^{\circ} 21^{\prime} 00^{\prime \prime} & 09^{\circ} 41^{\prime} 45^{\prime \prime}-09^{\circ} 37^{\prime} 45^{\prime \prime} & 2028 \\ 527 & 38^{\circ} 09^{\prime}-38^{\circ} 08^{\prime} & 25^{\circ} 30^{\prime}-25^{\circ} 39^{\prime} & 4020 \\ 536 & 37^{\circ} 54^{\prime} & 24^{\circ} 43^{\prime} 15^{\prime \prime} & 2178 \\ 537 & 37^{\circ} & 24,72^{\circ} & 2178 \\ 581 & 38.43^{\circ} & 26.64^{\circ} & 2139 \\ 624 & 38^{\circ} 59^{\prime} & 28^{\circ} 18^{\prime} & 2018-2102 \\ 631 & 43^{\circ} 32.43^{\prime} & 7^{\circ} 33.15^{\prime} & 2170 \\ 632 & 43^{\circ} 32^{\prime} 43^{\prime \prime} & 07^{\circ} 35^{\prime} 15^{\prime \prime} \mathrm{E} & 2170 \\ 650 & 36^{\circ} 54^{\prime} & 20^{\circ} 46^{\prime} 15^{\prime \prime}-20^{\circ} 05^{\prime} 45^{\prime \prime} & 4400 \\ 652 & 36^{\circ} 55^{\prime} & 22^{\circ} 22^{\prime} 45^{\prime \prime} & 4261 \\ 673 & 37^{\circ} 51^{\prime}-37^{\circ} 53^{\prime} & 26^{\circ} 53^{\prime} 45^{\prime \prime}-26^{\circ} 59^{\prime} 45^{\prime \prime} & 2252 \\ 738 & 37^{\circ} 40^{\prime} & 25^{\circ} 26^{\prime} & 2102 \\ 745 & 38^{\circ} 05^{\prime} & 23^{\circ} 50^{\prime} & 3465 \\ 747 & 38^{\circ} 54^{\prime} & 23^{\circ} 27^{\prime} & 5005 \\ 749 & 38^{\circ} 54^{\prime}-38^{\circ} 55^{\prime} & 21^{\circ} 06^{\prime} 45^{\prime \prime}-21^{\circ} 18^{\prime} 45^{\prime \prime} & 5005 \\ 753 & 39^{\circ} 50^{\prime}-39^{\circ} 54^{\prime} & 17^{\circ} 57^{\prime} 45^{\prime \prime}-18^{\circ} 06^{\prime} 45^{\prime \prime} & 4360 \\ 757 & 44^{\circ} 06^{\prime} & 10^{\circ} 22^{\prime} 45^{\prime \prime}-10^{\circ} 20^{\prime} 45^{\prime \prime} & 4900 \\ 778 & 33^{\circ} 58^{\prime} & 08^{\circ} 38^{\prime} & 2225 \\ 821 & 30^{\circ} 45^{\prime} & 15^{\circ} 20^{\prime} & 5440 \\ 1116 & 31^{\circ} 43^{\prime} 30^{\prime \prime} & & 2165 \\ & & & \end{array}$




\begin{tabular}{|c|c|c|c|}
\hline $\begin{array}{l}\text { Research Vessel, } \\
\text { Station }\end{array}$ & Latitude, $\mathbf{N}$ & $\begin{array}{l}\text { Longitude, } \mathbf{W} \\
\text { (E - when indicated) }\end{array}$ & Depth, m \\
\hline 1173 & $12^{\circ} 07^{\prime}$ & $33^{\circ} 33^{\prime}$ & 6035 \\
\hline 1182 & $14^{\circ} 47^{\prime}$ & $24^{\circ} 31^{\prime} 45^{\prime \prime}$ & 2478 \\
\hline 1306 & $37^{\circ} 16^{\prime} 00^{\prime \prime}-37^{\circ} 18^{\prime} 00^{\prime \prime}$ & $20^{\circ} 11^{\prime} 45^{\prime \prime}-20^{\circ} 15^{\prime} 45^{\prime \prime}$ & 4275 \\
\hline 1318 & $38^{\circ} 06^{\prime}$ & $26^{\circ} 13^{\prime} 45^{\prime \prime}$ & 3018 \\
\hline 1412 & $42^{\circ} 44^{\prime}$ & $28^{\circ} 22.75^{\prime}$ & 2200 \\
\hline 1420 & $42^{\circ} 53-42^{\circ} 54^{\prime}$ & $28^{\circ} 30,45^{\prime}$ & 2460 \\
\hline 1554 & $45.45^{\circ}$ & $06,08^{\circ}$ & 4780 \\
\hline 1558 & $45^{\circ} 27^{\prime}$ & $06^{\circ} 05^{\prime}$ & 4780 \\
\hline 1787 & $31^{\circ} 01^{\prime}$ & $23^{\circ} 03^{\prime}$ & 5413 \\
\hline 1789 & $31^{\circ} 06^{\prime}$ & $24^{\circ} 00^{\prime}$ & 5413 \\
\hline 2044 & $38^{\circ} 28^{\prime} 00^{\prime \prime}$ & $16^{\circ} 37^{\prime} 30^{\prime \prime}$ & 2286 \\
\hline 2048 & $32^{\circ} 32^{\prime} 30^{\prime \prime}$ & $17^{\circ} 02^{\prime}$ & 1968 \\
\hline 2111 & $31^{\circ} 45^{\prime} 30^{\prime \prime}$ & $42^{\circ} 42^{\prime} 30^{\prime \prime}$ & 3465 \\
\hline 2114 & $31^{\circ} 41^{\prime}$ & $42^{\circ} 40^{\prime}$ & $0-3000$ \\
\hline 2133 & $33^{\circ} 22^{\prime}$ & $39^{\circ} 12^{\prime}$ & 2422 \\
\hline 2948 & $46^{\circ} 45^{\prime} 45^{\prime \prime}$ & $05^{\circ} 50^{\prime}$ & 3910 \\
\hline 2964 & $46^{\circ} 17^{\prime} 30^{\prime \prime}$ & $05^{\circ} 42^{\prime}$ & 4380 \\
\hline 2983 & $45^{\circ} 28^{\prime}$ & $05^{\circ} 43^{\prime}$ & $0-4500$ \\
\hline 2986 & $45^{\circ} 07^{\prime} 30^{\prime \prime}$ & $07^{\circ} 06^{\prime}$ & 4870 \\
\hline 2990 & $43^{\circ} 45^{\prime} 30^{\prime \prime}$ & $09^{\circ} 41^{\prime}$ & 2320 \\
\hline 2993 & $44^{\circ} 08^{\prime}$ & $10^{\circ} 44^{\prime}$ & 5000 \\
\hline 2994 & $44^{\circ} 08^{\prime}$ & $10^{\circ} 44^{\prime}$ & 5000 \\
\hline 2997 & $44.48^{\circ}$ & $10.52^{\circ}$ & 4965 \\
\hline 3006 & $43^{\circ} 21^{\prime}$ & $10^{\circ} 02^{\prime}$ & 2779 \\
\hline 3119 & $32^{\circ} 30^{\prime} 30^{\prime \prime}$ & $17^{\circ} 00^{\prime}$ & 2380 \\
\hline 3223 & $30^{\circ} 50^{\prime}$ & $25^{\circ} 43^{\prime}$ & 5300 \\
\hline \multicolumn{4}{|c|}{ Professor Logatchev } \\
\hline & $76.43^{\circ}$ & $07.20^{\circ} \mathrm{E}$ & $2180-3460$ \\
\hline 32 & $76.04^{\circ}$ & $07.14^{\circ} \mathrm{E}$ & $2180-3460$ \\
\hline \multicolumn{4}{|l|}{ Ruth Ann (1969) } \\
\hline 2 & $39^{\circ} 22^{\prime} 24^{\prime \prime}$ & $17^{\circ} 51^{\prime} 06^{\prime \prime} \mathrm{E}$ & $2300-2400$ \\
\hline 7 & $38^{\circ} 55^{\prime}$ & $18^{\circ} 20^{\prime} \mathrm{E}$ & 2300 \\
\hline \multicolumn{4}{|l|}{ Sadko (1935 -1938) } \\
\hline $2 / 14$ & $76^{\circ} 19.08^{\prime}$ & $12^{\circ} 16^{\prime} \mathrm{E}$ & $2000-2500$ \\
\hline 3 & $76^{\circ} 20.04^{\prime}$ & $05^{\circ} 39^{\prime} \mathrm{E}$ & 3000 \\
\hline 6 & $78^{\circ} 04^{\prime}$ & $03^{\circ} 51^{\prime} \mathrm{E}$ & 2460 \\
\hline $9 / 30$ & $78.37^{\circ}$ & $03^{\circ} 52^{\prime} \mathrm{E}$ & 2300 \\
\hline 10 & $80^{\circ} 01.05^{\prime}$ & $03^{\circ} 19^{\prime} \mathrm{E}$ & 2380 \\
\hline 59 & $82^{\circ} 42^{\prime}$ & $87^{\circ} 03^{\prime} \mathrm{E}$ & 2365 \\
\hline 97 & $80^{\circ} 30^{\prime}$ & $144^{\circ} 33^{\prime} \mathrm{E}$ & $1800-2000$ \\
\hline 100 & $81^{\circ} 10^{\prime}$ & $137^{\circ} 17^{\prime} \mathrm{E}$ & 2500 \\
\hline 101 & $82^{\circ} 51^{\prime}$ & $137^{\circ} 23^{\prime} \mathrm{E}$ & $3700-3800$ \\
\hline \multicolumn{4}{|l|}{ Sarsia (1967) } \\
\hline 50 & $43^{\circ} 46.7^{\prime}$ & $03^{\circ} 38^{\prime}$ & 2379 \\
\hline S 50 & $43^{\circ} 46^{\prime}$ & $03^{\circ} 38^{\prime}$ & 2379 \\
\hline S-65 & $46^{\circ} 15^{\prime}$ & $04^{\circ} 50^{\prime}$ & 1922 \\
\hline \multicolumn{4}{|l|}{ Sarsia (1976) } \\
\hline 7601 & $43^{\circ} 52^{\prime}$ & $03^{\circ} 43^{\prime}$ & $3080-3100$ \\
\hline 7603 & $44^{\circ} 19^{\prime}$ & $03^{\circ} 35^{\prime}$ & 3860 \\
\hline 7626 & $43^{\circ} 47^{\prime}$ & $03^{\circ} 32^{\prime}$ & $2100-2500$ \\
\hline 7627 & $43^{\circ} 47^{\prime}$ & $03^{\circ} 46^{\prime}$ & 1925-1990 \\
\hline \multicolumn{4}{|l|}{ Sarsia (1977) } \\
\hline $74 / 8$ & $43.70^{\circ}$ & $03.63^{\circ}$ & 2300 \\
\hline $74 / 12$ & $43.62^{\circ}$ & $03.45^{\circ}$ & $1800-2100$ \\
\hline ST83 & $43.77^{\circ}$ & $03.80^{\circ}$ & 1970-2060 \\
\hline \multicolumn{4}{|l|}{ Sevastopol (1958) } \\
\hline 1057 & $65.47^{\circ}$ & $01^{\circ} 05^{\prime} \mathrm{E}$ & 2730 \\
\hline
\end{tabular}




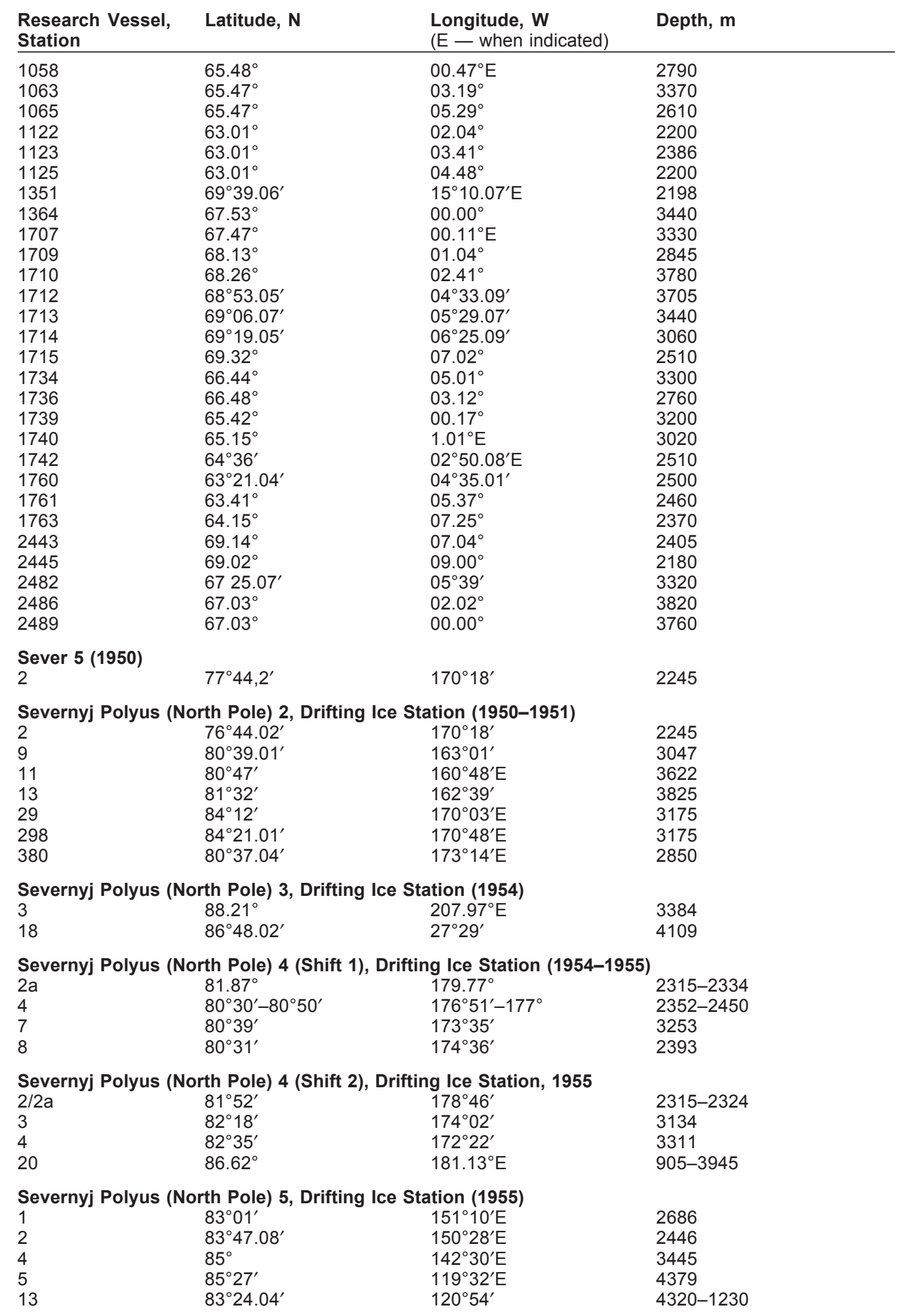




\begin{tabular}{|c|c|c|c|}
\hline $\begin{array}{l}\text { Research Vessel, } \\
\text { Station }\end{array}$ & Latitude, $\mathbf{N}$ & $\begin{array}{l}\text { Longitude, } \mathbf{w} \\
\text { (E - when indicated) }\end{array}$ & Depth, m \\
\hline
\end{tabular}

\begin{tabular}{|c|c|c|c|}
\hline \multicolumn{4}{|c|}{ Severnyj Polyus (North Pole) 22, Drifting Ice Station (1977) } \\
\hline 12 & $81^{\circ} 58^{\prime}$ & $127^{\circ} 22.2^{\prime}$ & 3410 \\
\hline 14 & $81^{\circ} 42^{\prime}$ & $126^{\circ} 50.5^{\prime}$ & 3510 \\
\hline 15 & $81^{\circ} 42^{\prime}$ & $126^{\circ} 50.5^{\prime}$ & 3510 \\
\hline 20 & $81^{\circ} 13^{\prime}$ & $128^{\circ} 31.8^{\prime}$ & 3540 \\
\hline 21 & $81^{\circ} 08^{\prime}$ & $128^{\circ} 23.8^{\prime}$ & 3550 \\
\hline 24 & $80^{\circ} 27^{\prime}$ & $129^{\circ} 02^{\prime}$ & 3590 \\
\hline 27 & $80^{\circ} 08^{\prime}$ & $128^{\circ} 12.9^{\prime}$ & $2750-2370$ \\
\hline 29 & $80^{\circ}$ & $128^{\circ}$ & 2630 \\
\hline 34 & $79^{\circ} 26^{\prime}$ & $127^{\circ} 38.8^{\prime}$ & 3290 \\
\hline 36 & $79,19^{\circ}$ & $128.94^{\circ}$ & 3340 \\
\hline 38 & $79,00^{\circ}$ & $129.00^{\circ}$ & 3380 \\
\hline 39 & $79^{\circ}$ & $129^{\circ}$ & 3370 \\
\hline 40 & $79^{\circ}$ & $129^{\circ}$ & 3380 \\
\hline 42 & $79^{\circ} 23^{\prime}$ & $128^{\circ} 27.8^{\prime}$ & 3440 \\
\hline 44 & $79^{\circ} 05^{\prime}$ & $127^{\circ} 09^{\prime} 9^{\prime \prime}$ & 3260 \\
\hline 47 & $79^{\circ} 04^{\prime} 5^{\prime \prime}$ & $126^{\circ} 43^{\prime} 5^{\prime \prime}$ & 3230 \\
\hline 48 & $79^{\circ} 04^{\prime}$ & $126^{\circ} 34^{\prime}$ & 3200 \\
\hline 49 & $79^{\circ} 07^{\prime}$ & $125^{\circ} 49.6^{\prime}$ & 3200 \\
\hline 50 & $78^{\circ} 45^{\prime}$ & $127^{\circ} 36^{\prime}$ & $2990-295$ \\
\hline 52 & $78^{\circ} 15^{\prime}$ & $127^{\circ} 59^{\prime}$ & 2850 \\
\hline 53 & $78^{\circ} 10^{\prime}$ & $128^{\circ} 01^{\prime}$ & 2810 \\
\hline 54 & $77^{\circ} 50^{\prime}$ & $125^{\circ} 19^{\prime}$ & 3110 \\
\hline 55 & $77^{\circ} 43^{\prime}$ & $125^{\circ} 00^{\prime}$ & 3170 \\
\hline 58 & $73^{\circ} 35^{\prime}$ & $159^{\circ} 05^{\prime}$ & $2700-1900$ \\
\hline
\end{tabular}

Severnyj Polyus (North Pole) 23, Drifting Ice Station (1978) 4 $81^{\circ} 45.09^{\prime}$

$158^{\circ} 43.05^{\prime} \mathrm{E}$

2821

Shackleton (1973)

152

$36^{\circ} 35.7^{\prime}-36^{\circ} 37.2^{\prime}$

$11^{\circ} 04,1^{\prime}-11^{\circ} 05.3^{\prime}$

$11^{\circ} 06,5^{\prime}-11^{\circ} 06.9^{\prime}$

$12^{\circ} 34.6^{\prime}-12^{\circ} 35.3^{\prime}$

$36^{\circ} 17.2^{\prime}-36^{\circ} 17.9^{\prime}$

169

$36^{\circ} 20.9^{\prime}-36^{\circ} 22.8^{\prime}$

$12^{\circ} 53,3^{\prime}-12^{\circ} 53.1^{\prime}$

2292-1691

2959-1946

3465-4014

3010-2210

Shackleton, 2A77 (1977)

$\begin{array}{ll}\text { ES } 118 & 54^{\circ} 39^{\prime} \\ \text { AT } 119 & 54^{\circ} 40^{\prime} \\ \text { ES } 120 & 54^{\circ} 39^{\prime} \\ 121 & 54^{\circ} 37^{\prime} \\ \text { AT } 121 & 54^{\circ} 37^{\prime} \\ \text { ES } 122 & 54^{\circ} 31^{\prime}\end{array}$

$12^{\circ} 14^{\prime}$

$12^{\circ} 14^{\prime} \quad 2908$

$12^{\circ} 16^{\prime}$

$12^{\circ} 06^{\prime} \quad 2910$

$12^{\circ} 09^{\prime} \quad 2910$

$12^{\circ} 31^{\prime} \quad 2951$

Shackleton (1980)

1901

$1903 / 1$

$1903 / 2$

$1903 / 4$

$1903 / 6$

$1903 / 7$

$1903 / 8$

Talisman (1883)

16

35

38

39

40

41

42

44

58

59 $48^{\circ} 29.7^{\prime}$

$47.60^{\circ}$

$47.60^{\circ}$

$47.60^{\circ}$

$47.55^{\circ}$

$47.50^{\circ}$

$47.52^{\circ}$

$34^{\circ} 01^{\prime}$

$32^{\circ} 04^{\prime}$

$30^{\circ} 09^{\prime}$

$30^{\circ} 08^{\prime}$

$30^{\circ} 03^{\prime}$

$30^{\circ} 01^{\prime}$

$29^{\circ} 58^{\prime}$

$29^{\circ} 52^{\prime}$

$27^{\circ} 35^{\prime}$

$27^{\circ} 32^{\prime}$ $10^{\circ} 23.3^{\prime}$

$09.73^{\circ}$

$09.73^{\circ}$

$09.75^{\circ}$

$09.58^{\circ}$

$09.57^{\circ}$

$09.45^{\circ}$

$08^{\circ} 32^{\prime}$

$10^{\circ} 23^{\prime}$

$11^{\circ} 41^{\prime}$

$11^{\circ} 42^{\prime}$

$11^{\circ} 42^{\prime}$

$11^{\circ} 46^{\prime}$

$11^{\circ} 41^{\prime}$

$11^{\circ} 47^{\prime}$

$14^{\circ} 15^{\prime}$

$14^{\circ} 09^{\prime}$
2280-2150

4120

4120-4165

4165

4240

4250-4265

3820-4000

2190

2105

2210

2200

2212

2115

2104

2083

2015

2013 


\begin{tabular}{|c|c|c|c|}
\hline $\begin{array}{l}\text { Research Vessel, } \\
\text { Station }\end{array}$ & Latitude, $\mathbf{N}$ & $\begin{array}{l}\text { Longitude, } \mathbf{W} \\
\text { (E - when indicated) }\end{array}$ & Depth, m \\
\hline $\begin{array}{l}75 \\
96 \\
97 \\
101 \\
118 \\
129 \\
130 \\
131 \\
133 \\
134 \\
135 \\
136 \\
137 \\
138 \\
139 \\
140 \\
142 \\
143 \\
144 \\
146 \\
147 \\
149 \\
150\end{array}$ & $\begin{array}{l}25^{\circ} 02^{\prime} \\
19^{\circ} 19^{\prime} \\
19^{\circ} 12^{\prime} \\
16^{\circ} 38^{\prime} \\
34^{\circ} 46^{\prime} \\
38^{\circ} 00^{\prime} \\
37^{\circ} 55^{\prime} \\
38^{\circ} 38^{\prime} \\
42^{\circ} 15^{\prime} \\
42^{\circ} 19^{\prime} \\
43^{\circ} 15^{\prime} \\
44^{\circ} 20^{\prime} \\
44^{\circ} 29^{\prime} \\
46^{\circ} 09^{\prime} \\
46^{\circ} 06^{\prime} \\
46^{\circ} 04^{\prime} \\
38^{\circ} 00^{\prime} \\
37^{\circ} 55^{\prime} \\
38^{\circ} 38^{\prime} \\
42^{\circ} 15^{\prime} \\
42^{\circ} 19^{\prime} \\
43^{\circ} 15^{\prime} \\
44^{\circ} 20^{\prime}\end{array}$ & $\begin{array}{l}16^{\circ} 51^{\prime} \\
18^{\circ} 02^{\prime} \\
17^{\circ} 57^{\prime} \\
18^{\circ} 24^{\prime} \\
33^{\circ} 51^{\prime} \\
27^{\circ} 13^{\prime} \\
27^{\circ} 02^{\prime} \\
25^{\circ} 06^{\prime} \\
21^{\circ} 17^{\prime} \\
21^{\circ} 16^{\prime} \\
19^{\circ} 20^{\prime} \\
17^{\circ} 11^{\prime} \\
13^{\circ} 32^{\prime} \\
09^{\circ} 16^{\prime} \\
06^{\circ} 50^{\prime} \\
04^{\circ} 26^{\prime} \\
27^{\circ} 05^{\prime} \\
27^{\circ} 02^{\prime} \\
25^{\circ} 06^{\prime} \\
21^{\circ} 17^{\prime} \\
22^{\circ} 16^{\prime} \\
19^{\circ} 20^{\prime} \\
17^{\circ} 11^{\prime}\end{array}$ & $\begin{array}{l}2325-2518 \\
2320-2333 \\
2324 \\
3200 \\
3175 \\
2155-2220 \\
2235 \\
2995 \\
3975 \\
4060 \\
4165 \\
4255 \\
4975-5005 \\
4787 \\
4789 \\
2285 \\
2155-2250 \\
2235 \\
2995 \\
3975 \\
4010-4060 \\
4165 \\
4255\end{array}$ \\
\hline $\begin{array}{l}\text { Thalassa (1970) } \\
\text { W } 425 \\
\text { W } 425\end{array}$ & $\begin{array}{l}44^{\circ} 10.0^{\prime} \\
44^{\circ} 10.0^{\prime}-44^{\circ} 10.0^{\prime}\end{array}$ & $\begin{array}{l}07^{\circ} 46.2^{\prime} \\
07^{\circ} 46.2^{\prime}-07^{\circ} 45.3^{\prime}\end{array}$ & $\begin{array}{l}2100 \\
2000-2110\end{array}$ \\
\hline $\begin{array}{l}\text { Thalassa (1971) } \\
\text { X } 336\end{array}$ & $44^{\circ} 11^{\prime}$ & $05^{\circ} 10^{\prime}$ & 1850-2050 \\
\hline $\begin{array}{l}\text { Thalassa (1973) } \\
\text { Z } 453\end{array}$ & $48^{\circ} 34^{\prime}-48^{\circ} 32^{\prime} 9$ & $10^{\circ} 51^{\prime}-10^{\circ} 49^{\prime} 0$ & 1975-2070 \\
\hline $\begin{array}{l}\text { Thor } \\
76 \\
164 \\
\text { AT } 164 \\
178 \\
\text { AT } 178\end{array}$ & $\begin{array}{l}49^{\circ} 27^{\prime} \\
62^{\circ} 10,5^{\prime} \\
62^{\circ} 10^{\prime} \\
48^{\circ} 04^{\prime} \\
48^{\circ} 04^{\prime}\end{array}$ & $\begin{array}{l}13^{\circ} 33^{\prime} \\
19^{\circ} 36^{\prime} \\
19^{\circ} 36^{\prime} \\
12^{\circ} 40^{\prime} \\
12^{\circ} 40^{\prime}\end{array}$ & $\begin{array}{l}2002-2100 \\
2150 \\
1900-2140 \\
4000 \\
4000\end{array}$ \\
\hline $\begin{array}{l}\text { Travailleur (1880) } \\
4\end{array}$ & $43^{\circ} 42^{\prime}$ & $03^{\circ} 01^{\prime}$ & 2651 \\
\hline $\begin{array}{l}\text { Travailleur (1881) } \\
1 \\
3 \\
4 \\
5 \\
16 \\
17 \\
18 \\
31 \\
36\end{array}$ & $\begin{array}{l}43^{\circ} 01^{\prime} \\
39^{\circ} 48^{\prime} \\
38^{\circ} 09^{\prime} \\
38^{\circ} 05^{\prime} \\
43^{\circ} 25^{\prime} \\
43^{\circ} 00^{\prime} \\
41^{\circ} 53^{\prime} \\
36^{\circ} 27^{\prime} \\
39^{\circ} 31^{\prime}\end{array}$ & $\begin{array}{l}09^{\circ} 37^{\prime} \\
09^{\circ} 52^{\prime} \\
09^{\circ} 43^{\prime} \\
09^{\circ} 42^{\prime} \\
07^{\circ} 22^{\prime} \mathrm{E} \\
07^{\circ} 33^{\prime} \mathrm{E} \\
08^{\circ} 23^{\prime} \mathrm{E} \\
08^{\circ} 13^{\prime} \\
09^{\circ} 59^{\prime}\end{array}$ & $\begin{array}{l}2018 \\
3307 \\
2505 \\
3165 \\
2068 \\
2660 \\
2465 \\
2100 \\
2660\end{array}$ \\
\hline $\begin{array}{l}\text { Travailleur (1882) } \\
13 \\
20 \\
23 \\
42 \\
43 \\
44 \\
50 \\
59\end{array}$ & $\begin{array}{l}44^{\circ} 07^{\prime} \\
41^{\circ} 30^{\prime} \\
38^{\circ} 21^{\prime} \\
31^{\circ} 54^{\prime} \\
30^{\circ} 17^{\prime} \\
30^{\circ} 14^{\prime} \\
29^{\circ} 55^{\prime} \\
40^{\circ} 36^{\prime}\end{array}$ & $\begin{array}{l}07^{\circ} 56^{\prime} \\
09^{\circ} 20^{\prime} \\
09^{\circ} 27^{\prime} \\
10^{\circ} 25^{\prime} \\
11^{\circ} 53^{\prime} \\
11^{\circ} 54^{\prime} \\
16^{\circ} 25^{\prime} \\
09^{\circ} 26^{\prime}\end{array}$ & $\begin{array}{l}2030 \\
2080 \\
2000 \\
2030 \\
2300 \\
2200 \\
3850 \\
2200\end{array}$ \\
\hline
\end{tabular}


Research Vessel, Latitude, N Station

Valdivia (1898-1899)

33

$24^{\circ} 35.3^{\prime}$

Valorous (1875)

$\begin{array}{ll}9 & 59^{\circ} 10^{\prime} \\ 12 & 56^{\circ} 11^{\prime} \\ 16 & 55^{\circ} 10^{\prime}\end{array}$

Vema, Cruise 16 (1960)

55

$55^{\circ} 48^{\prime}$

Vityaz (1979)

$\begin{array}{ll}7926 & 40^{\circ} 15.8^{\prime} \\ 7927 & 40^{\circ} 27.5^{\prime} \\ 7928 & 40^{\circ} 20.0^{\prime} \\ 7930 & 40^{\circ} 10.6^{\prime} \\ 7940 & 41^{\circ} 13^{\prime} \\ 7941 & 41^{\circ} 09.4^{\prime} \\ 7943 & 45^{\circ} 35.6^{\prime}\end{array}$

Vityaz II (1982)

$\begin{array}{ll}77 & 34^{\circ} 38.09^{\prime} \\ 79 & 34^{\circ} 54.30^{\prime} \\ 80 \mathrm{~B} & 35^{\circ} 38.08^{\prime} \\ 159 & 29^{\circ} 56.01^{\prime} \\ 161 & 29^{\circ} 51^{\prime} \\ 162 & 29^{\circ} 50.00^{\prime} \\ 164 & 29^{\circ} 48.07^{\prime} \\ 169 & 30^{\circ} 04.01^{\prime} \\ 170 & 30^{\circ} 03.08^{\prime}\end{array}$

Longitude, W

( $\mathrm{E}$ - when indicated)
Depth, m

$17^{\circ} 04.7^{\prime}$

2500

$50^{\circ} 25$

$37^{\circ} 41^{\prime}$

$25^{\circ} 58^{\prime}$

3150

2639-2653

3210-3264

$56^{\circ} 00^{\prime}$

2425

$12^{\circ} 26.3^{\prime} \mathrm{E}$

$12^{\circ} 40^{\prime}$

$13^{\circ} 22.9^{\prime} \mathrm{E}$

$06^{\circ} 04.01^{\prime} \mathrm{E}$

$14^{\circ} 54.2^{\prime}$

$14^{\circ} 39.5^{\prime}$

$12^{\circ} 35^{\prime}$

3540

3650

2400-2244

2890

5310-5370

5400

4860-4900

$37^{\circ} 25.00^{\prime}$

$45^{\circ} 39.00^{\prime}$

$52^{\circ} 03.02^{\prime}$

$28^{\circ} 13.00^{\prime}$

$28^{\circ} 06^{\prime}$

$28^{\circ} 08.06^{\prime}$

$27^{\circ} 54.01^{\prime}$

$28^{\circ} 52.00^{\prime}$

$28^{\circ} 44.00^{\prime}$
2500-2800

4440-4480

1940-2040

2480-2550

3340-3440

3080-3140

4280-4300

3100-3120

2000-2160

\section{Vöringen, Norwegian North Atlantic Expedition (1876)}

$\begin{array}{ll}40 & 63^{\circ} 22^{\prime} \\ 51 & 65^{\circ} 53^{\prime} \\ 52 & 65^{\circ} 47^{\prime} \\ 53 & 65^{\circ} 13^{\prime} \\ 177 & 69^{\circ} 25^{\prime} \\ 183 & 69^{\circ} 59^{\prime} \\ 213 & 70^{\circ} 23^{\prime} \\ 295 & 71^{\circ} 59^{\prime} \\ 297 & 72^{\circ} 36^{\prime} \\ 303 & 75^{\circ} 12^{\prime} \\ 353 & 77^{\circ} 585^{\prime}\end{array}$

$05^{\circ} 29^{\prime}$

$07^{\circ} 18^{\prime}$

$03^{\circ} 07^{\prime}$

$00^{\circ} 33^{\prime}$

$13^{\circ} 49^{\prime} \mathrm{E}$

$06^{\circ} 15^{\prime} \mathrm{E}$

$02^{\circ} 30^{\prime} \mathrm{E}$

$11^{\circ} 04^{\prime}$

$05^{\circ} 12^{\prime} \mathrm{E}$

$03^{\circ} 02^{\prime}$

$05^{\circ} 10^{\prime}$

2222

2127

3403

2814

2639

3127

3219

2222

2341

2195

2438

Walther Herwig, Cruise 45

$\begin{array}{ll}3 & 43^{\circ} 24^{\prime} \\ 47 & 45^{\circ} 50^{\prime} \\ 66 & 43^{\circ} 20^{\prime}\end{array}$

$15^{\circ} 06^{\prime}$

$17^{\circ} 14^{\prime}$

$19^{\circ} 21^{\prime}$

4700

4730

4280

Washington (1881)

8

$41^{\circ} 24^{\prime} 42^{\prime \prime}$

$07^{\circ} 43^{\prime} 28^{\prime \prime} \mathrm{E}$

2836-2809

Ymer (1980)

$\begin{array}{ll}\text { B8 (DE1) } & 82^{\circ} 22^{\prime} \\ \text { B9 (DE2) } & 81^{\circ} 51^{\prime} \\ \text { B10 (DE3) } & 81^{\circ} 40^{\prime}\end{array}$

$25^{\circ} 20^{\prime} \mathrm{E}$

$26^{\circ} 35^{\prime} \mathrm{E}$

3920

3270

$26^{\circ} 02^{\prime} \mathrm{E}$

2450 


\section{Research Programs}

Research Program, Latitude, N

Station

Longitude, $\mathbf{w}$
(E - when indicated)

Depth, m

\section{ABYPLAINE}

DS 01

DS 02

CP02

CP 03

DS 03

DS 04

CP05

CP 06

DS 06

DS 07

KR 07

CP 08

DS 09

KR 09

CP 10

DS 10

CP 11

DS 11

CP 12

DS 12

CP 13

DS 13

CP 15

CP 17

CP 18

CP 19

CP 20

CP 21

CP 22

CP 23

$37^{\circ} 18^{\prime}$

$37^{\circ} 20^{\prime}$

$37^{\circ} 20^{\prime}$

$36^{\circ} 49^{\prime}$

$36^{\circ} 30^{\prime}$

$34^{\circ} 53^{\prime}$

$34^{\circ} 54^{\prime}$

$34^{\circ} 49^{\prime}$

$34^{\circ} 53^{\prime}$

$34^{\circ} 06^{\prime}$

$34^{\circ} 05^{\prime}$

$33^{\circ} 02^{\prime}$

$39^{\circ} 59^{\prime}$

$42^{\circ} 52^{\prime}$

$42^{\circ} 50^{\prime}$

$42^{\circ} 50^{\prime}$

$34^{\circ} 07^{\prime}$

$43^{\circ} 00^{\prime}$

$34^{\circ} 05^{\prime}$

$44^{\circ} 40^{\prime}$

$39^{\circ} 59^{\prime}$

$44^{\circ} 41^{\prime}$

$40^{\circ} 00^{\prime}$

$42^{\circ} 45^{\prime}$

$42^{\circ} 51^{\prime}$

$43^{\circ} 00^{\prime}$

$42^{\circ} 59^{\prime}$

$42^{\circ} 58^{\prime}$

$44^{\circ} 42^{\prime}$

$44^{\circ} 41^{\prime}$

ABYPLAINE (1984)

CP 38
CP 39
CP 42
CP 66
CP $66-50$ bis
CP 68
CP 69
CP $69-167$

$47^{\circ} 33.75^{\prime}$

$47^{\circ} 32^{\prime}$

$46^{\circ} 22.7^{\prime}$

$35^{\circ} 21^{\prime}$

$35^{\circ} 21.3^{\prime}$

$35^{\circ} 12^{\prime}$

$35^{\circ} 11^{\prime}$

$35^{\circ} 11.4^{\prime}$

$15^{\circ} 33^{\prime}$

$15^{\circ} 37^{\prime}$

$15^{\circ} 38^{\prime}$

$19^{\circ} 09^{\prime}$

$18^{\circ} 43^{\prime}$

$21^{\circ} 26^{\prime}$

$21^{\circ} 27^{\prime}$

$21^{\circ} 20^{\prime}$

$22^{\circ} 03^{\prime}$

$17^{\circ} 04^{\prime}$

$17^{\circ} 05^{\prime}$

$21^{\circ} 59^{\prime}$

$15^{\circ} 04^{\prime}$

$15^{\circ} 54^{\prime}$

$15^{\circ} 05^{\prime}$

$12^{\circ} 56^{\prime}$

$17^{\circ} 07^{\prime}$

$14^{\circ} 04^{\prime}$

$17^{\circ} 07^{\prime}$

$17^{\circ} 53^{\prime}$

$15^{\circ} 01^{\prime}$

$17^{\circ} 49^{\prime}$

$15^{\circ} 05^{\prime}$

$15^{\circ} 57^{\prime}$

$15^{\circ} 53^{\prime}$

$14^{\circ} 03^{\prime}$

$14^{\circ} 06^{\prime}$

$14^{\circ} 00^{\prime}$

$18^{\circ} 01^{\prime}$

$17^{\circ} 57^{\prime}$

4350-4450

4220-4380

4490

4930

5500

5160

5120

5180

5220

4270

4270

5230

5320

4350

4315

4315

4270

5260

4260

4990

5270

4990

5330

4480

4330

5280

5260

5260

4990

4990

$08^{\circ} 42.15^{\prime}$

$08^{\circ} 38.4^{\prime}$

$12^{\circ} 36.8^{\prime}$

$08^{\circ} 10^{\prime}$

$08^{\circ} 10.5^{\prime}$

$07^{\circ} 53^{\prime}$

$07^{\circ} 50^{\prime}$

$07^{\circ} 50.5^{\prime}$

2100

2100

3815

2110

1948-2142

2035-2040

2028-2035

1978-2077

\section{ABYPLANE (1986)}

1
2
3
4
5
6
7
8
9
10
11
12

$39.78^{\circ}$

$37.30^{\circ}$

$36.50^{\circ}$

$36.80^{\circ}$

$34.80^{\circ}$

$32.03^{\circ}$

$32.10^{\circ}$

$34.07^{\circ}$

$39.92^{\circ}$

$42.73^{\circ}$

$42.95^{\circ}$

$44.65^{\circ}$

BENGAL 2

13078/1

$13078 / 11$

$13078 / 27$ $14.17^{\circ}$
$15.55^{\circ}$
$18.72^{\circ}$
$19.15^{\circ}$
$21.32^{\circ}$
$21.98^{\circ}$
$21.30^{\circ}$
$17.07^{\circ}$
$14.93^{\circ}$
$15.88^{\circ}$
$13.98^{\circ}$
$17.80^{\circ}$

$16^{\circ} 39.86^{\prime}-16^{\circ} 38.58^{\prime}$

$16^{\circ} 35.98^{\prime}$

$16^{\circ} 34.01^{\prime}-16^{\circ} 31.76^{\prime}$
5300

4200-4500

5500

4860-5040

5100-5160

5230-5250

5000-5020

4260-4270

5270-5320

4190-4480

5260-5280

4990

4844

4844

4844 $48^{\circ} 53.19^{\prime}$

$48^{\circ} 47.26^{\prime}-48^{\circ} 48.67^{\prime}$ 


\begin{tabular}{|c|c|c|c|}
\hline $\begin{array}{l}\text { Research Program, } \\
\text { Station }\end{array}$ & Latitude, N & $\begin{array}{l}\text { Longitude, } \mathbf{W} \\
\text { (E - when indicated) }\end{array}$ & Depth, m \\
\hline $\begin{array}{l}\text { BENGAL } 3 \\
13200 / 70 \\
13200 / 93 \\
13200 / 94\end{array}$ & 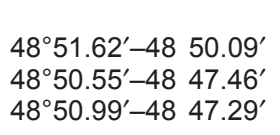 & $\begin{array}{l}16^{\circ} 31.80^{\prime}-16^{\circ} 33.98^{\prime} \\
16^{\circ} 25.30^{\prime}-16^{\circ} 30.42^{\prime} \\
16^{\circ} 23.03^{\prime}-16^{\circ} 32.23^{\prime}\end{array}$ & $\begin{array}{l}4845-4848 \\
4844-4849 \\
4847-4851\end{array}$ \\
\hline $\begin{array}{l}\text { BENGAL } 5 \\
13368 / 47 \\
13368 / 48 \\
13368 / 53\end{array}$ & $\begin{array}{l}48^{\circ} 51.63^{\prime}-4850.93^{\prime} \\
48^{\circ} 49.64^{\prime}-4845.78^{\prime} \\
48^{\circ} 50^{\prime}\end{array}$ & $\begin{array}{l}16^{\circ} 25.18^{\prime}-16^{\circ} 25.99^{\prime} \\
16^{\circ} 30.12^{\prime}-16^{\circ} 32.37^{\prime} \\
16^{\circ} 23.53^{\prime}\end{array}$ & $\begin{array}{l}4844 \\
4841-4845 \\
4842\end{array}$ \\
\hline $\begin{array}{l}\text { BENGAL } 6 \\
13627 / 11 \\
13627 / 24\end{array}$ & $\begin{array}{l}48^{\circ} 47.82^{\prime} \\
48^{\circ} 50.47^{\prime}\end{array}$ & $\begin{array}{l}16^{\circ} 40.37^{\prime} \\
16^{\circ} 44.37^{\prime}\end{array}$ & $\begin{array}{l}4847 \\
4840\end{array}$ \\
\hline $\begin{array}{l}\text { BIACores (1971) } \\
36 \\
95 \\
120 \\
126 \\
129 \\
130 \\
131 \\
163 \\
165 \\
171 \\
173 \\
173 A \\
174 \\
176 \\
185 \\
202 \\
206 \\
227 \\
235 \\
245 \\
249 \\
250 \\
251 \\
252\end{array}$ & $\begin{array}{l}38^{\circ} 11^{\prime} \\
39^{\circ} 04^{\prime} \\
39^{\circ} 03^{\prime} \\
39^{\circ} 19^{\prime} \\
38^{\circ} 58^{\prime} \\
38^{\circ} 55^{\prime} \\
39^{\circ} 04^{\prime} 5^{\prime} \\
37^{\circ} 27^{\prime} \\
37^{\circ} 33^{\prime} \\
37^{\circ} 58^{\prime} \\
37^{\circ} 57^{\prime} \\
37^{\circ} 57^{\prime} \\
38^{\circ} 06^{\prime} \\
38^{\circ} 01^{\prime} \\
38^{\circ} 00^{\prime} \\
37^{\circ} 27^{\prime} \\
37^{\circ} 21^{\prime} \\
37^{\circ} 10^{\prime} \\
37^{\circ} 18^{\prime} \\
40^{\circ} 57^{\prime} \\
45^{\circ} 50^{\prime} \\
45^{\circ} 54.5^{\prime} \\
47^{\circ} 38^{\prime} \\
47^{\circ} 35^{\prime}\end{array}$ & $\begin{array}{l}29^{\circ} 39^{\prime} \\
28^{\circ} 26^{\prime} \\
32^{\circ} 45^{\prime} \\
33^{\circ} 47^{\prime} \\
33^{\circ} 26^{\prime} \\
33^{\circ} 22^{\prime} \\
32^{\circ} 43.5^{\prime} \\
26^{\circ} 03^{\prime} \\
25^{\circ} 58^{\prime} \\
26^{\circ} 07^{\prime} \\
26^{\circ} 08^{\prime} \\
26^{\circ} 08^{\prime} \\
26^{\circ} 15^{\prime} \\
26^{\circ} 22^{\prime} \\
24^{\circ} 57^{\prime} \\
25^{\circ} 00^{\prime} \\
25^{\circ} 28^{\prime} \\
25^{\circ} 11^{\prime} \\
25^{\circ} 32^{\prime} \\
22^{\circ} 16^{\prime} \\
17^{\circ} 32^{\prime} \\
17^{\circ} 29.5^{\prime} \\
08^{\circ} 56^{\prime} \\
08^{\circ} 47^{\prime}\end{array}$ & $\begin{array}{l}2670 \\
2440 \\
2100 \\
3360 \\
3056-3000 \\
2950 \\
2120 \\
2350 \\
2050 \\
3215 \\
3225 \\
3225 \\
3094-3038 \\
2440-2720 \\
2150-2440 \\
2900 \\
2085-2096 \\
2160-2180 \\
2085-2115 \\
4270 \\
4620-4690 \\
4631 \\
3360-3600 \\
2550-2700\end{array}$ \\
\hline $\begin{array}{l}\text { BIOCYAN II (1983) } \\
\text { Cyana Dive } 18 \\
\text { (PL 18) } \\
\text { Cyana Dive } 22 \\
\text { (PL-22) }\end{array}$ & $\begin{array}{l}47^{\circ} 32^{\prime} \\
47^{\circ} 31^{\prime} 32^{\prime \prime}\end{array}$ & $\begin{array}{l}08^{\circ} 28^{\prime} \\
08^{\circ} 27^{\prime} 30^{\prime \prime}\end{array}$ & $\begin{array}{l}2000 \\
2000\end{array}$ \\
\hline $\begin{array}{l}\text { BIOGAS (1972-1974 } \\
1 \\
2 \\
3 \\
4 \\
5 \\
6\end{array}$ & $\begin{array}{l}47^{\circ} 29.2^{\prime}-47^{\circ} 36.1^{\prime} \\
47^{\circ} 28.1^{\prime}-47^{\circ} 36.4^{\prime} \\
47^{\circ} 31.5^{\prime}-47^{\circ} 38.3^{\prime} \\
46^{\circ} 27.3^{\prime}-46^{\circ} 32.8^{\prime} \\
44^{\circ} 20.9^{\prime}-44^{\circ} 30.4^{\prime} \\
44^{\circ} 04.6^{\prime}-44^{\circ} 11.3^{\prime}\end{array}$ & $\begin{array}{l}08^{\circ} 30.7^{\prime}-08^{\circ} 45.5^{\prime} \\
08^{\circ} 59.5^{\prime}-09^{\circ} 14^{\prime} \\
09^{\circ} 28.2^{\prime}-09^{\circ} 42^{\prime} \\
10^{\circ} 19.5^{\prime}-10^{\circ} 30^{\prime} \\
04^{\circ} 50.7^{\prime}-04^{\circ} 56.3^{\prime} \\
04^{\circ} 15^{\prime}-04^{\circ} 21.4^{\prime}\end{array}$ & $\begin{array}{l}1985-2360 \\
2695-3548 \\
3992-4300 \\
4518-4825 \\
4203-4510 \\
1845-2150\end{array}$ \\
\hline
\end{tabular}

The gear codes: DS (Drague Sanders - an epibenthic sledge), CP (Chalut à perche - a beam trawl), KG (Carottier USNEL - a box corer), KR (Carrotier REINECK - a box corer) and NA (Nasse - a baited trap).

$\begin{array}{lccc}\text { BIOGAS (Jean Charcot) }(1972) & & \\ \text { CP 01 } & 47^{\circ} 35^{\prime} & 08^{\circ} 39^{\prime} & 2245 \\ \text { CP 02 } & 47^{\circ} 33 & 08^{\circ} 41^{\prime} & 2177 \\ \text { CV 03 } & 47^{\circ} 30^{\prime} & 08^{\circ} 17^{\prime} & 2080 \\ \text { CP 04 } & 47^{\circ} 35^{\prime} & 09^{\circ} 31^{\prime} & 4200 \\ \text { CV 04 } & 47^{\circ} 29^{\prime} & 08^{\circ} 18^{\prime} & 2090 \\ \text { DS 04 } & 47^{\circ} 29^{\prime} & 08^{\circ} 18^{\prime} & 2090 \\ \text { DS 05 } & 47^{\circ} 27^{\prime} & 08^{\circ} 22^{\prime} & 2210\end{array}$


Research Program, Latitude, N Station

CP 05

CV 05

CP 06

CV 06

DS 06

DS 07

CP 07

CP 08

CV 08

CP 09

CV 09

DS 09

CP 10

CV 10

DS 10

DS 11

CP 11

CP 12

DS 12

CV 12

CP 13

CV 13

DS 13

CP 14

CV 14

CP 15

DS 15

CP 16

DS 16

CP 17

DS 17

DS 18

CP 18

CV 18

CP 19

DS 19

CP 20

DS 21

CP 21

CP 22

CV 23

CP 23

DS 23

CP 24

CV 24

CP 25

CV 25

DS 25

CP 26

CV 26

DS 26

CV 27

CP 27

CV 28

CP 28

CV 29

CV 30

DS 31

CP 32

CV 32

DS 32

CP 33
Longitude, w

( $E$ - when indicated)

$10^{\circ} 20^{\prime} \quad 3850$

$08^{\circ} 18^{\prime} \quad 2350$

$04^{\circ} 54^{\prime} \quad 4460$

$08^{\circ} 16^{\prime} \quad 2200$

$08^{\circ} 18^{\prime} \quad 2090$

$08^{\circ} 15^{\prime} \quad 2170$

$04^{\circ} 16^{\prime}$

$08^{\circ} 39^{\prime} \quad 2177$

$08^{\circ} 34^{\prime} 2$

$08^{\circ} 44^{\prime}$

$08^{\circ} 44^{\prime} \quad 2199$

$08^{\circ} 16^{\prime}$

$08^{\circ} 44^{\prime} \quad 2878$

$08^{\circ} 41^{\prime}$

$08^{\circ} 33^{\prime}$

$08^{\circ} 34^{\prime}$

$09^{\circ} 07^{\prime}$

$09^{\circ} 12^{\prime} \quad 2925$

$08^{\circ} 35^{\prime} \quad 2180$

$09^{\circ} 12^{\prime}$

$09^{\circ} 38^{\prime}$

$09^{\circ} 34^{\prime}$

$08^{\circ} 40^{\prime} \quad 2165$

$09^{\circ} 36^{\prime} \quad 4237$

$09^{\circ} 36^{\prime}$

$10^{\circ} 29^{\prime}$

$08^{\circ} 40^{\prime} \quad 2246$

$10^{\circ} 19^{\prime} \quad 4706$

$08^{\circ} 41^{\prime} \quad 2325$

$10^{\circ} 20^{\prime}$

$08^{\circ} 46^{\prime}$

$08^{\circ} 54^{\prime} \quad 2138$

$10^{\circ} 26^{\prime}$

$09^{\circ} 37^{\prime} \quad 4120$

$04^{\circ} 51^{\prime}$

$09^{\circ} 04^{\prime}$

$04^{\circ} 51^{\prime} \quad 4459$

$04^{\circ} 40^{\prime}$

$04^{\circ} 49^{\prime}$

$04^{\circ} 55^{\prime}$

$08^{\circ} 34^{\prime}$

$04^{\circ} 21^{\prime} \quad 1980$

$10^{\circ} 21^{\prime}$

$04^{\circ} 16^{\prime}$

$08^{\circ} 34^{\prime} \quad 2025$

$04^{\circ} 17^{\prime}$

$08^{\circ} 33^{\prime}$

$08^{\circ} 33^{\prime}$

$08^{\circ} 33^{\prime} \quad 2115$

$09^{\circ} 05^{\prime} \quad 2822$

$04^{\circ} 15^{\prime} \quad 2076$

$09^{\circ} 32^{\prime} \quad 4023$

$08^{\circ} 26^{\prime}$

$09^{\circ} 36^{\prime}$

$09^{\circ} 36^{\prime} \quad 4023$

$09^{\circ} 38^{\prime} \quad 4158$

$10^{\circ} 20^{\prime}$

$09^{\circ} 04^{\prime}$

$08^{\circ} 31^{\prime}$

$04^{\circ} 16^{\prime}$

$08^{\circ} 05^{\prime} \quad 2138$

$08^{\circ} 48^{\prime}$ 


\begin{tabular}{|c|c|c|c|}
\hline $\begin{array}{l}\text { Research Program, } \\
\text { Station }\end{array}$ & Latitude, N & $\begin{array}{l}\text { Longitude, } \mathbf{W} \\
(\mathrm{E}-\text { when indicated })\end{array}$ & Depth, m \\
\hline CV 33 & $44^{\circ} 05^{\prime}$ & $04^{\circ} 18^{\prime}$ & 1913 \\
\hline DS 33 & $47^{\circ} 40^{\prime}$ & $08^{\circ} 05^{\prime}$ & 2338 \\
\hline CV 34 & $44^{\circ} 27^{\prime}$ & $04^{\circ} 49^{\prime}$ & 4406 \\
\hline CP 34 & $47^{\circ} 32^{\prime}$ & $08^{\circ} 25^{\prime}$ & 1970 \\
\hline CP 35 & $46^{\circ} 34^{\prime}$ & $10^{\circ} 23^{\prime}$ & 4720 \\
\hline CV 35 & $46^{\circ} 31^{\prime}$ & $10^{\circ} 30^{\prime}$ & 4721 \\
\hline DS 35 & $47^{\circ} 34^{\prime}$ & $08^{\circ} 41^{\prime}$ & 2226 \\
\hline CV 36 & $47^{\circ} 34^{\prime}$ & $09^{\circ} 39^{\prime}$ & 4209 \\
\hline DS 36 & $47^{\circ} 33^{\prime}$ & $08^{\circ} 36^{\prime}$ & 2147 \\
\hline CP 37 & $47^{\circ} 34^{\prime}$ & $08^{\circ} 39^{\prime}$ & 2175 \\
\hline CV 37 & $47^{\circ} 33^{\prime}$ & $09^{\circ} 14^{\prime}$ & 3000 \\
\hline CV 38 & $47^{\circ} 31^{\prime}$ & $08^{\circ} 59^{\prime}$ & 2695 \\
\hline CV 39 & $47^{\circ} 34^{\prime}$ & $08^{\circ} 45^{\prime}$ & 2350 \\
\hline CV 40 & $47^{\circ} 33^{\prime}$ & $09^{\circ} 02^{\prime}$ & 2860 \\
\hline DS 40 & $47^{\circ} 36^{\prime}$ & $09^{\circ} 04^{\prime}$ & 3345 \\
\hline CV 41 & $47^{\circ} 27^{\prime}$ & $09^{\circ} 01^{\prime}$ & 3800 \\
\hline DS 41 & $47^{\circ} 28^{\prime}$ & $09^{\circ} 07^{\prime}$ & 3548 \\
\hline DS 48 & $44^{\circ} 29^{\prime}$ & $04^{\circ} 54^{\prime}$ & 4203 \\
\hline DS 49 & $44^{\circ} 06^{\prime}$ & $04^{\circ} 16^{\prime}$ & 1845 \\
\hline DS 50 & $44^{\circ} 09^{\prime}$ & $04^{\circ} 16^{\prime}$ & 2124 \\
\hline DS 51 & $44^{\circ} 11^{\prime}$ & $04^{\circ} 15^{\prime}$ & 2430 \\
\hline DS 52 & $44^{\circ} 06^{\prime}$ & $04^{\circ} 22^{\prime}$ & 2006 \\
\hline DS 53 & $44^{\circ} 30^{\prime}$ & $04^{\circ} 56^{\prime}$ & 4425 \\
\hline DS 55 & $47^{\circ} 35^{\prime}$ & $09^{\circ} 41^{\prime}$ & 4125 \\
\hline DS 57 & $47^{\circ} 31^{\prime}$ & $09^{\circ} 08^{\prime}$ & 2906 \\
\hline DS 58 & $47^{\circ} 34^{\prime}$ & $09^{\circ} 08^{\prime}$ & 2775 \\
\hline DS 59 & $47^{\circ} 32^{\prime}$ & $09^{\circ} 06^{\prime}$ & 2790 \\
\hline DS 60 & $47^{\circ} 27^{\prime}$ & $09^{\circ} 07^{\prime}$ & 2742 \\
\hline DS 61 & $47^{\circ} 35^{\prime}$ & $08^{\circ} 39^{\prime}$ & 2250 \\
\hline DS 62 & $47^{\circ} 33^{\prime}$ & $08^{\circ} 40^{\prime}$ & 2175 \\
\hline DS 63 & $47^{\circ} 33^{\prime}$ & $08^{\circ} 35^{\prime}$ & 2126 \\
\hline DS 64 & $47^{\circ} 29^{\prime}$ & $08^{\circ} 37^{\prime}$ & 2156 \\
\hline DS 65 & $47^{\circ} 36^{\prime}$ & $08^{\circ} 40^{\prime}$ & 2360 \\
\hline DS 66 & $47^{\circ} 28^{\prime}$ & $09^{\circ} 00^{\prime}$ & 3480 \\
\hline DS 67 & $47^{\circ} 31^{\prime}$ & $09^{\circ} 35^{\prime}$ & 4150 \\
\hline DS 70 & $44^{\circ} 09^{\prime}$ & $04^{\circ} 17^{\prime}$ & 2150 \\
\hline DS 71 & $47^{\circ} 34^{\prime}$ & $08^{\circ} 34^{\prime}$ & 2194 \\
\hline DS 73 & $47^{\circ} 32^{\prime}$ & $09^{\circ} 06^{\prime}$ & 2805 \\
\hline DS 74 & $47^{\circ} 33^{\prime}$ & $09^{\circ} 08^{\prime}$ & 2777 \\
\hline DS 75 & $47^{\circ} 28^{\prime}$ & $09^{\circ} 08^{\prime}$ & 3250 \\
\hline DS 76 & $47^{\circ} 35^{\prime}$ & $09^{\circ} 33^{\prime}$ & 4228 \\
\hline DS 77 & $47^{\circ} 32^{\prime}$ & $09^{\circ} 35^{\prime}$ & 4240 \\
\hline DS 78 & $46^{\circ} 31^{\prime}$ & $10^{\circ} 24^{\prime}$ & 4706 \\
\hline DS 79 & $46^{\circ} 30^{\prime}$ & $10^{\circ} 27^{\prime}$ & 4715 \\
\hline DS 81 & $46^{\circ} 28^{\prime}$ & $10^{\circ} 25^{\prime}$ & 4715 \\
\hline DS 82 & $44^{\circ} 25^{\prime}$ & $04^{\circ} 53^{\prime}$ & 4462 \\
\hline DS 86 & $44^{\circ} 05^{\prime}$ & $04^{\circ} 19^{\prime}$ & 1950 \\
\hline DS 87 & $44^{\circ} 05^{\prime}$ & $04^{\circ} 19^{\prime}$ & 1913 \\
\hline KG 147 & $47^{\circ} 33^{\prime}$ & $08^{\circ} 41^{\prime}$ & 2190 \\
\hline KG 151 & $47^{\circ} 34^{\prime}$ & $08^{\circ} 39^{\prime}$ & 2205 \\
\hline KG 172 & $47^{\circ} 32^{\prime}$ & $09^{\circ} 06^{\prime}$ & 2820 \\
\hline KG 208 & $47^{\circ} 35^{\prime}$ & $09^{\circ} 40^{\prime}$ & 4130 \\
\hline \multicolumn{4}{|c|}{ BIOGAS (Thalassa) (1973) } \\
\hline VI CP 01 & $47^{\circ} 30^{\prime}$ & $09^{\circ} 07^{\prime} 4$ & 3056 \\
\hline VI CP 02 & $47^{\circ} 33^{\prime}$ & $08^{\circ} 41^{\prime}$ & 2177 \\
\hline \multicolumn{4}{|c|}{ BIOGAS II (Jean Charcot) (1973) } \\
\hline CV 18 & $47^{\circ} 32^{\prime}$ & $09^{\circ} 36^{\prime}$ & 4120 \\
\hline CV 20 & $47^{\circ} 37^{\prime}$ & $08^{\circ} 34^{\prime}$ & 2282 \\
\hline DS 30 & $47^{\circ} 38^{\prime}$ & $09^{\circ} 33^{\prime}$ & 4160 \\
\hline DS 31 & $47^{\circ} 32^{\prime}$ & $09^{\circ} 04^{\prime}$ & 2813 \\
\hline DS 32 & $47^{\circ} 32^{\prime}$ & $08^{\circ} 05^{\prime}$ & 2138 \\
\hline
\end{tabular}




\begin{tabular}{|c|c|c|c|}
\hline $\begin{array}{l}\text { Research Program, } \\
\text { Station }\end{array}$ & Latitude, $\mathbf{N}$ & $\begin{array}{l}\text { Longitude, } \mathbf{W} \\
\text { (E - when indicated) }\end{array}$ & Depth, m \\
\hline DS 33 & $47^{\circ} 39^{\prime}$ & $08^{\circ} 05^{\prime}$ & 2338 \\
\hline 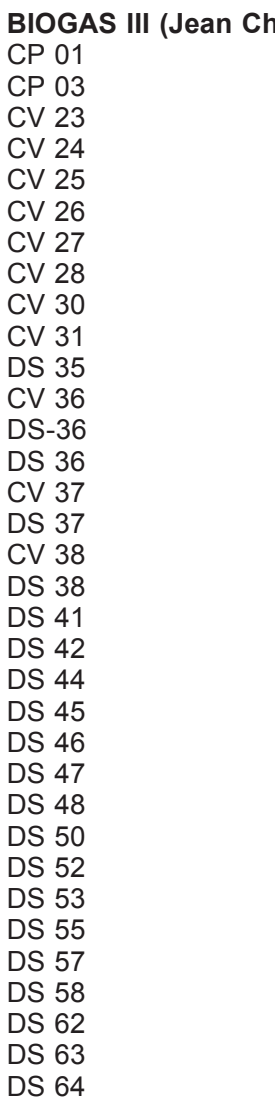 & $\begin{array}{l}\operatorname{arcot})(1973) \\
47^{\circ} 34.06^{\prime} \\
47^{\circ} 32.07^{\prime} \\
47^{\circ} 32^{\prime} \\
47^{\circ} 33^{\prime} 7 \\
47^{\circ} 32^{\prime} \\
47^{\circ} 33^{\prime \prime} 9 \\
47^{\circ} 34^{\prime} \\
47^{\circ} 35.3^{\prime} \\
46^{\circ} 32^{\prime} \\
44^{\circ} 20.9^{\prime} \\
47^{\circ} 34^{\prime} \\
47^{\circ} 34.01^{\prime} \\
47^{\circ} 32^{\prime} \\
47^{\circ} 32^{\prime} \\
47^{\circ} 33.05^{\prime} \\
47^{\circ} 31^{\prime} \\
47^{\circ} 30.09^{\prime} \\
47^{\circ} 32^{\prime} \\
47^{\circ} 28^{\prime} \\
47^{\circ} 32^{\prime} \\
47^{\circ} 33^{\prime} \\
47^{\circ} 34^{\prime} \\
46^{\circ} 28^{\prime} \\
44^{\circ} 26^{\prime} \\
44^{\circ} 29^{\prime} \\
44^{\circ} 09^{\prime} \\
44^{\circ} 06.03^{\prime} \\
44^{\circ} 30.04^{\prime} \\
47^{\circ} 34.09^{\prime} \\
47^{\circ} 30.08^{\prime} \\
47^{\circ} 34.04^{\prime} \\
47^{\circ} 32.08^{\prime} \\
47^{\circ} 32.08^{\prime} \\
47^{\circ} 29.02^{\prime}\end{array}$ & $\begin{array}{l}08^{\circ} 38.08^{\prime} \\
08^{\circ} 34^{\prime} \\
08^{\circ} 34^{\prime} \\
08^{\circ} 34^{\prime} 3 \\
08^{\circ} 32^{\prime} \\
09^{\circ} 05^{\prime \prime} 3 \\
09^{\circ} 32^{\prime} \\
09^{\circ} 35.9^{\prime} \\
10^{\circ} 20^{\prime} \\
04^{\circ} 52.8^{\prime} \\
08^{\circ} 40^{\prime} \\
09^{\circ} 38.05^{\prime} \\
08^{\circ} 36^{\prime} \\
08^{\circ} 36^{\prime} \\
09^{\circ} 14^{\prime} \\
08^{\circ} 34^{\prime} \\
08^{\circ} 59.05^{\prime} \\
08^{\circ} 36^{\prime} \\
09^{\circ} 07^{\prime} \\
09^{\circ} 35^{\prime} \\
09^{\circ} 42^{\prime} \\
09^{\circ} 38^{\prime} \\
10^{\circ} 23^{\prime} \\
04^{\circ} 50^{\prime} \\
04^{\circ} 54^{\prime} \\
04^{\circ} 15^{\prime} \\
04^{\circ} 22.04^{\prime} \\
04^{\circ} 56.03^{\prime} \\
09^{\circ} 40.09^{\prime} \\
09^{\circ} 07.06^{\prime} \\
09^{\circ} 08.02^{\prime} \\
08^{\circ} 40^{\prime} \\
08^{\circ} 35^{\prime} \\
08^{\circ} 30.07^{\prime}\end{array}$ & $\begin{array}{l}2245 \\
2119 \\
2034 \\
2025 \\
2044 \\
2822 \\
4023 \\
4023 \\
4518 \\
4293 \\
2226 \\
4209 \\
2147 \\
2147 \\
3000 \\
2110 \\
2695 \\
2138 \\
3548 \\
4104 \\
3992 \\
4260 \\
4521 \\
4230 \\
4203 \\
2124 \\
2006 \\
4425 \\
4125 \\
2906 \\
2775 \\
2175 \\
2126 \\
2156\end{array}$ \\
\hline $\begin{array}{l}\text { BIOGAS (Thalassa) } \\
\text { VI CP } 19 \\
\text { CP } 21\end{array}$ & $\begin{array}{l}(1974) \\
44^{\circ} 24.9^{\prime} \\
44^{\circ} 21.2^{\prime}\end{array}$ & $\begin{array}{l}05^{\circ} 51.3^{\prime} \\
04^{\circ} 49.3^{\prime}\end{array}$ & $\begin{array}{l}4434 \\
4453\end{array}$ \\
\hline $\begin{array}{l}\text { BIOGAS IV (Jean Ch } \\
\text { CP } 01 \\
\text { CV } 01 \\
\text { CP } 02 \\
\text { CP } 03 \\
\text { CP } 04 \\
\text { CV } 36 \\
\text { CV } 37 \\
\text { CV } 38 \\
\text { DS } 51 \\
\text { DS } 52 \\
\text { DS } 53 \\
\text { DS } 54 \\
\text { DS } 55 \\
\text { DS } 56 \\
\text { DS } 57 \\
\text { DS } 58 \\
\text { DS } 59 \\
\text { DS } 60 \\
\text { DS } 61 \\
\text { DS } 62\end{array}$ & $\begin{array}{l}\text { larcot) (1974) } \\
47^{\circ} 34^{\prime} \\
47^{\circ} 34^{\prime} 6 \\
47^{\circ} 33^{\prime} \\
47^{\circ} 32^{\prime} 7 \\
47^{\circ} 32^{\prime} \\
47^{\circ} 34^{\prime} \\
47^{\circ} 28^{\prime}-33^{\prime} \\
47^{\circ} 30^{\prime} \\
44^{\circ} 11^{\prime} \\
44^{\circ} 06^{\prime} \\
44^{\circ} 30^{\prime} \\
46^{\circ} 31^{\prime} \\
47^{\circ} 34^{\prime} \\
47^{\circ} 32^{\prime} \\
47^{\circ} 30.08^{\prime} \\
47^{\circ} 34^{\prime} \\
47^{\circ} 31^{\prime} \\
47^{\circ} 26^{\prime} \\
47^{\circ} 34^{\prime} \\
47^{\circ} 32^{\prime}\end{array}$ & $\begin{array}{l}08^{\circ} 38^{\prime} \\
08^{\circ} 38^{\prime} 8 \\
08^{\circ} 41^{\prime} \\
08^{\circ} 34^{\prime} \\
9^{\circ} 11^{\prime} 42^{\prime \prime} \\
09^{\circ} 38^{\prime} \\
09^{\circ} 00^{\prime}-14^{\prime} \\
08^{\circ} 59^{\prime} \\
04^{\circ} 15^{\prime} \\
04^{\circ} 22^{\prime} \\
04^{\circ} 56^{\prime} \\
10^{\circ} 29^{\prime} \\
09^{\circ} 40^{\prime} \\
09^{\circ} 28^{\prime} \\
09^{\circ} 07.06^{\prime} \\
09^{\circ} 08^{\prime} \\
09^{\circ} 06^{\prime} \\
09^{\circ} 07^{\prime} \\
08^{\circ} 38^{\prime} \\
08^{\circ} 40^{\prime}\end{array}$ & $\begin{array}{l}2245 \\
2245 \\
2177 \\
2119 \\
2700 \\
4209 \\
3000 \\
2695 \\
2430 \\
2006 \\
4425 \\
4659 \\
4125 \\
4050 \\
2906 \\
2775 \\
2790 \\
3742 \\
2250 \\
2175\end{array}$ \\
\hline
\end{tabular}




\begin{tabular}{|c|c|c|c|}
\hline $\begin{array}{l}\text { Research Program, } \\
\text { Station }\end{array}$ & Latitude, N & $\begin{array}{l}\text { Longitude, } \mathbf{w} \\
(\mathrm{E}-\text { when indicated })\end{array}$ & Depth, m \\
\hline $\begin{array}{l}\text { DS } 63 \\
\text { DS } 64 \\
\text { KR } 31 \\
\text { KR } 33 \\
\text { KR } 35 \\
\text { KR-37 } \\
\text { KR } 39\end{array}$ & $\begin{array}{l}47^{\circ} 32^{\prime} \\
47^{\circ} 29^{\prime} \\
47^{\circ} 37^{\prime} \\
47^{\circ} 30^{\prime} \\
47^{\circ} 26^{\prime} \\
47^{\circ} 33^{\prime} 48^{\prime \prime} \\
47^{\circ} 33^{\prime}\end{array}$ & $\begin{array}{l}08^{\circ} 35^{\prime} \\
08^{\circ} 30^{\prime} \\
09^{\circ} 41^{\prime} \\
09^{\circ} 06^{\prime} \\
09^{\circ} 08^{\prime} \\
08^{\circ} 38^{\prime} 36^{\prime \prime} \\
08^{\circ} 36^{\prime}\end{array}$ & $\begin{array}{l}2126 \\
2156 \\
4097 \\
2963 \\
4140 \\
2205 \\
2179\end{array}$ \\
\hline $\begin{array}{l}\text { BIOGAS V (1974) } \\
\text { CP } 05 \\
\text { CP } 07 \\
\text { CP } 09 \\
\text { CP } 39 \\
\text { CV } 39 \\
\text { CV } 40 \\
\text { CV } 41 \\
\text { CP } 42 \\
\text { DS } 65 \\
\text { CP 66-50bis } \\
\text { DS } 66 \\
\text { DS } 67 \\
\text { CP } 68 \\
\text { CP } 69 \\
\text { CP } 69-167 \\
\text { DS } 68 \\
\text { DS } 69 \\
\text { DS } 70 \\
\text { KR } 50\end{array}$ & $\begin{array}{l}46^{\circ} 29^{\prime} \\
44^{\circ} 10^{\prime} \\
47^{\circ} 33^{\prime} \\
47^{\circ} 32^{\prime} \\
47^{\circ} 33^{\prime} \\
47^{\circ} 33^{\prime} 1 \\
47^{\circ} 27^{\prime} \\
46^{\circ} 22.7^{\prime} \\
47^{\circ} 36^{\prime} \\
35^{\circ} 21.35 \\
47^{\circ} 28^{\prime} \\
47^{\circ} 31^{\prime} \\
35^{\circ} 11.9^{\prime} \\
35^{\circ} 11.4^{\prime} \\
35^{\circ} 11.4 \\
46^{\circ} 26^{\prime} \\
44^{\circ} 21^{\prime} \\
44^{\circ} 08^{\prime} \\
46^{\circ} 33^{\prime}\end{array}$ & $\begin{array}{l}10^{\circ} 20^{\prime} \\
04^{\circ} 16^{\prime} \\
08^{\circ} 44.01^{\prime} \\
08^{\circ} 38.4^{\prime} \\
08^{\circ} 45^{\prime} \\
09^{\circ} 01^{\prime} 9 \\
09^{\circ} 01^{\prime} \\
12^{\circ} 36.8 \\
08^{\circ} 40^{\prime} \\
08^{\circ} 10.5 \\
09^{\circ} 00^{\prime} \\
09^{\circ} 35^{\prime} \\
07^{\circ} 52.6^{\prime} \\
07^{\circ} 50.5^{\prime} \\
07^{\circ} 50.5 \\
10^{\circ} 23^{\prime} \\
04^{\circ} 52^{\prime} \\
04^{\circ} 17^{\prime} \\
10^{\circ} 23^{\prime}\end{array}$ & $\begin{array}{l}3850 \\
2170 \\
2171 \\
2100 \\
2350 \\
2860 \\
3800 \\
3815 \\
2360 \\
1948-2142 \\
3480 \\
4150 \\
2035 \\
2028 \\
1978-2077 \\
4550 \\
4510 \\
2150 \\
4750\end{array}$ \\
\hline $\begin{array}{l}\text { BIOGAS VI (1974) } \\
\text { CP } 08 \\
\text { CP } 09 \\
\text { CP } 10 \\
\text { CP } 11 \\
\text { CP } 11 \\
\text { CP } 12 \\
\text { CP } 13 \\
\text { CV } 13 \\
\text { CP } 14 \\
\text { CP } 15 \\
\text { CP } 16 \\
\text { CP } 17 \\
\text { CP } 18 \\
\text { CP } 19 \\
\text { CP } 20 \\
\text { CP } 21 \\
\text { CP } 22 \\
\text { CP } 23 \\
\text { CV } 37 \\
\text { CV } 41 \\
\text { KR } 66 \\
\text { DS } 71 \\
\text { DS } 72 \\
\text { DS } 73 \\
\text { DS } 74 \\
\text { DS } 75 \\
\text { DS } 76 \\
\text { DS } 77 \\
\text { DS } 78 \\
\text { DS } 79 \\
\text { DS } 80 \\
\text { DS } 81 \\
\text { DS } 82\end{array}$ & $\begin{array}{l}44^{\circ} 33^{\prime} \\
47^{\circ} 33^{\prime} \\
47^{\circ} 29.6^{\prime} \\
47^{\circ} 28^{\prime}-33^{\prime} \\
47^{\circ} 30^{\prime} \\
47^{\circ} 32^{\prime} 30^{\prime \prime} \\
47^{\circ} 34^{\prime} \\
47^{\circ} 31.08^{\prime} \\
47^{\circ} 32^{\prime} \\
46^{\circ} 32^{\prime} \\
46^{\circ} 27^{\prime} \\
46^{\circ} 30^{\prime} \\
46^{\circ} 30^{\prime} \\
44^{\circ} 24^{\prime} \\
44^{\circ} 23.2^{\prime} \\
44^{\circ} 21^{\prime} \\
44^{\circ} 22.9^{\prime} \\
44^{\circ} 05^{\prime} \\
47^{\circ} 33.5^{\prime} \\
47^{\circ} 27^{\prime} \\
46^{\circ} 31.07^{\prime} \\
47^{\circ} 34^{\prime} \\
47^{\circ} 38.06^{\prime} \\
47^{\circ} 32^{\prime} 06^{\prime \prime} \\
47^{\circ} 33^{\prime} \\
47^{\circ} 28^{\prime} \\
47^{\circ} 34.8 \\
47^{\circ} 31^{\prime} \\
47^{\circ} 31^{\prime} \\
46^{\circ} 30^{\prime} \\
46^{\circ} 29^{\prime} \\
46^{\circ} 28^{\prime} \\
44^{\circ} 25^{\prime}\end{array}$ & $\begin{array}{l}08^{\circ} 38^{\prime} \\
08^{\circ} 44^{\prime} \\
09^{\circ} 04.5^{\prime} \\
09^{\circ} 00^{\prime}-14^{\prime} \\
9^{\circ} 07^{\prime} 4 \\
09^{\circ} 11^{\prime} 36^{\prime \prime} \\
09^{\circ} 38^{\prime} \\
09^{\circ} 34.2^{\prime} \\
09^{\circ} 35.9^{\prime} \\
10^{\circ} 28^{\prime} \\
10^{\circ} 25^{\prime} \\
10^{\circ} 19^{\prime} \\
10^{\circ} 26^{\prime} \\
04^{\circ} 51^{\prime} \\
04^{\circ} 51.4^{\prime} \\
04^{\circ} 49^{\prime} \\
04^{\circ} 54.8^{\prime} \\
04^{\circ} 21^{\prime} \\
09^{\circ} 14^{\prime} \\
09^{\circ} 01^{\prime} \\
10^{\circ} 27.04^{\prime} \\
08^{\circ} 33^{\prime} \\
08^{\circ} 36.01^{\prime} \\
09^{\circ} 06^{\prime} \\
09^{\circ} 07^{\prime} \\
09^{\circ} 07^{\prime} \\
09^{\circ} 33^{\prime} 3^{\prime \prime} \\
09^{\circ} 34^{\prime} \\
10^{\circ} 23^{\prime} \\
10^{\circ} 27^{\prime} \\
10^{\circ} 29^{\prime} \\
10^{\circ} 24^{\prime} \\
04^{\circ} 52^{\prime}\end{array}$ & $\begin{array}{l}2177 \\
2171 \\
2878 \\
3056 \\
3056 \\
2925 \\
4134 \\
4252 \\
4237 \\
4715 \\
4825 \\
4706 \\
4721 \\
4434 \\
4459 \\
4453 \\
4475 \\
1980 \\
3000 \\
3800 \\
4700 \\
2194 \\
2250 \\
2805 \\
2777 \\
3250 \\
4228 \\
4240 \\
4706 \\
4715 \\
4720 \\
4715 \\
4462\end{array}$ \\
\hline
\end{tabular}




\begin{tabular}{|c|c|c|c|}
\hline $\begin{array}{l}\text { Research Program, } \\
\text { Station }\end{array}$ & Latitude, N & $\begin{array}{l}\text { Longitude, } \mathbf{W} \\
(\mathrm{E}-\text { when indicated })\end{array}$ & Depth, m \\
\hline $\begin{array}{l}\text { DS } 84 \\
\text { DS } 85 \\
\text { CP } 23\end{array}$ & $\begin{array}{l}44^{\circ} 25^{\prime} \\
44^{\circ} 23^{\prime} \\
44^{\circ} 05^{\prime}\end{array}$ & $\begin{array}{l}04^{\circ} 52^{\prime} \\
04^{\circ} 50^{\prime} \\
04^{\circ} 21^{\prime}\end{array}$ & $\begin{array}{l}4466 \\
4462 \\
1980\end{array}$ \\
\hline $\begin{array}{l}\text { BIOGAS VII (1978) } \\
\text { CP } 26 \\
\text { CP } 28\end{array}$ & $\begin{array}{l}47^{\circ} 28^{\prime}-35^{\prime} \\
47^{\circ} 29.5^{\prime}\end{array}$ & $\begin{array}{l}08^{\circ} 25^{\prime}-45^{\prime} \\
09^{\circ} 03.5^{\prime}\end{array}$ & $\begin{array}{l}2115 \\
3380\end{array}$ \\
\hline $\begin{array}{l}\text { BIOGAS VIII (Jean C } \\
\text { CP } 30 \\
\text { KG } 148 \\
\text { KG } 149\end{array}$ & $\begin{array}{l}\text { harcot) (1979 } \\
47^{\circ} 28^{\prime}-33^{\prime} \\
47^{\circ} 28^{\prime}-35^{\prime} \\
47^{\circ} 28^{\prime}-35^{\prime}\end{array}$ & $\begin{array}{l}09^{\circ} 00^{\prime}-14^{\prime} \\
08^{\circ} 25^{\prime}-45^{\prime} \\
08^{\circ} 25^{\prime}-45^{\prime}\end{array}$ & $\begin{array}{l}3100 \\
2165 \\
2165\end{array}$ \\
\hline $\begin{array}{l}\text { BIOGAS VIII (Le Nor } \\
\text { CP } 29 \\
\text { CP } 30 \\
\text { KG } 141 \\
\text { KG } 142 \\
\text { KG } 144 \\
\text { KG } 145 \\
\text { KG } 147 \\
\text { KG } 148 \\
\text { KG } 149 \\
\text { KG } 150 \\
\text { KG } 151 \\
\text { KG } 152 \\
\text { KG } 153 \\
\text { KG } 155 \\
\text { KG } 156 \\
\text { KG } 157 \\
\text { KG } 158 \\
\text { KG } 160\end{array}$ & $\begin{array}{l}\text { oit) (1979) } \\
47^{\circ} 31^{\prime} \\
47^{\circ} 29^{\prime} \\
47^{\circ} 34^{\prime} \\
47^{\circ} 33^{\prime} \\
47^{\circ} 34^{\prime} \\
47^{\circ} 33^{\prime} \\
47^{\circ} 33^{\prime} \\
47^{\circ} 33^{\prime} \\
47^{\circ} 33^{\prime} \\
47^{\circ} 33^{\prime} \\
47^{\circ} 34^{\prime} \\
47^{\circ} 33^{\prime} \\
47^{\circ} 33^{\prime} \\
47^{\circ} 33^{\prime} \\
47^{\circ} 33^{\prime} \\
47^{\circ} 34^{\prime} \\
47^{\circ} 33^{\prime} \\
47^{\circ} 34^{\prime}\end{array}$ & $\begin{array}{l}09^{\circ} 04^{\prime} \\
09^{\circ} 06^{\prime} \\
08^{\circ} 40^{\prime} \\
08^{\circ} 40^{\prime} \\
08^{\circ} 40^{\prime} \\
08^{\circ} 39^{\prime} \\
08^{\circ} 41^{\prime} \\
08^{\circ} 49^{\prime} \\
08^{\circ} 39^{\prime} \\
08^{\circ} 40^{\prime} \\
08^{\circ} 39^{\prime} \\
08^{\circ} 40^{\prime} \\
08^{\circ} 41^{\prime} \\
08^{\circ} 39^{\prime} \\
08^{\circ} 39^{\prime} \\
08^{\circ} 40^{\prime} \\
08^{\circ} 39^{\prime} \\
08^{\circ} 40^{\prime}\end{array}$ & $\begin{array}{l}2690 \\
3100 \\
2204 \\
2182 \\
2165-2225 \\
2170 \\
2190 \\
2170 \\
2165-2225 \\
2142 \\
2205 \\
2160 \\
2142 \\
2187 \\
2207 \\
2227 \\
2167 \\
2224\end{array}$ \\
\hline $\begin{array}{l}\text { BIOGAS IX (1980) } \\
\text { CP } 32 \\
\text { CP } 33 \\
\text { CP } 37 \\
\text { KG } 167 \\
\text { KG } 168 \\
\text { KG } 169 \\
\text { KG } 170 \\
\text { KG } 171 \\
\text { KG } 172 \\
\text { KG } 173 \\
\text { KG } 174 \\
\text { KG } 175 \\
\text { KG } 176 \\
\text { KG } 177 \\
\text { KG } 178 \\
\text { KG } 179 \\
\text { KG } 180 \\
\text { KG } 181 \\
\text { KG } 183 \\
\text { KG } 184 \\
\text { KG } 185\end{array}$ & $\begin{array}{l}47^{\circ} 30^{\prime} 23^{\prime \prime} \\
47^{\circ} 33^{\prime} \\
47^{\circ} 28^{\prime}-35^{\prime} \\
47^{\circ} 32^{\prime} \\
47^{\circ} 32^{\prime} \\
47^{\circ} 32^{\prime} \\
47^{\circ} 32^{\prime} \\
47^{\circ} 32^{\prime} \\
47^{\circ} 32^{\prime} \\
47^{\circ} 32^{\prime} \\
47^{\circ} 32^{\prime} \\
47^{\circ} 32^{\prime} \\
47^{\circ} 32^{\prime} \\
47^{\circ} 32^{\prime} \\
47^{\circ} 32^{\prime} \\
47^{\circ} 32^{\prime} \\
47^{\circ} 32^{\prime} \\
47^{\circ} 32^{\prime} \\
47^{\circ} 32^{\prime} \\
47^{\circ} 32^{\prime} \\
47^{\circ} 32^{\prime}\end{array}$ & $\begin{array}{l}08^{\circ} 32^{\prime} 15^{\prime \prime} \\
08^{\circ} 39^{\prime} \\
08^{\circ} 25^{\prime}-45^{\prime} \\
09^{\circ} 06^{\prime} \\
09^{\circ} 05^{\prime} \\
09^{\circ} 05^{\prime} \\
09^{\circ} 06^{\prime} \\
09^{\circ} 06^{\prime} \\
09^{\circ} 06^{\prime} \\
09^{\circ} 04^{\prime} \\
09^{\circ} 06^{\prime} \\
09^{\circ} 06^{\prime} \\
09^{\circ} 06^{\prime} \\
09^{\circ} 05^{\prime} \\
09^{\circ} 05^{\prime} \\
09^{\circ} 05^{\prime} \\
09^{\circ} 05^{\prime} \\
09^{\circ} 06^{\prime} \\
09^{\circ} 06^{\prime} \\
09^{\circ} 05^{\prime} \\
09^{\circ} 06^{\prime}\end{array}$ & $\begin{array}{l}2170 \\
2115 \\
2175 \\
2825 \\
2798 \\
2798 \\
2810 \\
2798 \\
2820 \\
2740 \\
2885 \\
2825 \\
2807 \\
2738 \\
2770 \\
2730 \\
2848 \\
2805 \\
2847 \\
2805 \\
2828\end{array}$ \\
\hline $\begin{array}{l}\text { BIOGAS XI (1981) } \\
\text { PL } 18 \\
\text { PL } 22 \\
\text { CP } 35 \\
\text { CP } 36 \\
\text { CP } 37 \\
\text { CP } 38\end{array}$ & $\begin{array}{l}47^{\circ} 32.1^{\prime} \\
36^{\circ} 41^{\prime} \\
46^{\circ} 34^{\prime} \\
47^{\circ} 33^{\prime} \\
47^{\circ} 34^{\prime} \\
47^{\circ} 33.8^{\prime}\end{array}$ & $\begin{array}{l}08^{\circ} 27.8^{\prime} \\
11^{\circ} 35^{\prime} \\
10^{\circ} 23^{\prime} \\
09^{\circ} 39^{\prime} \\
08^{\circ} 40^{\prime} \\
08^{\circ} 42.2^{\prime}\end{array}$ & $\begin{array}{l}2000 \\
2300-2700 \\
4720 \\
4000 \\
2175 \\
2100\end{array}$ \\
\hline
\end{tabular}


Appendix 1. List of Stations

\begin{tabular}{|c|c|c|c|}
\hline $\begin{array}{l}\text { Research Program, } \\
\text { Station }\end{array}$ & Latitude, N & $\begin{array}{l}\text { Longitude, } \mathbf{W} \\
(\mathrm{E}-\text { when indicated })\end{array}$ & Depth, m \\
\hline KG 203 & $47^{\circ} 34.9^{\prime}$ & $09^{\circ} 39.8^{\prime}$ & 4210 \\
\hline KG 205 & $47^{\circ} 35^{\prime}$ & $09^{\circ} 36^{\prime}$ & 4140 \\
\hline KG 206 & $47^{\circ} 35^{\prime}$ & $09^{\circ} 36^{\prime}$ & 4130 \\
\hline KG 207 & $47^{\circ} 35^{\prime}$ & $09^{\circ} 36^{\prime}$ & 4135 \\
\hline KG 208 & $47^{\circ} 35^{\prime}$ & $09^{\circ} 36^{\prime}$ & 4130 \\
\hline KG 209 & $47^{\circ} 35^{\prime}$ & $09^{\circ} 36^{\prime}$ & 4190 \\
\hline KG 210 & $47^{\circ} 35^{\prime}$ & $09^{\circ} 36^{\prime}$ & 4190 \\
\hline KG 211 & $47^{\circ} 35^{\prime}$ & $09^{\circ} 36^{\prime}$ & 4170 \\
\hline KG 212 & $47^{\circ} 35^{\prime}$ & $09^{\circ} 36^{\prime}$ & 4130 \\
\hline KG 213 & $47^{\circ} 35^{\prime}$ & $09^{\circ} 36^{\prime}$ & 4150 \\
\hline KG 214 & $47^{\circ} 35^{\prime}$ & $09^{\circ} 36^{\prime}$ & 4125 \\
\hline KG 215 & $47^{\circ} 35^{\prime}$ & $09^{\circ} 36^{\prime}$ & 4110 \\
\hline KG 216 & $47^{\circ} 35^{\prime}$ & $09^{\circ} 36^{\prime}$ & 4200 \\
\hline KG 218 & $47^{\circ} 35^{\prime}$ & $09^{\circ} 36^{\prime}$ & 4171 \\
\hline KG 229 & $47^{\circ} 35^{\prime}$ & $09^{\circ} 36^{\prime}$ & 2160 \\
\hline \multicolumn{4}{|l|}{ BIOICE (2001-2004) } \\
\hline 2854 & $62.336^{\circ}$ & $16.99^{\circ}$ & 2074 \\
\hline 2855 & $62.34^{\circ}$ & $16.997^{\circ}$ & 2074 \\
\hline 2856 & $62.342^{\circ}$ & $16.988^{\circ}$ & 2074 \\
\hline 2859 & $61.837^{\circ}$ & $16.881^{\circ}$ & 2270 \\
\hline 2860 & $61.724^{\circ}$ & $16.958^{\circ}$ & 2295 \\
\hline 2861 & $61.737^{\circ}$ & $16.948^{\circ}$ & 2298 \\
\hline 2862 & $61.168^{\circ}$ & $18.008^{\circ}$ & 2399 \\
\hline 2863 & $61.17^{\circ}$ & $18.043^{\circ}$ & 2400 \\
\hline 2914 & $64.906^{\circ}$ & $29.979^{\circ}$ & 2005 \\
\hline 3012 & $61.37^{\circ}$ & $15.316^{\circ}$ & 2133 \\
\hline 3070 & $62.281^{\circ}$ & $15.336^{\circ}$ & 2069 \\
\hline 3072 & $61.894^{\circ}$ & $15.136^{\circ}$ & 2082 \\
\hline 3073 & $61.896^{\circ}$ & $15.139^{\circ}$ & 2083 \\
\hline 3074 & $61.905^{\circ}$ & $15.146^{\circ}$ & 2085 \\
\hline 3075 & $62.003^{\circ}$ & $16.000^{\circ}$ & 2192 \\
\hline 3076 & $61.998^{\circ}$ & 15.984 & 2191 \\
\hline 3077 & $62.275^{\circ}$ & $16.694^{\circ}$ & 2046 \\
\hline 3169 & $60.565^{\circ}$ & $22.088^{\circ}$ & 2349 \\
\hline 3170 & $60.566^{\circ}$ & $22.082^{\circ}$ & 2350 \\
\hline 3171 & $60.093^{\circ}$ & $20.862^{\circ}$ & 2708 \\
\hline 3172 & $60.09^{\circ}$ & $20.855^{\circ}$ & 2709 \\
\hline 3173 & $60.09^{\circ}$ & $20.854^{\circ}$ & 2709 \\
\hline 3176 & $60.034^{\circ}$ & $22.453^{\circ}$ & 2537 \\
\hline 3203 & $64.851^{\circ}$ & $07.861^{\circ}$ & 2612 \\
\hline 3204 & $64.862^{\circ}$ & $07.909^{\circ}$ & 2613 \\
\hline 3207 & $65.72^{\circ}$ & $07.005^{\circ}$ & 2006 \\
\hline 3208 & $65.732^{\circ}$ & $07.016^{\circ}$ & 2002 \\
\hline 3210 & $66.228^{\circ}$ & $06.863^{\circ}$ & 2544 \\
\hline 3211 & $66.202^{\circ}$ & $06.867^{\circ}$ & 2545 \\
\hline 3213 & $67.023^{\circ}$ & $06.194^{\circ}$ & 3006 \\
\hline 3214 & $67.03^{\circ}$ & $06.197^{\circ}$ & 3003 \\
\hline 3216 & $67.098^{\circ}$ & $07.452^{\circ}$ & 2014 \\
\hline 3230 & $68.702^{\circ}$ & $10.216^{\circ}$ & 2108 \\
\hline 3571 & $63.504^{\circ}$ & $29.64^{\circ}$ & 2233 \\
\hline 3572 & $63.502^{\circ}$ & $29.637^{\circ}$ & 2238 \\
\hline 3574 & $63.377^{\circ}$ & $29.92^{\circ}$ & 2355 \\
\hline 3637 & $68.449^{\circ}$ & $10.146^{\circ}$ & 2069 \\
\hline 3638 & $68.444^{\circ}$ & $10.176^{\circ}$ & 2065 \\
\hline 3648 & $68.952^{\circ}$ & $10.547^{\circ}$ & 2215 \\
\hline 3649 & $68.941^{\circ}$ & $10.594^{\circ}$ & 2214 \\
\hline \multicolumn{4}{|l|}{ BIOMEDE I (1976) } \\
\hline 2 & $42^{\circ} 40^{\prime}$ & $06^{\circ} 00^{\prime} \mathrm{E}$ & $2770-2420$ \\
\hline 3 & $42^{\circ} 17^{\prime}$ & $06^{\circ} 00^{\prime} \mathrm{E}$ & $2420-2500$ \\
\hline 4 & $42^{\circ} 00^{\prime}$ & $06^{\circ} 00^{\prime} \mathrm{E}$ & $2460-2500$ \\
\hline 5 & $41^{\circ} 47^{\prime}$ & $06^{\circ} 00^{\prime} \mathrm{E}$ & $2500-2520$ \\
\hline
\end{tabular}




\begin{tabular}{|c|c|c|c|}
\hline $\begin{array}{l}\text { Research Program, } \\
\text { Station }\end{array}$ & Latitude, $\mathbf{N}$ & $\begin{array}{l}\text { Longitude, } \mathbf{W} \\
(\mathrm{E}-\text { when indicated })\end{array}$ & Depth, m \\
\hline $\begin{array}{l}6 \\
7 \\
12 \\
13 \\
14\end{array}$ & $\begin{array}{l}41^{\circ} 47^{\prime} \\
41^{\circ} 47^{\prime} \\
42^{\circ} 15^{\prime} \\
42^{\circ} 25^{\prime} \\
42^{\circ} 40^{\prime}\end{array}$ & $\begin{array}{l}06^{\circ} 34^{\prime} \mathrm{E} \\
07^{\circ} 03^{\prime} \mathrm{E} \\
07^{\circ} 38^{\prime} \mathrm{E} \\
07^{\circ} 04^{\prime} \mathrm{E} \\
06^{\circ} 45^{\prime} \mathrm{E}\end{array}$ & $\begin{array}{l}2500-2600 \\
2660-2680 \\
2700 \\
2640-2660 \\
2520-2560\end{array}$ \\
\hline $\begin{array}{l}\text { BIOMEDE II (1981) } \\
6 \\
11 \\
17 \\
201 \mathrm{C} \\
202 \mathrm{C} \\
204 \mathrm{E} \\
210 \mathrm{C} \\
211 \mathrm{C} \\
211 \mathrm{E} \\
215 \mathrm{C} \\
217 \mathrm{C} \\
217 \mathrm{E}\end{array}$ & $\begin{array}{l}39^{\circ} 40^{\prime} \\
40^{\circ} 20^{\prime} \\
41^{\circ} 00^{\prime} \\
41^{\circ} 00^{\prime} \\
40^{\circ} 58^{\prime} \\
40^{\circ} 19^{\prime} \\
40^{\circ} 00^{\prime} \\
40^{\circ} 19^{\prime} \\
40^{\circ} 20^{\prime} \\
39^{\circ} 40^{\prime} \\
41^{\circ} 02^{\prime} \\
41^{\circ} 03^{\prime}\end{array}$ & $\begin{array}{l}04^{\circ} 56^{\prime} \mathrm{E} \\
06^{\circ} 43^{\prime} \\
07^{\circ} 25^{\prime} \\
05^{\circ} 00^{\prime} \mathrm{E} \\
05^{\circ} 49^{\prime} \mathrm{E} \\
05^{\circ} 47^{\prime} \mathrm{E} \\
06^{\circ} 38^{\prime} \mathrm{E} \\
06^{\circ} 44^{\prime} \mathrm{E} \\
06^{\circ} 44^{\prime} \mathrm{E} \\
07^{\circ} 26^{\prime} \mathrm{E} \\
07^{\circ} 25^{\prime} \mathrm{E} \\
07^{\circ} 26^{\prime} \mathrm{E}\end{array}$ & $\begin{array}{l}2610 \\
2775-2795 \\
2775 \\
2570 \\
2550 \\
2677 \\
2730 \\
2792 \\
2775 \\
2690 \\
2775 \\
2730\end{array}$ \\
\hline $\begin{array}{l}\text { BIOVEMA } \\
\text { CP } 01 \\
\text { CP } 02 \\
\text { CP } 03 \\
\text { CP } 04 \\
\text { CP } 05 \\
\text { CP } 06 \\
\text { DS } 03 \\
\text { DS } 05 \\
\text { DS } 09 \\
\text { DS } 11\end{array}$ & $\begin{array}{l}10^{\circ} 58^{\prime} 03 \\
10^{\circ} 59^{\prime} \\
10^{\circ} 47^{\prime} 13^{\prime \prime} \\
10^{\circ} 45^{\prime} 97 \\
10^{\circ} 46^{\prime} 23 \\
11^{\circ} 34^{\prime} 2^{\prime \prime} \\
10^{\circ} 47^{\prime} 10^{\prime \prime} \\
10^{\circ} 45^{\prime} 97 \\
11^{\circ} 36^{\prime} 04^{\prime \prime} \\
11^{\circ} 37^{\prime} 05^{\prime \prime}\end{array}$ & $\begin{array}{l}45^{\circ} 14^{\prime} 03 \\
45^{\circ} 15^{\prime} \\
42^{\circ} 41^{\prime} 01^{\prime \prime} \\
42^{\circ} 40^{\prime} 04 \\
42^{\circ} 40^{\prime} 41 \\
32^{\circ} 53^{\prime} 5^{\prime \prime} \\
42^{\circ} 41^{\prime} 01^{\prime \prime} \\
42^{\circ} 40^{\prime} 29 \\
32^{\circ} 51^{\prime} 08^{\prime \prime} \\
32^{\circ} 53^{\prime} 08^{\prime \prime}\end{array}$ & $\begin{array}{l}5100 \\
5073 \\
5127 \\
5100 \\
5100 \\
5880 \\
5150 \\
5100 \\
5875 \\
5867\end{array}$ \\
\hline $\begin{array}{l}\text { BYOCYAN II } \\
\text { PL } 18\end{array}$ & $47^{\circ} 32.05^{\prime}$ & $8^{\circ} 27.55^{\prime}$ & 2000 \\
\hline $\begin{array}{l}\text { CANCAP III (1987) } \\
3-020\end{array}$ & $32^{\circ} 53^{\prime}$ & $16^{\circ} 21^{\prime}$ & 2830-3120 \\
\hline $\begin{array}{l}\text { CANCAP V } \\
5004 \\
5016 \\
5042 \\
5043\end{array}$ & $\begin{array}{l}38^{\circ} 06^{\prime} \\
37^{\circ} 21^{\prime} \\
36^{\circ} 50^{\prime} \\
36^{\circ} 46^{\prime}\end{array}$ & $\begin{array}{l}24^{\circ} 49^{\prime} \\
25^{\circ} 29^{\prime} \\
24^{\circ} 42^{\prime} \\
24^{\circ} 44^{\prime}\end{array}$ & $\begin{array}{l}2400-3100 \\
2000-2100 \\
2775 \\
2800-2950\end{array}$ \\
\hline $\begin{array}{l}\text { CYMOR } \\
\text { DR } 13 \\
\text { DR } 15\end{array}$ & $\begin{array}{l}47^{\circ} 44^{\prime} \\
47^{\circ} 44^{\prime}\end{array}$ & $\begin{array}{l}08^{\circ} 35^{\prime} 14^{\prime \prime} \\
08^{\circ} 21^{\prime}\end{array}$ & $\begin{array}{l}3150 \\
2420\end{array}$ \\
\hline $\begin{array}{l}\text { CYMOR II (1981) } \\
\text { DR } 2 \\
\text { Dr } 24\end{array}$ & $\begin{array}{l}47^{\circ} 47^{\prime} \\
47^{\circ} 41.38^{\prime}\end{array}$ & $\begin{array}{l}08^{\circ} 49^{\prime} \\
08^{\circ} 31.30^{\prime}\end{array}$ & $\begin{array}{l}2600 \\
2600\end{array}$ \\
\hline $\begin{array}{l}\text { ECOFER } 1 \\
\text { CP } 01 \\
\text { CP } 02\end{array}$ & $\begin{array}{l}44^{\circ} 46.20^{\prime} \\
4^{\circ} 46.14^{\prime}\end{array}$ & $\begin{array}{l}02^{\circ} 38.15^{\prime} \\
02^{\circ} 38.92^{\prime}\end{array}$ & $\begin{array}{l}3017 \\
3033\end{array}$ \\
\hline $\begin{array}{l}\text { GAY HEAD - BERML } \\
15 \\
20\end{array}$ & $\begin{array}{l}\text { JDA Transec } \\
35.62^{\circ} \\
31.88^{\circ}\end{array}$ & $\begin{array}{l}30.85^{\circ} \\
26.00^{\circ}\end{array}$ & $\begin{array}{l}3200 \\
2560\end{array}$ \\
\hline $\begin{array}{l}\text { GEOMANCHE } \\
\text { DR } 20\end{array}$ & $48^{\circ} 26.6^{\prime}$ & $11^{\circ} 19,9^{\prime}$ & 2344 \\
\hline $\begin{array}{l}\text { GESTLANTE } 2 \text { (1967 } \\
117 \text { D13 }\end{array}$ & $45^{\circ} 46^{\prime}$ & $04^{\circ} 06^{\prime}$ & 2480 \\
\hline $\begin{array}{l}\text { ICE ISLAND (1963-1 } \\
\text { Core } 71\end{array}$ & $\begin{array}{l}\text { 974) } \\
75^{\circ} 43.56^{\prime}\end{array}$ & $140^{\circ} 36.79^{\prime}$ & 3709 \\
\hline
\end{tabular}


Research Program, Latitude, N
Station Longitude, $\mathbf{W} \quad$ Depth, $\mathrm{m}$

\begin{tabular}{llll}
\hline Core 184 & $79^{\circ} 31.77^{\prime}$ & $174^{\circ} 07.64^{\prime}$ & 3709 \\
Core 190 & $79^{\circ} 35.24^{\prime}$ & $172^{\circ} 29.63^{\prime}$ & 2810 \\
Core 198 & $80^{\circ} 22.19^{\prime}$ & $172^{\circ} 33.92^{\prime}$ & 3198 \\
Core 201 & $79^{\circ} 54.73^{\prime}$ & $171^{\circ} 26.68^{\prime}$ & 2962 \\
Core 206 & $79^{\circ} 41.24^{\prime}$ & $170^{\circ} 13.45^{\prime}$ & 3242 \\
Core 214 & $80^{\circ} 17.43^{\prime}$ & $159^{\circ} 30.94^{\prime}$ & 3021 \\
Core 284 & $83^{\circ} 47.34^{\prime}$ & $145^{\circ} 50.92^{\prime}$ & 2681 \\
Core 290 & $84^{\circ} 23.40^{\prime}$ & $143^{\circ} 51.19^{\prime}$ & 2262 \\
Core 294 & $84^{\circ} 56.62^{\prime}$ & $145^{\circ} 34.04^{\prime}$ & 2234 \\
Core 304 & $85^{\circ} 28.29^{\prime}$ & $143^{\circ} 08.52^{\prime}$ & 2277 \\
Core 306 & $85^{\circ} 24.93^{\prime}$ & $145^{\circ} 12.85^{\prime}$ & 2263 \\
Core 310 & $85^{\circ} 43.80^{\prime}$ & $142^{\circ} 39.12^{\prime}$ & 2016 \\
Core 319 & $84^{\circ} 52.04^{\prime}$ & $136^{\circ} 02.41^{\prime}$ & 2674 \\
Core 323 & $84^{\circ} 17.80^{\prime}$ & $135^{\circ} 06.17^{\prime}$ & 2732 \\
Core 365 & $84^{\circ} 28.48^{\prime}$ & $131^{\circ} 22.31^{\prime}$ & 2215 \\
Core 429 & $86^{\circ} 03.08^{\prime}$ & $133^{\circ} 55.29^{\prime}$ &
\end{tabular}

INCAL (1976)

The INCAL Cruise worked in the same area as BIOGAS but sampled at Stations 1-4 (see BIOGAS) only.

\begin{tabular}{|c|c|c|c|}
\hline $1-3$ & $57^{\circ} 58^{\prime}$ & $10^{\circ} 45^{\prime}$ & 2068-2093 \\
\hline $1-5$ & $56^{\circ} 30^{\prime}$ & $11^{\circ} 10^{\prime}$ & 2483-2505 \\
\hline $1-8$ & $55^{\circ} 02^{\prime}$ & $12^{\circ} 40^{\prime}$ & 2884-2897 \\
\hline $2-1$ & $50^{\circ} 14^{\prime}$ & $13^{\circ} 10^{\prime}$ & 2500-2719 \\
\hline $2-2$ & $48^{\circ} 20^{\prime}$ & $15^{\circ} 15^{\prime}$ & $4823-4829$ \\
\hline $2-3$ & $47^{\circ} 30^{\prime}$ & $09^{\circ} 35^{\prime}$ & $4217-4364$ \\
\hline $2-4$ & $46^{\circ} 00^{\prime}$ & $10^{\circ} 20^{\prime}$ & 4793-4826 \\
\hline CP 01 & $56^{\circ} 37^{\prime}$ & $10^{\circ} 45^{\prime}$ & 2049 \\
\hline CP 01 & $57^{\circ} 58^{\prime}$ & $10^{\circ} 55^{\prime}$ & 2040-2068 \\
\hline DS 01 & $57^{\circ} 59^{\prime} 7$ & $10^{\circ} 39^{\prime} 8$ & 2091 \\
\hline KR 01 & $57^{\circ} 59^{\prime}$ & $10^{\circ} 41^{\prime}$ & 2093 \\
\hline OS 01 & $50^{\circ} 19^{\prime} 4$ & $13^{\circ} 10^{\prime} 9$ & 2634 \\
\hline PE 01 & $48^{\circ} 25^{\prime} 9$ & $15^{\circ} 15^{\prime} 5$ & 4823 \\
\hline WS 01 & $50^{\circ} 19^{\prime}$ & $13^{\circ} 07^{\prime}$ & $2544-2550$ \\
\hline WS 01 & $50^{\circ} 19^{\prime} 4$ & $13^{\circ} 08^{\prime} 1$ & $2502-2606$ \\
\hline CP 02 & $57^{\circ} 58^{\prime}$ & $10^{\circ} 45^{\prime}$ & 2091 \\
\hline DS 02 & $57^{\circ} 59^{\prime}$ & $10^{\circ} 49^{\prime}$ & 2081 \\
\hline OS 02 & $48^{\circ} 19^{\prime}$ & $15^{\circ} 16^{\prime}$ & 4829 \\
\hline PE 02 & $46^{\circ} 02^{\prime}$ & $10^{\circ} 19^{\prime}$ & 4796 \\
\hline WS 02 & $50^{\circ} 20^{\prime}$ & $12^{\circ} 56^{\prime}$ & 2498-2502 \\
\hline CP 03 & $57^{\circ} 58^{\prime}$ & $11^{\circ} 08^{\prime}$ & 2466 \\
\hline CP 03 & $56^{\circ} 38^{\prime}$ & $11^{\circ} 06^{\prime}$ & 2466 \\
\hline OS 03 & $46^{\circ} 03^{\prime}$ & $10^{\circ} 19^{\prime}$ & 4798 \\
\hline WS 03 & $48^{\circ} 19^{\prime}$ & $15^{\circ} 23^{\prime}$ & 4829 \\
\hline CP 04 & $56^{\circ} 33^{\prime}$ & $11^{\circ} 12^{\prime}$ & $2498-2500$ \\
\hline OS 04 & $46^{\circ} 03^{\prime}$ & $10^{\circ} 11^{\prime}$ & $4796-4822$ \\
\hline WS 04 & $48^{\circ} 18^{\prime}$ & $15^{\circ} 13^{\prime}$ & 4829 \\
\hline CP 05 & $55^{\circ} 00^{\prime}$ & $12^{\circ} 31^{\prime}$ & 2884 \\
\hline DS 05 & $56^{\circ} 28^{\prime}$ & $11^{\circ} 12^{\prime}$ & 2503 \\
\hline OS 05 & $47^{\circ} 31^{\prime}$ & $09^{\circ} 34^{\prime}$ & 4296 \\
\hline WS 05 & $46^{\circ} 03^{\prime}$ & $10^{\circ} 14^{\prime}$ & 4800 \\
\hline CP 06 & $55^{\circ} 02^{\prime} 3$ & $12^{\circ} 40^{\prime} 3$ & 2888 \\
\hline DS 06 & $56^{\circ} 26^{\prime}$ & $11^{\circ} 11^{\prime}$ & 2494 \\
\hline KR 06 & $55^{\circ} 02^{\prime}$ & $12^{\circ} 43^{\prime}$ & 2891 \\
\hline OS 06 & $46^{\circ} 27^{\prime}$ & $09^{\circ} 36^{\prime}$ & 4316 \\
\hline CP 07 & $55^{\circ} 03^{\prime}$ & $12^{\circ} 46^{\prime}$ & 2895 \\
\hline DS 07 & $55^{\circ} 01^{\prime}$ & $12^{\circ} 32^{\prime}$ & 2884 \\
\hline KR 07 & $55^{\circ} 02^{\prime}$ & $12^{\circ} 43^{\prime}$ & 2891 \\
\hline OS 07 & $47^{\circ} 31^{\prime}$ & $09^{\circ} 34^{\prime}$ & 4250 \\
\hline WS 07 & $47^{\circ} 28^{\prime}$ & $09^{\circ} 34^{\prime}$ & $4277-4281$ \\
\hline CP 08 & $50^{\circ} 15^{\prime}$ & $13^{\circ} 15^{\prime}$ & 2644 \\
\hline DS 08 & $55^{\circ} 02^{\prime}$ & $12^{\circ} 33^{\prime}$ & 2888 \\
\hline OS 08 & $47^{\circ} 32^{\prime}$ & $09^{\circ} 39^{\prime}$ & 4327 \\
\hline
\end{tabular}




\begin{tabular}{|c|c|c|c|}
\hline $\begin{array}{l}\text { Research Program, } \\
\text { Station }\end{array}$ & Latitude, N & $\begin{array}{l}\text { Longitude, } \mathbf{W} \\
\text { (E - when indicated) }\end{array}$ & Depth, m \\
\hline WS 08 & $47^{\circ} 29^{\prime}$ & $09^{\circ} 34^{\prime}$ & $4287-4294$ \\
\hline WS 08 & $47^{\circ} 31^{\prime}$ & $09^{\circ} 34^{\prime}$ & 4300 \\
\hline ICP 09 & $50^{\circ} 14^{\prime}$ & $13^{\circ} 16^{\prime}$ & 2675 \\
\hline DS 09 & $55^{\circ} 08^{\prime}$ & $12^{\circ} 53^{\prime}$ & 2897 \\
\hline WS 09 & $47^{\circ} 28^{\prime}$ & $09^{\circ} 34^{\prime}$ & $4277-4294$ \\
\hline CP 10 & $48^{\circ} 26^{\prime}$ & $15^{\circ} 10^{\prime}$ & 4823 \\
\hline DS 10 & $50^{\circ} 13^{\prime}$ & $13^{\circ} 16^{\prime}$ & 2719 \\
\hline WS 10 & $47^{\circ} 31^{\prime}$ & $09^{\circ} 40^{\prime}$ & 4354 \\
\hline CP 11 & $48^{\circ} 20^{\prime}$ & $15^{\circ} 14^{\prime}$ & 4823 \\
\hline DS 11 & $48^{\circ} 19^{\prime}$ & $15^{\circ} 12^{\prime}$ & 4823 \\
\hline KR 11 & $48^{\circ} 20^{\prime}$ & $15^{\circ} 17^{\prime}$ & 4829 \\
\hline CP 12 & $46^{\circ} 01^{\prime}$ & $10^{\circ} 17^{\prime}$ & 4796 \\
\hline DS 12 & $46^{\circ} 02^{\prime}$ & $10^{\circ} 11^{\prime}$ & 4796 \\
\hline $\mathrm{CP} 13$ & $46^{\circ} 03^{\prime}$ & $10^{\circ} 14^{\prime}$ & 4800 \\
\hline DS 13 & $46^{\circ} 02^{\prime}$ & $10^{\circ} 17^{\prime}$ & 4822 \\
\hline DS 14 & $47^{\circ} 33^{\prime}$ & $09^{\circ} 35^{\prime}$ & 4251 \\
\hline KR 14 & $47^{\circ} 29.08^{\prime}$ & $09^{\circ} 37.04^{\prime}$ & 4299 \\
\hline DS 15 & $47^{\circ} 34^{\prime}$ & $09^{\circ} 39^{\prime}$ & 4211 \\
\hline CP 15 & $47^{\circ} 26^{\prime}$ & $09^{\circ} 35$ & 4182 \\
\hline CP 16 & $47^{\circ} 30^{\prime}$ & $09^{\circ} 37^{\prime}$ & $4240-4262$ \\
\hline DS 16 & $47^{\circ} 30^{\prime}$ & $09^{\circ} 33^{\prime}$ & 4268 \\
\hline KR 17 & $47^{\circ} 31^{\prime}$ & $09^{\circ} 32^{\prime}$ & 4268 \\
\hline \multicolumn{4}{|l|}{ MAC 81 (1981) } \\
\hline Box No14 & $47^{\circ} 33.4^{\prime}$ & $08^{\circ} 33.7^{\prime}$ & 2120 \\
\hline
\end{tabular}

\section{MAR-ECO}

See under RV G.O.Sars

\begin{tabular}{ll} 
MEDINAUT (1998) & \\
MN8 & $35^{\circ} 20^{\prime}$ \\
MN13 & $35^{\circ} 20^{\prime}$ \\
NORATALANTE (1969) \\
B 1 & $55^{\circ} 08^{\prime}$ \\
E 1 & $53^{\circ} 55^{\prime}$ \\
C 4 & $35^{\circ} 41^{\prime}$ \\
B 5 & $55^{\circ} 42^{\prime}$ \\
6 & $55^{\circ} 07^{\prime}$ \\
E 8 & $36^{\circ} 49^{\prime}$ \\
B 10 & $36^{\circ} 58^{\prime}$ \\
B 11 & $38^{\circ} 20^{\prime}$ \\
B 12 & $36^{\circ} 22^{\prime}$ \\
E 12 & $36^{\circ} 25^{\prime}$ \\
E13 & $45^{\circ} 08^{\prime}$ \\
B 13 & $35^{\circ} 59^{\prime}$ \\
B 14 & $37^{\circ} 21^{\prime} 01^{\prime}-37^{\circ} 19.05^{\prime}$ \\
E 14 & $46^{\circ} 42.02^{\prime}-46^{\circ} 43.05^{\prime}$ \\
B 16 & $45^{\circ} 35^{\prime}$ \\
B 17 & $45^{\circ} 13^{\prime}$ \\
B 18 & $46^{\circ} 40^{\prime}$ \\
B 19 & $47^{\circ} 29^{\prime}$ \\
P11-B2 & $54^{\circ} 12^{\prime} 09$ \\
P12-E2 & $54^{\circ} 21^{\prime} 06$ \\
42 & $58^{\circ} 47^{\prime} 7$ \\
P62-C3 & $36^{\circ} 47^{\prime} 04$ \\
63 & $36^{\circ} 48^{\prime} 5$ \\
P65-B10 & $36^{\circ} 58^{\prime} 02$ \\
P67-B11 & $38^{\circ} 20^{\prime} 00$ \\
124 & $47^{\circ} 29.6^{\prime}$ \\
132 D12 & $47^{\circ} 41^{\prime} 07^{\prime \prime}$ \\
13 & \\
\hline
\end{tabular}

$30^{\circ} 16.5^{\prime} \mathrm{E}$
$30^{\circ} 16^{\prime} \mathrm{E}$
$15^{\circ} 11^{\prime}$
$17^{\circ} 53^{\prime}$
$10^{\circ} 04^{\prime}$
$49^{\circ} 20^{\prime}$
$15^{\circ} 11^{\prime} 2$
$27^{\circ} 06^{\prime}$
$26^{\circ} 20^{\prime}$
$25^{\circ} 22^{\prime}$
$08^{\circ} 43^{\prime}$
$08^{\circ} 49^{\prime}$
$05^{\circ} 31^{\prime}$
$09^{\circ} 33^{\prime}$
$10^{\circ} 46.06^{\prime}-10^{\circ} 45.09^{\prime}$
$09^{\circ} 57.02^{\prime}-09^{\circ} 54.05^{\prime}$
$03^{\circ} 51^{\prime}$
$05^{\circ} 31^{\prime}$
$10^{\circ} 08^{\prime}$
$08^{\circ} 24^{\prime}$
$27^{\circ} 51^{\prime} 05$
$27^{\circ} 00^{\prime} 02$
$52^{\circ} 56^{\prime} 5$
$27^{\circ} 11^{\prime} 07$
$27^{\circ} 06^{\prime} 0$
$26^{\circ} 20^{\prime} 00$
$25^{\circ} 21^{\prime} 00$
$08^{\circ} 22.6^{\prime}$
$08^{\circ} 30^{\prime} 06^{\prime \prime}$

2030

2030

2215-2233

2420

4500

3676

2215

3663

2771-2917

2750-2850

2875

2573-2820

4760

4206-4250

5110-5970

4660-4795

3950-4150

4700

4690

2047-2149

3085

3175

3610

3670

3663

2871

2844

2149-2210

3100

NORBI (1975)

1

$64^{\circ} 26^{\prime}-64^{\circ} 19^{\prime}$

$01^{\circ} 36^{\prime}-01^{\circ} 44^{\prime} \mathrm{E}$

2500-2700 


\begin{tabular}{|c|c|c|c|}
\hline $\begin{array}{l}\text { Research Program, } \\
\text { Station }\end{array}$ & Latitude, N & $\begin{array}{l}\text { Longitude, } \mathbf{W} \\
(\mathrm{E}-\text { when indicated })\end{array}$ & Depth, m \\
\hline 2 & $65^{\circ} 12^{\prime}-65^{\circ} 29^{\prime}$ & $00^{\circ} 01^{\prime}-00^{\circ} 05^{\prime}$ & $2900-3000$ \\
\hline 3 & $66^{\circ} 45^{\prime}-66^{\circ} 47^{\prime}$ & $01^{\circ} 21^{\prime}-02^{\circ} 01^{\prime}$ & $3350-3670$ \\
\hline 4 & $69^{\circ} 05^{\prime}-69^{\circ} 18^{\prime}$ & $04^{\circ} 11^{\prime}-04^{\circ} 41^{\prime} \mathrm{E}$ & $3210-3213$ \\
\hline 5 & $69^{\circ} 20^{\prime}-69^{\circ} 43^{\prime}$ & $10^{\circ} 11^{\prime}-10^{\circ} 43^{\prime} \mathrm{E}$ & $2930-2960$ \\
\hline 6 & $76^{\circ} 54^{\prime}-77^{\circ} 00^{\prime}$ & $00^{\circ} 57^{\prime}-00^{\circ} 02^{\prime} \mathrm{E}$ & $3193-3200$ \\
\hline 7 & $76^{\circ} 01^{\prime}-76^{\circ} 02^{\prime}$ & $01^{\circ} 49^{\prime}-01^{\circ} 41^{\prime}$ & 3709 \\
\hline 8 & $74^{\circ} 42^{\prime}-74^{\circ} 43^{\prime}$ & $03^{\circ} 03^{\prime}-03^{\circ} 30^{\prime}$ & $3595-3617$ \\
\hline 9 & $73^{\circ} 32^{\prime}-73^{\circ} 35^{\prime}$ & $07^{\circ} 39^{\prime}-07^{\circ} 26^{\prime}$ & $3210-3266$ \\
\hline 10 & $73^{\circ} 28^{\prime}-73^{\circ} 27^{\prime}$ & $10^{\circ} 06^{\prime}-09^{\circ} 50^{\prime}$ & 2937-2941 \\
\hline 11 & $73^{\circ} 36^{\prime}-73^{\circ} 30^{\prime}$ & $13^{\circ} 39^{\prime}-13^{\circ} 35^{\prime}$ & $2470-2500$ \\
\hline $1(\mathrm{CP} 01)$ & $64^{\circ} 24.3^{\prime}-64^{\circ} 23.5^{\prime}$ & $01^{\circ} 43.9^{\prime}-01^{\circ} 44.7^{\prime} \mathrm{E}$ & 2615-2577 \\
\hline $1(\mathrm{CP} 02)$ & $64^{\circ} 26^{\prime}$ & $01^{\circ} 36^{\prime} \mathrm{E}$ & 2714 \\
\hline 1(DS 02) & $64^{\circ} 24.6^{\prime}-64^{\circ} 23.8^{\prime}$ & $01^{\circ} 36.3^{\prime}-01^{\circ} 36.4^{\prime} \mathrm{E}$ & $2653-2653$ \\
\hline $\mathrm{CP} 03$ & $65^{\circ} 16^{\prime}$ & $00^{\circ} 02^{\prime}$ & 2904 \\
\hline DS 03 & $64^{\circ} 19.09^{\prime}$ & $01^{\circ} 39.08^{\prime} \mathrm{E}$ & 2538 \\
\hline $2(\mathrm{CP} 02)$ & $65^{\circ} 13.5^{\prime}$ & $00^{\circ} 05.6^{\prime}$ & 2913 \\
\hline $2(\mathrm{CP} 03)$ & $65^{\circ} 13.5^{\prime}$ & $00^{\circ} 05.6^{\prime}$ & 2913 \\
\hline $2(\mathrm{CP} 04)$ & $65^{\circ} 13.06^{\prime}-65^{\circ} 12.05^{\prime}$ & $00^{\circ} 05.06^{\prime}-00^{\circ} 03.08^{\prime}$ & 2913-2866 \\
\hline 2 (DS 04) & $65^{\circ} 29.00^{\prime}-65^{\circ} 28.05^{\prime}$ & $00^{\circ} 02.05^{\prime}-00^{\circ} 02.05^{\prime} \mathrm{E}$ & $3016-3016$ \\
\hline DS 05 & $65^{\circ} 29.00^{\prime}-65^{\circ} 28.05^{\prime}$ & $00^{\circ} 02.05^{\prime}-00^{\circ} 02.03^{\prime} \mathrm{E}$ & $3016-3016$ \\
\hline $3(\mathrm{CP} 05)$ & $66^{\circ} 45.09^{\prime}-66^{\circ} 46.01^{\prime}$ & $02^{\circ} 01.09^{\prime}-01^{\circ} 58.04^{\prime}$ & 3369-3369 \\
\hline $3(\mathrm{CP} 06)$ & $66^{\circ} 46.02^{\prime}-66^{\circ} 46.05^{\prime}$ & $01^{\circ} 44.09^{\prime}-01^{\circ} 42.2^{\prime}$ & $3522-3645$ \\
\hline 3(DS 06) & $66^{\circ} 46.07^{\prime}-66^{\circ} 46.05^{\prime}$ & $01^{\circ} 33.01^{\prime}-01^{\circ} 31.2^{\prime}$ & $3672-3658$ \\
\hline $\mathrm{CP} 07$ & $69^{\circ} 05^{\prime}$ & $04^{\circ} 42^{\prime \prime} \mathrm{E}$ & 3213 \\
\hline 3(DS 07) & $66^{\circ} 45.03^{\prime}-66^{\circ} 45.04^{\prime}$ & $01^{\circ} 26.06^{\prime}-01^{\circ} 25.06^{\prime}$ & $3612-3612$ \\
\hline $\mathrm{CP} 08$ & $69^{\circ} 07^{\prime}$ & $04^{\circ} 40^{\prime \prime} \mathrm{E}$ & 3213 \\
\hline DS 08 & $69^{\circ} 14^{\prime}$ & $04^{\circ} 18^{\prime \prime} \mathrm{E}$ & 3213 \\
\hline 4(DS 09) & $69^{\circ} 09.08^{\prime}-69^{\circ} 09.04^{\prime}$ & $04^{\circ} 32.02^{\prime}-04^{\circ} 33.00^{\prime} \mathrm{E}$ & 3211 \\
\hline $5(\mathrm{CP} 09)$ & $69^{\circ} 42.6^{\prime}-69^{\circ} 41.9^{\prime}$ & $10^{\circ} 43.0^{\prime}-10^{\circ} 39.9^{\prime} \mathrm{E}$ & 2930 \\
\hline $5(\mathrm{CP} 10)$ & $69^{\circ} 21.09^{\prime}-69^{\circ} 20.06^{\prime}$ & $10^{\circ} 25.02^{\prime}-10^{\circ} 28.00^{\prime} \mathrm{E}$ & 2966 \\
\hline DS 10 & $69^{\circ} 38.04^{\prime}$ & $10^{\circ} 28.06^{\prime}$ & 2939 \\
\hline KR10 & $69^{\circ} 28^{\prime}$ & $10^{\circ} 12.05^{\prime} \mathrm{E}$ & 2957 \\
\hline CP 11 & $69^{\circ} 30^{\prime}$ & $10^{\circ} 30^{\prime} \mathrm{E}$ & 2945 \\
\hline $5(\mathrm{DS} 11)$ & $69^{\circ} 33^{\prime}$ & $10^{\circ} 22^{\prime} \mathrm{E}$ & 2957 \\
\hline $6(\mathrm{CP} 12)$ & $77^{\circ} 00.07^{\prime}-77^{\circ} 00.01^{\prime}$ & $00^{\circ} 57.06^{\prime}-01^{\circ} 04.00^{\prime} \mathrm{E}$ & 3193-3195 \\
\hline DS 12 & $76^{\circ} 54.04^{\prime}$ & $01^{\circ} 44.06^{\prime} \mathrm{E}$ & 3200 \\
\hline $7(\mathrm{CP} 13)$ & $76^{\circ} 01.04^{\prime}-76^{\circ} 02.05^{\prime}$ & $01^{\circ} 49.04^{\prime}-01^{\circ} 41.01^{\prime}$ & 3709-3709 \\
\hline DS 13 & $76^{\circ} 54^{\prime}$ & $01^{\circ} 49^{\prime \prime} \mathrm{E}$ & 3193 \\
\hline $7(\mathrm{DS} 14)$ & $76^{\circ} 02.07^{\prime}-76^{\circ} 02.05^{\prime}$ & $01^{\circ} 47.00^{\prime}-01^{\circ} 43.02^{\prime}$ & 3709-3709 \\
\hline $8(C P 14)$ & $74^{\circ} 42.00^{\prime}-74^{\circ} 42.08^{\prime}$ & $03^{\circ} 03.06^{\prime}-03^{\circ} 09.06^{\prime}$ & $3617-3524$ \\
\hline 8(DS 15) & $74^{\circ} 42.09^{\prime}-74^{\circ} 43.01^{\prime}$ & $03^{\circ} 27.06^{\prime}-03^{\circ} 30.06^{\prime}$ & 3595-3595 \\
\hline $9(\mathrm{CP} 15)$ & $73^{\circ} 33.00^{\prime}-73^{\circ} 32.08^{\prime}$ & $07^{\circ} 37.09^{\prime}-07^{\circ} 39.02^{\prime}$ & $3210-3210$ \\
\hline 9(DS 16) & $73^{\circ} 35.03^{\prime}-73^{\circ} 34.09^{\prime}$ & $07^{\circ} 26.00^{\prime}-07^{\circ} 27.07^{\prime}$ & $3266-3257$ \\
\hline $9(\mathrm{KR} 19)$ & $73^{\circ} 37^{\prime} 02^{\prime \prime}$ & $07^{\circ} 26^{\prime} 03^{\prime \prime}$ & 3294 \\
\hline $10(\mathrm{CP} 16)$ & $73^{\circ} 28.02^{\prime}-73^{\circ} 28.03^{\prime}$ & $10^{\circ} 06.06^{\prime}-10^{\circ} 02.06^{\prime}$ & 2937-2937 \\
\hline 10(DS 17) & $73^{\circ} 27.09^{\prime}-73^{\circ} 28.01^{\prime}$ & $09^{\circ} 50.05^{\prime}-09^{\circ} 53.04^{\prime}$ & 2941-2941 \\
\hline $11(\mathrm{CP} 17)$ & $73^{\circ} 30.07^{\prime}-73^{\circ} 32.03^{\prime}$ & $13^{\circ} 39.06^{\prime}-13^{\circ} 39.06^{\prime}$ & $2502-2475$ \\
\hline 11(DS 18) & $73^{\circ} 36.03^{\prime}-73^{\circ} 35.09^{\prime}$ & $13^{\circ} 35.01^{\prime}-13^{\circ} 35.08^{\prime}$ & $2470-2470$ \\
\hline DS 20 & $73^{\circ} 28.1^{\prime}$ & $09^{\circ} 48^{\prime}$ & 2904 \\
\hline KR 20 & $73^{\circ} 28.1^{\prime}$ & $09^{\circ} 48^{\prime}$ & 2904 \\
\hline
\end{tabular}

Norwegian North-Atlantic Expediton (Norskenordhavs Expediton ) (1876-1878) See under RV Vöringen

$\begin{array}{llll}\text { POLYGAS (1971) } & & & \\ \text { DS 04 } & 37.27^{\circ} & 06.30^{\circ} \mathrm{E} & 2632 \\ \text { DS 09 } & 38.45^{\circ} & 04.13^{\circ} \mathrm{E} & 2447 \\ \text { DS 10 } & 40.98^{\circ} & 05.05^{\circ} \mathrm{E} & 2665 \\ \text { DS 12 } & 42.25^{\circ} & 04.47^{\circ} \mathrm{E} & 2090 \\ \text { DS 13 } & 39.77^{\circ} & 04.98^{\circ} \mathrm{E} & 2699 \\ \text { POLYGAS (1972) } & & & 2108 \\ \text { CV 08 } & 47^{\circ} 30^{\prime} 7 & 08^{\circ} 40^{\prime} 06 & \end{array}$




\begin{tabular}{|c|c|c|c|}
\hline $\begin{array}{l}\text { Research Program, } \\
\text { Station }\end{array}$ & Latitude, N & $\begin{array}{l}\text { Longitude, } \mathbf{W} \\
\text { (E - when indicated) }\end{array}$ & Depth, m \\
\hline $\begin{array}{l}\text { CV } 09 \\
\text { CV } 10 \\
\text { CP } 11 \\
33 C V 11 \\
\text { DS } 11 \\
\text { CV } 12 \\
\text { CV } 13 \\
\text { CV } 14 \\
\text { CV } 15 \\
\text { DS } 15 \\
\text { DS } 16 \\
\text { DS } 17 \\
\text { DS } 18 \\
\text { CV } 20 \\
\text { DS } 20 \\
\text { DS } 21 \\
\text { DS } 22 \\
\text { DS } 23 \\
\text { DS } 25 \\
\text { DS } 26 \\
\text { DS } 27 \\
\text { DS } 28\end{array}$ & $\begin{array}{l}47^{\circ} 31^{\prime} \\
47^{\circ} 29.01^{\prime} \\
47^{\circ} 31^{\prime} \\
47^{\circ} 29^{\prime} \\
47^{\circ} 35^{\prime} \\
47^{\circ} 32^{\prime} 5 \\
47^{\circ} 31^{\prime} \\
47^{\circ} 32.09^{\prime} \\
46^{\circ} 32^{\prime} \\
47^{\circ} 35^{\prime} \\
47^{\circ} 38^{\prime} \\
47^{\circ} 32^{\prime} \\
47^{\circ} 31^{\prime} \\
47^{\circ} 37^{\prime} \\
47^{\circ} 33^{\prime} \\
47^{\circ} 31^{\prime} \\
47^{\circ} 34^{\prime} \\
46^{\circ} 32^{\prime} \\
44^{\circ} 08^{\prime} \\
44^{\circ} 08.2^{\prime} \\
44^{\circ} 25^{\prime} 3 \\
46^{\circ} 23^{\prime}\end{array}$ & $\begin{array}{l}08^{\circ} 43^{\prime} \\
08^{\circ} 16.1^{\prime} \\
08^{\circ} 41^{\prime} \\
08^{\circ} 16^{\prime} \\
08^{\circ} 33^{\prime} \\
09^{\circ} 06^{\prime} 2 \\
09^{\circ} 34^{\prime} \\
09^{\circ} 36.30^{\prime} \\
10^{\circ} 28^{\prime} \\
08^{\circ} 40^{\prime} \\
08^{\circ} 41^{\prime} \\
08^{\circ} 45^{\prime} \\
08^{\circ} 44^{\prime} \\
08^{\circ} 34^{\prime} \\
09^{\circ} 36^{\prime} \\
09^{\circ} 40^{\prime} \\
09^{\circ} 38^{\prime} \\
10^{\circ} 21^{\prime} \\
04^{\circ} 15^{\prime} \\
04^{\circ} 15^{\prime} \\
04^{\circ} 44^{\prime} 5 \\
04^{\circ} 47^{\prime}\end{array}$ & $\begin{array}{l}2119 \\
2103-2141 \\
2108 \\
2134 \\
2205 \\
2775 \\
4252 \\
4246 \\
4700 \\
2246 \\
2325 \\
2103 \\
2138 \\
2282 \\
4226 \\
4190 \\
4144 \\
4734 \\
2076-2100 \\
2076 \\
4411 \\
4413\end{array}$ \\
\hline $\begin{array}{l}\text { POLYMEDE I (1970) } \\
\text { CV } 04 \\
\text { DS } 04 \\
\text { DS } 05 \\
\text { DS } 10 \\
\text { DS } 11 \\
\text { DS } 12 \\
\text { DS } 14 \\
\text { KR-0413 } \\
\text { KR-0515 } \\
\text { KR-1031 }\end{array}$ & $\begin{array}{l}38^{\circ} 01^{\prime} \\
39^{\circ} 16.5^{\prime} \\
37^{\circ} 50.07^{\prime} \\
40^{\circ} 59.03^{\prime} \\
40^{\circ} 58^{\prime} \\
42^{\circ} 15.00^{\prime} \\
37^{\circ} 17^{\prime} 48^{\prime \prime} \\
37^{\circ} 56^{\prime} 07^{\prime \prime} \\
38^{\circ} 04^{\prime} 06^{\prime \prime} \\
38^{\circ} 05^{\prime} 04^{\prime \prime}\end{array}$ & $\begin{array}{l}07^{\circ} 31^{\prime} \mathrm{E} \\
06^{\circ} 18.4^{\prime} \mathrm{E} \\
05^{\circ} 22.00^{\prime} \mathrm{E} \\
04^{\circ} 28.05^{\prime} \mathrm{E} \\
04^{\circ} 01^{\prime} \mathrm{E} \\
04^{\circ} 28.05^{\prime} \mathrm{E} \\
09^{\circ} 00^{\prime} 12^{\prime \prime} \\
07^{\circ} 31^{\prime} 06^{\prime \prime} \mathrm{E} \\
08^{\circ} 26^{\prime} 03^{\prime \prime} \mathrm{E} \\
03^{\circ} 07^{\prime} 00^{\prime \prime} \mathrm{E}\end{array}$ & $\begin{array}{l}2824 \\
2632 \\
2090 \\
2665 \\
2110 \\
2090 \\
2500 \\
3542 \\
2430 \\
2917\end{array}$ \\
\hline $\begin{array}{l}\text { POLYMEDE II (1972) } \\
\text { DS } 07 \\
\text { DS-012 } \\
\text { DS-2145 } \\
\text { DS-2477 }\end{array}$ & $\begin{array}{l}37.05^{\circ} \\
39^{\circ} 34^{\prime} 36^{\prime \prime} \\
35^{\circ} 58^{\prime} 36^{\prime \prime} \\
37^{\circ} 06^{\prime} 12^{\prime \prime}\end{array}$ & $\begin{array}{l}03.58^{\circ} \mathrm{E} \\
12^{\circ} 24^{\prime} 54^{\prime \prime} \mathrm{E} \\
01^{\circ} 12^{\prime} 30^{\prime \prime} \\
00^{\circ} 20^{\prime} 06^{\prime \prime} \mathrm{E}\end{array}$ & $\begin{array}{l}2335 \\
3385 \\
2415 \\
2640\end{array}$ \\
\hline $\begin{array}{l}\text { SEAMOUNT } 1 \text { (1987) } \\
\text { CP } 30 \\
\text { CP } 102\end{array}$ & $\begin{array}{l}36^{\circ} 44 \\
35^{\circ} 05^{\prime} 6\end{array}$ & $\begin{array}{l}11^{\circ} 23^{\prime} \\
13^{\circ} 07^{\prime} 3\end{array}$ & $\begin{array}{l}1940-2075 \\
2010-2100\end{array}$ \\
\hline $\begin{array}{l}\text { SEAMOUNT } 2 \\
\text { TS } 267 \\
\text { CP } 268\end{array}$ & $\begin{array}{l}34^{\circ} 22.50^{\prime} \\
34^{\circ} 22.03^{\prime}-34^{\circ} 20.54^{\prime}\end{array}$ & $\begin{array}{l}30^{\circ} 22.50^{\prime} \\
30^{\circ} 23.14^{\prime}-30^{\circ} 25.00^{\prime}\end{array}$ & $\begin{array}{l}2235 \\
2205-2145\end{array}$ \\
\hline $\begin{array}{l}\text { SKAGERRAK Exped } \\
28 \mathrm{~V}\end{array}$ & $\begin{array}{l}\text { iton } \\
35^{\circ} 40^{\prime}\end{array}$ & $08^{\circ} 16$ & $2150-2300$ \\
\hline $\begin{array}{l}\text { SWEDISH ARCTIC E } \\
26 \\
27\end{array}$ & $\begin{array}{l}\text { xpediton (1898) } \\
78^{\circ} 19^{\prime} \\
77^{\circ} 52^{\prime}\end{array}$ & $\begin{array}{l}08^{\circ} 41^{\prime} \mathrm{E} \\
03^{\circ} 05^{\prime} \mathrm{E}\end{array}$ & $\begin{array}{l}2700 \\
2750\end{array}$ \\
\hline $\begin{array}{l}\text { SWEDISH ZOOLOGI } \\
13 \\
29\end{array}$ & $\begin{array}{l}\text { CAL POLAR Expeditc } \\
72^{\circ} 01^{\prime} \\
72^{\circ} 42^{\prime}\end{array}$ & $\begin{array}{l}900) \\
08^{\circ} 33^{\prime} \\
14^{\circ} 49^{\prime}\end{array}$ & $\begin{array}{l}2400 \\
2000\end{array}$ \\
\hline $\begin{array}{l}\text { SWEDISH DEEP-SE } \\
313 \\
329 \text { (Haul 3) } \\
357 \text { (Haul 6) } \\
387 \\
401 \text { (Haul 14) }\end{array}$ & $\begin{array}{l}\text { A Expediton (1947-19 } \\
30^{\circ} 05^{\prime} \\
09^{\circ} 38^{\prime} \\
02^{\circ} 26^{\prime} \\
40^{\circ} 35^{\prime}-40^{\circ} 34^{\prime} \\
43^{\circ} 40^{\prime}\end{array}$ & $\begin{array}{l}17^{\circ} 18^{\prime} \\
26^{\circ} 20^{\prime} \\
39^{\circ} 26^{\prime} \\
35^{\circ} 24^{\prime}-35^{\circ} 52^{\prime} \\
18^{\circ} 45^{\prime}\end{array}$ & $\begin{array}{l}4267-4255 \\
5610-5600 \\
4474-4430 \\
4540-4600 \\
5000-5025\end{array}$ \\
\hline
\end{tabular}

